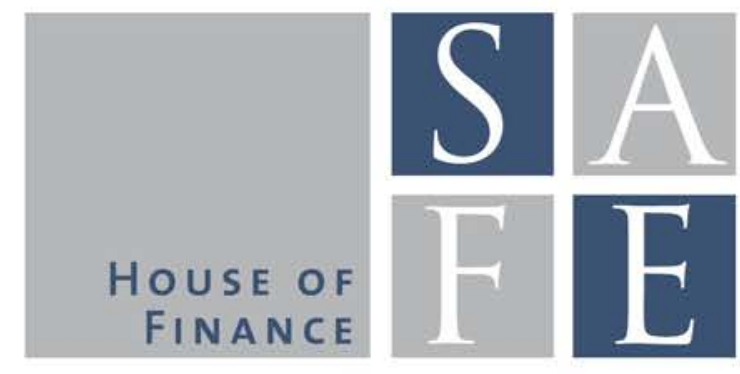

WORKING PAPER SERIES

Alberto Alesina - Carlo Favero - Francesco Giavazzi

\title{
The output effect of fiscal consolidation plans
}

SAFE Working Paper No. 76

SAFE I Sustainable Architecture for Finance in Europe A cooperation of the Center for Financial Studies and Goethe University Frankfurt 


\section{Non-Technical Summary}

The key question in estimating the effects of fiscal policy on output is how to identify shifts in fiscal policy that are "exogenous", that is are not a response to the state of output - as would be the case, for instance, of a fiscal expansion induced by a fall in output. Following the approach pioneered by Romer and Romer (2010), Devries at al (2011) have collected and described - using the records available in official documents - the multi-year fiscal consolidation plans announced (and then implemented or revised) by seventeen OECD countries over a quarter of a century (1980-2005). Among all stabilization plans these authors have selected those that were designed to reduce a budget deficit and to put the public debt on a sustainable path, which should guarantee their "exogeneity".

Using the Devries et al (2011) data we have been able to make progress on question of anticipated versus unanticipated shifts in fiscal policy and permanent versus transitory shifts. We find that it matters crucially how the consolidation occurs. Fiscal adjustments based upon spending cuts are much less costly in terms of output losses than tax-based ones. The difference is remarkable in its size and it cannot be explained by different monetary policies during the two types of adjustments. We find instead that the heterogeneity in the effects of the two types of fiscal adjustments is mainly due to the response of private investment, rather than that to consumption growth. Interestingly, the responses of business and consumers' confidence to different types of fiscal adjustment show the same asymmetry as investment and consumption: business confidence (unlike consumer confidence) picks up immediately after expenditure-based adjustments.

The strength and the statistical significance of our results depend crucially on the innovative approach that we adopt to simulate the impact of fiscal adjustments. Rather than simulating the impact of exogenous fiscal shocks, we study the response of output (and of the other variables of interest) to multi-period fiscal consolidation plans - that is sequences of tax increases and spending cuts, announced in some year and then implemented or revised in subsequent years. We allow for differences in the "style" of these plans across countries, and we show that these differences are a critical factor in order to obtain more precise estimates of the response of the economy to a consolidation plan. 


\title{
The output effect of fiscal consolidation plans
}

\author{
Alberto Alesina, Carlo Favero and Francesco Giavazzi * \\ This version: October 2014
}

\begin{abstract}
We show that the correct experiment to evaluate the effects of a fiscal adjustment is the simulation of a multi year fiscal plan rather than of individual fiscal shocks. Simulation of fiscal plans adopted by 16 OECD countries over a 30-year period supports the hypothesis that the effects of consolidations depend on their design. Fiscal adjustments based upon spending cuts are much less costly, in terms of output losses, than tax-based ones and have especially low output costs when they consist of permanent rather than stop and go changes in taxes and spending. The difference between tax-based and spending-based adjustments appears not to be explained by accompanying policies, including monetary policy. It is mainly due to the different response of business confidence and private investment.
\end{abstract}

*Alesina: Harvard University, IGIER-Bocconi, CEPR and NBER. aalesina@harvard.edu. Favero: Deutsche Bank Chair, IGIER-Bocconi, and CEPR. carlo.favero@unibocconi.it. Giavazzi: IGIER-Bocconi, MIT, CEPR and NBER, francesco.giavazzi@unibocconi.it. We thank Silvia Ardagna, Olivier Blanchard, Giancarlo Corsetti, Marco Del Negro, Jeff Frankel, Daniel Leigh, Guido Lorenzoni, Roberto Perotti, Andrea Pescatori, David Romer, Christopher Sims, Guido Tabellini and participants in seminars at ECB, Bank of Italy, Federal Reserve Bank of San Francisco, Federal Reserve Bank of New York, ISoM, LBS, Northwestern, NYU Stern, Bocconi, and the NBER conferences on Sovereign Debt and Financial Crises and The Euro Crisis. Diana Morales, Madina Karamysheva, Omar Barbiero, Armando Miano, Matteo Paradisi and Andrea Passalacqua provided outstanding research assistance. We also thank Antonio Giannino and Francesca Zambrini for careful editing. This paper was initially funded as part of the Growth and Sustainability Policies for Europe project (GRASP \#244725) by the European Commission's 7th Framework Programme. We also gratefully acknowledge research support from the Research Center SAFE, funded by the State of Hessen initiative for research LOEWE. 
Keywords: fiscal adjustment, confidence, investment

JEL Classification: H60, E62

\section{Introduction}

Do sharp reductions of government deficits (labeled fiscal adjustments or fiscal consolidations) cause large output losses? This paper argues that the correct methodology to answer this question requires studying fiscal plans, rather than individual shifts in fiscal variables as it is normally done in the literature. Large fiscal consolidations are typically multi-year processes in which a government announces and then implements a sequence of deficit reduction policies. These plans are often revised and adjusted during the course of their implementation generating a complex interaction of expected and unexpected policy actions which should be accounted for. ${ }^{1}$ In this paper we use narratively identified fiscal adjustments to build exogenous plans.

When fiscal policy is conducted through multi-year plans, fiscal adjustments in each year - say year $t$ - consist of three components: unexpected shifts in fiscal variables (announced upon implementation in year $t$ ), shifts implemented at time $t$ but announced in previous years, and future announced corrections (announced at time $t$ for implementation in some future year). The announcements for future periods are a measure of anticipated policy changes. In principle even a plan which is announced and starts in year $t$ could have been anticipated before $t$ : our narrative measure does not allow for this possibility. Moreover, our interest is mainly in the composition of fiscal adjustments: this is often the result of a complex political game, which makes predicting the composition of an adjustment very difficult.

Fiscal plans generate inter-temporal and intra-temporal correlations among changes in spending and revenues. The inter-temporal correlation is the one between the announced (future) and the unanticipated (current) components of a plan — what we shall call the "style" of a plan. The intra-temporal correlation is that between the changes in revenues and spending that determines the composition of a plan. As argued by Ramey (2011a, b) distinguishing between announced and unanticipated shifts in fiscal variables, and allowing them to have different effects on output, is crucial for evaluating fiscal multipliers. The literature, however, (see e.g. Mertens and Ravn 2011) has

\footnotetext{
${ }^{1}$ Drautzburg and Uhlig (2013) take a first step in the direction of the identification of plans by allowing VAR-identified shocks to be correlated.
} 
so far studied the different effects of anticipated and unanticipated shifts in fiscal variables assuming that they are orthogonal. This is not the case in our sample where the correlation between anticipated and unanticipated shifts is non zero and reflects the style of a fiscal plan. Thus estimates of the coefficients (e.g. of an unanticipated change in fiscal variables) obtained from a regression that excludes anticipated changes would be biased. Likewise, experiments designed to study, via a dynamic simulation, the effects of announced and unanticipated shifts should not violate the correlation between the two. The same is true for fiscal multipliers (and the associated experiments) estimated assuming that changes in revenues and spending are orthogonal, thus omitting either one or the other from the estimated model, as e.g. in the Romer and Romer (2010) study of the tax multiplier.

We build fiscal plans starting from the episodes of fiscal adjustment constructed at the IMF by Devries et al (2011, D\&al) and used in Guajardo et al (forthcoming). These episodes cover 17 OECD countries between 1978 and 2009. Among all stabilization episodes these authors have selected those that were designed to reduce a budget deficit and to put the public debt on a sustainable path. As a result, they are unlikely to be systematically correlated with other developments affecting output, and thus they can be considered as exogenous for the estimation of the short-term effects of fiscal consolidation on economic activity. It has been observed (Jordà and Taylor 2013) that shifts in fiscal variables identified through the narrative method - and in particular the episodes we use in this paper to construct plans are predictable. We show that this finding is a consequence of fiscal policy being conducted through multi-year plans. The fact that episodes of fiscal consolidation can be predicted from their past realizations, or from the realization of other variables, different from output growth, does not invalidate exogeneity of the plan. We discuss in much detail this issue below. ${ }^{2}$

\footnotetext{
${ }^{2}$ We also show how plans can be simulated starting from policy shifts not predictable from their own past. The problem that arises when analyzing fiscal plans (as clearly illustrated in Leeper et al 2008 and Leeper 2010) is that fiscal foresight - the fact that agents are informed of announced, but not yet realized, shifts in fiscal variables — causes a misalignment between the information set used by the econometrician in a VAR and that available to economic agents (see Lippi and Reichlin 1994). The consequence is that the exogenous combination of unanticipated and announced fiscal corrections, that characterizes a plan, cannot be uniquely recovered from VAR innovations. The solution is to adopt, as we do in this paper, the "narrative" approach introduced by Romer and Romer (2010) which does not suffer from this problem because exogenous shifts in fiscal variables are not reconstructed via the inversion of the moving average representation of a
} 
The D\&al data document the shifts in taxes or spending that are implemented in a given year - say year $t$ - and announced in year $t$ for future periods with a 3-years horizon. Using these data we construct fiscal plans. A plan is composed, for each year, of unexpected fiscal adjustments (announced upon implementation at time $t$ ), adjustments implemented at time $t$ but which had been announced in previous years, and future announced corrections (announced at time $t$ for implementation in the future). Analyzing these plans we find that countries adopt different styles for their fiscal consolidations. The degree of correlation between the unanticipated and announced part of a plan varies from being very strong and positive, to being negative. We have "reversal plans", in which a fiscal tightening in the year a plan is first introduced is accompanied by the announcement of looser fiscal policy in subsequent years, and "persistent plans" in which unanticipated and announced fiscal actions move in the same direction.

Having constructed exogenous fiscal plans we classify them in tax-based (TB) and expenditure-based (EB) on the basis of the relative importance of tax increases and spending cuts in each plan. This allows us to capture the intra-temporal correlation between tax hikes and expenditure cuts. As noted above, allowing for shifts in taxes and spending to be correlated is crucial for evaluating (for instance through an impulse response) fiscal multipliers. To analyze the impact of fiscal plans on macroeconomic variables we follow Romer and Romer (2010) and estimate a truncated moving average (MA) representation of various macroeconomic variables: output growth, consumption growth, etc. We do this for a panel of countries, since if we were to study the macroeconomic effects of fiscal consolidations using plans for a single country we would have too few observations. We thus pool together fiscal adjustment plans from different countries. Pooling, however, is problematic in the presence of heterogeneity (see, for example, Favero, Giavazzi and Perego 2011). We address heterogeneity estimating a quasi-panel, that is pooling the international evidence but allowing for two sources of heterogeneity: (i) different styles of fiscal consolidations across countries and (ii) different effects of TB and EB plans within each country.

Our results show that the effects of fiscal consolidations depend on their design and in particular on two characteristics: their composition (tax hikes

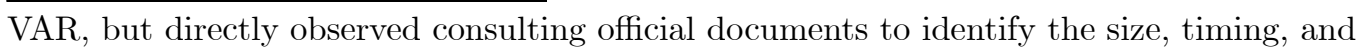
motivation for the fiscal actions taken or announced by the government. This approach obviously relies on an accurate reading of policymakers' intentions. 
vs. spending cuts) and their consistency over time (i.e. whether changes in revenues and spending are permanent or transitory). Spending-based adjustments have been associated on average with mild and short-lived recessions, in many cases with no recession at all. Instead, tax-based adjustments have been followed by prolonged and deep recessions. It is worth emphasizing that these are averages, estimated over several plans: an average of small or zero recession can be the result of some bigger recessionary episodes and, in some cases, even of expansionary fiscal adjustments. We also find that fiscal adjustments may be associated with especially low output costs when they are permanent rather than stop and go. The difference between spending-based and tax-based adjustments is remarkable in its size and cannot be explained by different monetary policy responses. The difference in the output effects of the two types of fiscal adjustment is mainly due to the response of private investment, rather than that of consumption growth. ${ }^{3}$ Interestingly, the responses of business and consumers' confidence to different types of fiscal adjustment show the same asymmetry as investment and consumption: business confidence (unlike consumer confidence) picks up immediately after the start of an expenditure-based adjustment.

The result that spending-based fiscal adjustments are, on average, nonrecessionary or only very mildly recessionary, brings support to a vast literature started by Giavazzi and Pagano (1990) and recently extended and summarized by Alesina and Ardagna (2010, 2012). This literature, using simple data analysis and case studies, suggested that indeed spending-based fiscal adjustments - differently from tax-based ones - can have very small or no output costs at all. ${ }^{4}$ Those results, as indeed ours, were obtained studying periods during which nominal interest rates had not reached the zero lower bound (ZLB) and therefore the central bank could accompany the fiscal contraction with a monetary expansion. To rule out the possibility that our results are driven by an heterogenous endogenous response of monetary

\footnotetext{
${ }^{3}$ This result is consistent with Alesina et al (2002).

${ }^{4}$ Alesina and Ardagna (2010) and the literature which they summarize identified consolidation episodes using measures of large changes in cyclically adjusted budget deficits. Large reductions in this variable were assumed exogenous to output fluctuations, and thus an indication of active policies to reduce deficits. This, admittedly imperfect, approach is criticized by Guajardo et al (forthcoming). Interestingly, while Guajardo et al are critical of the possibility of costless fiscal adjustments, the results of the present paper show that a careful analysis using the D\&al data (the same they use) but recognizing that fiscal adjustments are carried out via plans, not isolated shocks, leads to a picture which is remarkably similar.
} 
policy to tax-based and spending-based adjustments, we split our sample in two groups of observations: euro area countries from 1999 onwards, and noneuro area countries pooled with euro area countries before 1999. In euro area countries from 1999 onwards the response of monetary policy is constrained, in that the ECB sets its policy by looking at general euro area conditions and should not respond to macroeconomic events in single countries. Our finding of heterogeneity between tax-based and expenditure-based adjustments is robust when the output response to fiscal policy is allowed to be different between EMU and non-EMU countries. To investigate the role of monetary policy we also run a counter-factual experiment. We shut down the response of innovations in monetary policy to exogenous fiscal contractions, thus investigating what the output response to a fiscal contraction would be monetary policy did not respond to fiscal adjustments. We find that the differences are minor and that spending-based adjustments are less costly than tax-based ones even when monetary policy is not allowed to react to the adjustment. Finally, we also show that the difference between tax-based and expenditure-based adjustments is not driven by their timing relative to the business cycle, nor by accompanying policies: the particular policy we investigate is labor market reform.

The paper is organized as follows. The next section briefly reviews the theory and the empirical evidence on fiscal adjustments Section 3 describes the data, and illustrates our strategy for constructing fiscal plans. Section 4 presents our empirical model and discusses our estimation strategy. Section 5 reports our results. Section 6 presents robustness checks, including the role of monetary policy. The last section concludes.

\section{Tax-based and spending-based stabilizations: theory and empirical evidence}

Gathering empirical evidence on the effect on output of a fiscal stabilization is particularly relevant given that alternative theories have different predictions on this effect. Wealth effects, intertemporal substitution and distortions determine the effect of fiscal policy on output in neoclassical models (see Baxter and King1993). These three channels operate differently in the case of tax increases or expenditure cuts. With lump sum taxes, and when agents derive no benefits from public spending, a reduction in government spending raises 
private wealth because future expected taxes fall. Private consumption increases and (if leisure and consumption are normal goods) labor supply falls. Since in this model labor demand does not change when government spending changes, hours worked decrease, the real wage increases and output falls. For output to increase following a reduction in wasteful government spending, taxes need to be distortionary and the intertemporal substitution elasticity sufficiently high. Intuitively this happens because, when the intertemporal substitution elasticity is high, the wealth effect produced by a cut in government spending is small relative to the substitution effect generated by the reduction in distortionary taxes, that increases the net return to investment and/or labor.

The literature considering the effects of fiscal policy on the components of aggregate demand has typically focused on consumption. An exception is Alesina et al (2002) which analyzes (theoretically and empirically) the differential effects of spending cuts and tax increases on private investment. These authors show that lower government spending may imply, through lower taxes on capital, higher investment and possibly higher output. The size of these effects will depend upon the transitory or permanent nature of the change in expenditure (Corsetti and Meier 2009). An increase in taxation will instead have an unambiguous contractionary effect on output as the negative wealth effect on the demand side (both on consumption and on investment) is combined with the negative effect of increased distortions on the supply side. A reduction in government employment could instead be expansionary. Consider first a competitive labour market: the reduction in government employment generates a positive wealth effect. If both leisure and consumption are normal goods, consumption and leisure will increase and labour supply will decrease, but not enough to completely offset the lower demand for government employment. Hence, we should observe a reduction in real wages: the resulting increase in profits will raise investment, both during the transition and in steady state. When wages are bargained between firms and unions, a reduction in government employment may affect real wages both in the public and in the private sector. In a similar vein, Alesina and Perotti (1997) show how, in unionized economies, increases in income taxes translate into higher wage demand by unions, higher unit labor costs and a loss of competitiveness for domestic firms.

Confidence - a variable that our results suggest responds to shifts in fiscal variables - and uncertainty may also influence output fluctuations (Bloom 2009, Dixit and Pindyck 1994). Fluctuations in the degree of uncertainty 
produce rapid drops and rebounds in aggregate output and employment since higher uncertainty causes firms to temporarily pause their investment and hiring; productivity growth also falls and thus this pause in activity freezes reallocation across units. Again, for virtually all the channels discussed above, it should matter whether the spending cuts are perceived as permanent or transitory, as wealth effects will be larger for permanent spending cuts.

Textbook Keynesian models and new Keynesian models with less than perfectly flexible prices, predict that spending cuts are always recessionary (see e.g. De Long and Summers 2012, Galì et al 2007) and that the multiplier for government spending should be larger in theory than that for taxes. Recent research finds that this result might also emerge at the ZLB. Christiano et al (2011) calculate that at the ZLB the spending multiplier turns positive (spending cuts reduce output) and, in their calibration, as large as 3.7. The channel through which this can happen is the expectation of future deflation. If prices are sticky, consumers expect prices to fall when firms will be able to adjust them. This raises the real interest rate inducing consumers to postpone consumption. Eggerston (2010) similarly, and through the same mechanism, finds that the multiplier for a cut in labor taxes flips sign at the ZLB. In his calibration a $1 \%$ cut in labor taxes switches from being positive to negative, at -1.02 . Our episodes do not include periods of ZLB, but we show that our results, regarding the lower costs of expenditure based adjustments versus tax based ones should survive at ZLB, since they do not depend on different responses of monetary policy to the two types of adjustments. The accumulation of data on these recent episodes will allow progress on this specific issue. The empirical literature based on Var-identified shocks suggests that tax multipliers are larger than spending multipliers (see Ramey 2013 for a survey). Multipliers are also found to be larger during recessions (Auerbach and Gorodnichenko 2012, Giavazzi and McMahon 2013, Ramey 2013), although Ramey et al (2013) cast some doubts on this evidence.

Finally, a different strand of the literature emphasizes the role of accompanying policies. Christiano et al (2011), Alesina and Ardagna (1998, 2012) and Perotti (2013) show that certain supply-side polices, such as labor market and product market liberalization, wage agreements with the unions and reduction in unionization level, can help reduce or even eliminate the output losses associated with spending cuts. 


\section{Identification of exogenous fiscal plans}

We construct multi-year exogenous fiscal plans reclassifying the fiscal episodes identified, using the narrative method, by D\&al As mentioned in the introduction, D\&al data report the shifts in taxes or spending that are implemented in a given year - say year $t$ - and announced in year $t$ for future periods with a 3-years horizon. Using these data we construct fiscal plans specifying, for each year, unexpected shifts in fiscal variables (announced upon implementation at time $t$ ), adjustments implemented at time $t$ which had been announced in previous years, and corrections announced at time $t$ for implementation in the future. Implementing fiscal policy through plans means that fiscal corrections in each year can be written as follows

$$
\begin{aligned}
e_{i, t} & =e_{i, t}^{u}+e_{i . t, 0}^{a}+\sum_{j=1}^{\text {horiz }} e_{i, t, j}^{a} \\
e_{i, t}^{u} & =\tau_{i, t}^{u}+g_{i, t}^{u} \\
e_{i, t, j}^{a} & =\tau_{i, t, j}^{a}+g_{i, t, j}^{a} \\
\tau_{i, t, 0}^{a} & =\tau_{i, t-1,1}^{a} \\
\tau_{i, t, j}^{a} & =\tau_{i, t-1, j+1}^{a}+\left(\tau_{i, t, j}^{a}-\tau_{i, t-1, j+1}^{a}\right) j \geqslant 1 \\
g_{i, t, 0}^{a} & =g_{i, t-1,1}^{a} \\
g_{i, t, j}^{a} & =g_{i, t-1, j+1}^{a}+\left(g_{i, t, j}^{a}-g_{i, t-1, j+1}^{a}\right) i \geqslant 1
\end{aligned}
$$

Total fiscal corrections in each year consist of increases in taxes and cuts to expenditures. Unexpected shifts in fiscal variables by the fiscal authorities in country $i$ are labeled respectively $\tau_{i, t}^{u}$ and $g_{i, t}^{u}$. We define $\tau_{i, t, j}^{a}$ and $g_{i, t, j}^{a}$ the tax and expenditure changes announced at date $t$ with an anticipation horizon of $j$ years (i.e. to be implemented in year $t+j$ ). In the data recovered from the documents consulted by D\&al fiscal plans almost never extend beyond a 3 -year horizon: thus we take $j=3$ as the maximum anticipation horizon ${ }^{5}$. Finally, $\tau_{i, t, 0}^{a}\left(g_{i, t, 0}^{a}\right)$ denotes the tax (expenditure) changes implemented in year $t$ that had been announced in previous years. Note that we record a modification of an announced measure upon implementation as an unexpected shift in policy.

\footnotetext{
${ }^{5}$ In the sample there are a few occurences of policy shifts anticipated four and five years ahead. Their number is too small to allow us to include them in our estimation.
} 
In principle, as already mentioned in the Introduction, even an unexpected plan could have been informally anticipated (e.g. through a public debate): we have no way of measuring this possibility. However, we think that this occurrence is unlikely since the composition of fiscal adjustments is quite hard to anticipate with a reasonable amount of certainty until the plan is finally approved. Moreover, our interest is mainly in the composition of fiscal adjustments, which is often the result of a complex political game, which makes predicting the composition of an adjustment very difficult.

To allow for a potentially heterogenous effect of plans according to their nature, we distinguish them in Tax-Based (TB) or Expenditure-Based (EB) plans adopting the following rule

$$
\text { if } \begin{aligned}
\left(\tau_{t}^{u}+\tau_{t, 0}^{a}+\sum_{j=1}^{\text {horiz }} \tau_{t, j}^{a}\right) & >\left(g_{t}^{u}+g_{t, 0}^{a}+\sum_{j=1}^{\text {horiz }} g_{t, j}^{a}\right) \\
\text { then } T B_{t} & =1 \text { and } E B_{t}=0, \\
\text { else } T B_{t} & =0 \text { and } E B_{t}=1, \forall t
\end{aligned}
$$

The construction of our plans is such that the sum of the anticipated and the unanticipated components of each fiscal correction is always equal to the original episodes coded by D\&al, except in 7 cases: we discuss this point in section 4.4 .2 below. In such cases, after checking the original sources, we have decided to change their coding, Detailed reasons are explained in the Data Appendix ${ }^{6}$.

Before describing in greater detail our strategy for the construction of fiscal plans we describe the data in detail.

\subsection{The data}

The episodes of exogenous fiscal adjustments identified by D\&al cover 17 OECD countries: Australia, Austria, Belgium, Canada, Denmark, Finland, France, Germany, Ireland, Italy, Japan, the Netherlands, Portugal, Spain,

\footnotetext{
${ }^{6}$ For example, according to D\&al, the Italian Delegation Law of 1993 implied an expenditure-based fiscal consolidation amounting to Lit 31 trillion (1994 OECD Economic Surveys, p.44-45). However, the OECD report quantifies the expenditure cuts of the Delegation Law to Lit 43.5 trillion. Lit 31 trillion was the targeted primary surplus decided in May 1993 and it was incorrently regarded as the total amount of expenditure cuts in the 1993 entry for Italy. When we encountered such cases we revised the magnitude of the shocks going back to the sources cited within the text.
} 
Sweden, the United Kingdom, and the United States. The frequency of the data is annual and the sample runs from 1978 to $2009 .{ }^{7}$ D\&al use the records available in official documents to identify the size, timing and principal motivation for the fiscal actions taken by each country. In particular, they examine policymakers' intentions and actions as described in contemporaneous policy documents, which represent a response to past decisions and economic conditions rather than to current or prospective conditions. They emphasize that "If a consolidation is motivated primarily by restraining domestic demand, we do not include it in our database". The historical sources examined include Budget Reports, Budget Speeches, Central Bank Reports, Convergence and Stability Programs submitted by EU governments to the European Commission, IMF Reports and OECD Economic Surveys. In addition, they examine country specific sources, such as, among other, various reports by the Congressional Budget Office and the Economic Reports of the President for the United States, the Journal Officiel de la Republique Francaise for France. Two examples of such exogenous fiscal plans are the U.S. 1993 Omnibus Budget Reconciliation Act, which involved raising taxes and cutting spending "not to reduce the risk of economic overheating, but because policymakers saw it as a prudent policy change with potential long-term benefits" and the European plans adopted in the second part of the 1990s to meet the Maastricht criteria and join the euro. For most countries the concept of government adopted is the "general government", which includes both the central State administration and all levels of local governments. For three federal countries (Canada, Australia and the United States) the data only refer to the central government (e.g. the Federal government for the US). This would affect the results if local authorities systematically moved their budget, for instance to offset the effect of changes in the central budget.

Following the methodology outlined above we construct, starting from the D\&al episodes, unanticipated and anticipated shifts in taxes and spending. A few measures that were announced but for which "the historical record shows that they were not implemented at all" are dropped from the D\&al database. There are only five instances in our sample in which this happened - that is individual announcements were not recorded because never implementedone each in Japan, Italy, Germany, the UK and the Netherlands (a case which is irrelevant for us since, as we discuss below, we drop this country). In these

$\begin{array}{cll}{ }^{7} \text { The dataset is } & \text { available on the } \text { IMF } & \text { website } \\ \text { (http://www.imf.org/external/pubs/cat/longres.aspx?sk=24892.0). }\end{array}$


cases we have not questioned the D\&al call. All other announcements are assumed to be credible and, thus, recorded.

Our identification strategy applies to a panel of countries the idea originally proposed by Romer and Romer (2010) for the U.S. to identify major tax policy changes not dictated by business cycle fluctuations. In the D\&al data tax increases are measured, as in Romer and Romer (2010), by the expected revenue effect of each change in the tax code, as a percent of GDP in the year the change in the tax code is adopted by Congress. Spending cuts (also measured as percent of GDP ) are changes in expenditure relative to the level that was expected without the policy shift, not relative to the previous year. Thus a spending cut for year $t+1$ does not necessarily imply a reduction in government spending relative to year $t$, but only relative to what would have happened in year $t+1$ without the policy shift. ${ }^{8}$ This is the correct way to measure spending cuts if we want to capture the effect of new information. The criteria used by D\&al to identify episodes of exogenous fiscal adjustment differ, however, from those adopted by Romer and Romer (2010) in two important dimensions. The latter focus only on revenue shifts and identify two main types of legislated exogenous tax changes: those driven by long-run motives, such as to foster long-run growth, and those aiming to deal with budget deficits. D\&al, instead, consider both expenditure and revenue shifts and focus only on fiscal actions motivated by the objective of reducing the budget deficit ${ }^{9}$. This means that, since only policy shifts which have a negative impact on the deficit are recorded (that is only tax increases and expenditure cuts) the identified shifts do not have zero mean. Having a series of adjustments that occur always in the same direction raises the possibility that the series is truncated. However, given the authors' identification criteria, these truncated shocks should correspond to tax cuts or increases in expenditure engineered because the deficit was perceived as too low or the surplus too high. These cases are quite unlikely ${ }^{10}$.

\footnotetext{
${ }^{8}$ This way to measure spending cuts is the one that was used in the United States in 2013 to measure the effect of the so-called "Sequester".

${ }^{9}$ If a fiscal consolidation is offset by fiscal actions motivated by a long run gowth objective, D\&al compute the sum of the two measures (deficit-driven and long-run growth) and call a consolidation if the overall change in policy yields budgetary savings.

${ }^{10}$ Although we cannot check for truncation for all the countries in our sample, we can for the U.S., comparing the D\&al with the Romer and Romer (2010) shocks. The latter include both positive and negative observations, and are constructed aggregating tax shocks that are deficit-driven and tax shocks driven by a long-run growth motive. Deficit-driven fiscal expansions never occur in the Romer and Romer sample because all tax shocks driven by
} 


\subsection{Constructing plans}

We shall illustrate how we use the D\&al episodes to construct fiscal plans with two examples: the plans introduced in Italy in 1991 and in Australia in 1984. The case of Italy is illustrated in Table 1. D\&al state that "...The narrative analysis leads to the conclusion that in 1991 fiscal consolidation amounted to 2.77 percent of GDP, with tax hikes worth 1.69 percent of GDP and spending cuts of 1.08 percent of GDP. Fiscal consolidation was motivated by government debt reduction, as the Bank of Italy Annual Report 1990 (p. 69) explains ... However, as reported by the IMF in its 1992 Recent Economic Developments document ( $p$. 21), a number of the tax measures introduced in 1991-Lit 19.4 trillion (1.26 of GDP)-were of a one-off nature.... The expiration in 1993 of one-off tax measures introduced in previous years was worth 1.20 percent of GDP...". The first row of Table 1 illustrates our classification of this narrative record.

\section{Insert Table 1 here}

Note that the plan introduced in 1991 was subsequently modified, in 1992 and in 1993, with the introduction of further unanticipated tax hikes of 2.85 and 3.2 per cent of GDP respectively, and additional spending cuts worth 1.9 and 3.12 per cent of the GDP. As we highlight below Italy is indeed a country which does not implement permanent fiscal shifts. These modifications are illustrated in the second and third rows of Table 1 . The classification strategy illustrated in equation (1) leads to labelling the 1991-1993 Italian adjustment as EB. Note that this happens because the tax hike introduced in 1991, despite being larger than the corresponding spending cuts, is transitory, while the spending cut is permanent. This multi-year labelling strategy does not lead to marginal cases - in which a label is attributed on the basis of a negligible difference between the share of tax hikes and expenditure cuts in the overall adjustment. The data show that in most cases a political decision was made as to the nature of the fiscal consolidation: EB or TB. In only 3 plans (out of 57 ) the share of spending cuts is between $49 \%$ and $51 \%$ of the total consolidation; in 7 cases it is between $48 \%$ and $52 \%$; in 15 cases

the long-run motive are expansionary (i.e. negative tax shocks), and all the deficit-driven tax shocks are contractionary (i.e. positive tax shocks). Therefore, the Romer and Romer deficit-driven shocks, which are directly comparable to those identified by D\&al, show no evidence of truncation. 
it is between $45 \%$ and $55 \%$; in most plans it is either smaller than $40 \%$ or larger than $60 \%$. Table 1 in the Data Appendix lists our classification of all episodes in TB and EB.

We cannot observe the realizations of announced plans, because the narrative method allows to identify exogenous corrections at the time when they are announced, but only total expenditure and receipts are observed upon implementation, that is both the effects of exogenous shifts and shifts induced by the cycle. Thus we cannot control - since we do not observe it for the possibility that the composition of an adjustment changes (relative to what had been announced) when it is implemented. We do observe, however, if the total adjustment differs from what had been announced.

Our second example is Australia. The plan which was introduced in 1985 with a series of sequential adjustments, lasted until 1988. After the December 1984 elections - in which the Labour party surprisingly defeated the sitting liberals - the government announced a sequence of medium-term spending cuts aimed at reducing a large inherited budget deficit. Table 2 illustrates this episode. The plan announced in 1984 featured no change in taxation and spending cuts of 0,45 per cent of GDP each year in 1985 and 1986. In 1986 the plan was revised: the new plan called for additional spending cuts of 0.4 of GDP in 1986, of 0.26 in 1987 and a very small reversal of -0.08 in 1988 . In the revised plan revenue increases were also introduced: a tax increase of 0.17 of GDP in 1986, a further increase of 0.19 of GDP in 1987 and an almost complete reversal $(-0.29)$ in 1988. All four years are labelled as periods of EB adjustment. Note that because the revisions for 1988 were announced as part of a multi-year plan, 1988 is labelled as a year of EB adjustment even if in that year we observe an (anticipated) reduction in taxation larger that the (anticipated) increase in expenditure. This would not be the case if we (incorrectly) overlooked plans and only considered year-to-year fiscal adjustments.

As the Australian and Italian examples illustrate, the procedure used to label corrections as TB or EB uses only information available in real time: the labelling of each plan is decided on the basis of information available when the plan is announced and implemented. This labelling can therefore be used to estimate and simulate the real time effects of the adoption of a plan and to detect potential differences between EB and TB plans. ${ }^{11}$

\footnotetext{
${ }^{11}$ This would not be possible with alternative classification schemes. For instance, using the success of adjustments, say in terms of their ability to stabilize the debt/GDP ratio
} 


\section{Insert Table 2 here}

The results of our classification of episodes for each country is reported in Table 3. Sometimes fiscal plans change nature over time: for instance they start as an EB plan and at some point turn into a TB plan. One example of a policy reversal is Canada in 1991. A plan initially labelled as TB was modified, after some time, to deliver the majority of corrections on the expenditure side. At the time of the announcement we label such a plan TB, but it then shifts to EB when the new announcement is made and tax hikes are replaced by spending cuts. The coding of different episodes is implemented using two dummies, EB and TB, that take values of one when the relevant adjustment is implemented, and zero otherwise.

\section{Insert Table 3 here}

As already noted, fiscal plans - at least those in our dataset - differ not only in their composition (EB vs. TB) but also in the correlation between unanticipated and anticipated shifts in fiscal variables-what we have labelled the "style" of a plan. This is determined by the observed correlation between unanticipated and anticipated shifts announced at time $t$. A permanent fiscal correction is characterized by zero or positive correlation between $e_{t}^{u}$ and $e_{t, j}^{a}$ $(j>1)$. Instead, stop-and-go adjustments display a negative correlation between $e_{i, t}^{u}$ and $e_{i, t, j}^{a}(j>1)$.

\subsection{Summing up.}

The D\&al episodes document, over the period 1978-2009, for 17 OECD countries, a total of 563 individual exogenous shifts in government spending and taxes (unanticipated and anticipated). Using this information we construct annual fiscal plans. We use only 14 countries, dropping the Netherlands for the reason illustrated below in Section 4.4.2, and Sweden and Finland because for these two countries we lack data on confidence, one of the variables whose response to shifts in fiscal variables we analyze: the results including Sweden and Finland for the variables for which data are available are essentially identical. Thus our baseline results cover 14 countries: 4 non-European

to identify their status. Success can be a useful classification criterion within sample, but it is useless for out-of-sample analyses, since the success of a plan cannot be determined upon its announcement. 
countries (the U.S., Canada, Australia and Japan), 2 EU countries that are not members of the monetary union (Denmark and the U.K.) and 8 Euro area countries (Germany, France, Italy, Spain, Austria, Belgium, Ireland, Portugal).

\section{The Empirical Model: Specification, Esti- mation and Simulation}

We estimate the effect of fiscal adjustments on several variables: per capita GDP growth (all growth rates are annual), private consumption growth, the growth in private fixed capital formation ${ }^{12}$, the change in short-term (3- month) interest rates, inflation, the (log of ) the Economic Sentiment Indicator (ESI) for both consumers and firms computed by the OECD or the European Commission. The sources of our data and all data transformations are described in the Data Appendix.

\subsection{Specification}

The model we estimate, (2), is a multi-country system of (truncated) moving average representations for the variable of interest, $\Delta z_{i, t}$ (in turn per capita GDP growth, private consumption growth, etc.). We estimate a quasi-panel which allows for two types of heterogeneity: within-country heterogeneity in the effects of TB and EB plans on the left-hand-side variable, and between-

\footnotetext{
${ }^{12}$ Except for Italy and Spain where lack of separate data on private investment at the beginning of the sample forces us to study total investment: private plus public. Our results are unaffected if we drop these two countries.
} 
country heterogeneity in the style of a plan

$$
\begin{aligned}
\Delta z_{i, t}= & \alpha+B_{1}(L) e_{i, t}^{u} * T B_{i, t}+B_{2}(L) e_{i, t, 0}^{a} * T B_{i, t}+ \\
& C_{1}(L) e_{i, t}^{u} * E B_{i, t}+C_{2}(L) e_{i, t, 0}^{a} * E B_{i, t}+ \\
& +\sum_{j=1}^{3} \gamma_{j} e_{i, t, j}^{a} * E B_{i, t}+\sum_{j=1}^{3} \delta_{j} e_{i, t, j}^{a} * T B_{i, t}+\lambda_{i}+\chi_{t}+u_{i, t} \\
e_{i, t, 1}^{a}= & \varphi_{1, i} e_{i, t}^{u}+v_{1, i, t} \\
e_{i, t, 2}^{a}= & \varphi_{2, i} e_{i, t}^{u}+v_{2, i, t} \\
e_{i, t, 3}^{a}= & \varphi_{3, i} e_{i, t}^{u}+v_{3, i, t} \\
e_{i, t, 0}^{a}= & e_{i, t-1,1}^{a} \\
e_{i, t, j}^{a}= & e_{i, t-1, j+1}^{a}+\left(e_{i, t, j}^{a}-e_{i, t-1, j+1}^{a}\right) j \geqslant 1
\end{aligned}
$$

where $\lambda_{i}$ and $\chi_{t}$ are country and time fixed effects.

In (2) shifts in fiscal policy affect the economy through three components. First, unanticipated changes in fiscal stance, $e_{i, t}^{u}$, announced at time $t$ and implemented at time $t$; second, the implementation at time $t$ of policy shifts that had been announced in the past, $e_{i, t, 0}^{a}$; third, the anticipation of future changes in fiscal policy, announced at time $t$, to be implemented at a future date, $e_{i, t, j}^{a}$ for $j=1,2,3$. Our moving average representation is truncated because the length of the $B(L)$ and $C(L)$ polynomials is limited to three-years. This truncation, however, does not affect the possibility of correctly estimating the fiscal multipliers, as all omitted shocks and all information lagged $t-4$ and earlier are orthogonal to the variables included in our specification ${ }^{13}$. The moving-average representation is specified to al-

\footnotetext{
${ }^{13}(2)$ differs from a VAR. The usual practice in VAR models is to derive impulse responses first by estimating the model in autoregressive form, then by identifying structural shocks from the VAR residuals, and finally inverting the VAR representation to obtain the infinite MA representation in which all variables included in the VAR are expressed as linear functions of a distributed lag of structural shocks. The coefficients in this representation (that are not directly estimated) define the impulse response function. In our case, since we observe the structural shocks from the narrative method, we can directly compute impulse responses, thus following the estimation procedure adopted by Romer and Romer (2010). The advantage of observable narrative shocks is that they allow to compute impulse responses omitting - differently from a standard VAR - a large amount of information which would be orthogonal to the shocks included in the regression. Therefore, parsimony in the specification is paired with consistent (though not efficient) estimation. We pay a cost in terms of precision, as the omitted information affects the size of the confidence intervals of the impulse response functions.
} 
low for different effects of unanticipated and anticipated adjustments. Also different coefficients are allowed for adjustment announced in the past and implemented at time $\mathrm{t}$ and adjustments announced at time $\mathrm{t}$ for the future. To avoid double counting we exclude lags of future of $e_{i, t, j}^{a}$, as their dynamic effect is captured by $e_{i, t+j, 0}^{a}$. The parameters $\varphi_{1, i}, \varphi_{2, i}, \varphi_{3, i}$ are estimated on a country by country basis on the time series of the narrative fiscal shocks. In other words (2) is a quasi-panel: we impose cross-country restrictions on the $B, C$ and $\gamma$ coefficients, but we allow for within- and between-country heterogeneity. "Within" because responses of $\Delta z_{i, t}$ to fiscal adjustments will be different for TB and EB plans. "Between" because they will also differ across countries as the $\varphi^{\prime} s$ differ, according to each country's specific style.

\subsection{Estimation}

The model is estimated, for each macro variable we analyze, output growth, consumption growth, etc., by SUR (Seemingly Unrelated Regressions) to take into account simultaneous cross-country correlations of residuals . The overall model contains a total of 56 equations: 4 equations for each of the 14 countries. The total number of estimated parameters is 100: 18 common parameters, 14 country fixed effects, 26 time dummies and $\left(14^{*} 3\right)$ parameters in the equations linking unexpected to expected shocks. We expect that our specification will deliver much more precise estimates of the coefficients than those normally obtained in VAR for a number of reasons. First, what we estimate is a quasi-panel version of the truncated MA representation adopted by Romer and Romer (2010) for U.S. data: the cross-sectional dimension allows us to significantly enlarge the sample size and the precision of the estimates. Second, consistently with the SUR estimation of the quasi-panel model, we bootstrap residuals by taking into account the fact that there is cross-sectional correlation among them. Third, plans identified by the narrative record, differently from shocks identified in a VAR, are observable and they are therefore not resampled when confidence intervals are constructed by bootstrap methods. Finally, allowing for an heterogenous effect of TB and EB plans reduces the size of residuals in the estimated model.

\subsection{Simulation}

We use the estimated model to simulate the effect of an average adjustment plan which is allowed to be heterogenous across countries and across type 
of stabilization (EB or TB). The main advantage of this strategy is that we simulate an average of plans actually observed in our sample. Given our specification it would be tempting to analyze alternative consolidation plans and to simulate their effect of output using only the moving average representation of the model. Think for example of testing the effectiveness of front-loaded plans ("bite the bullet" or "cold turkey"), versus back-loaded ones (Saint Augustine: "Lord, make me chaste; but not yet." ${ }^{14}$, or of testing "shrinking the government" plans (which cut both taxes and spending), versus conventional fiscal austerity plans (which cut spending but raise taxes). This would be technically feasible, but in doing so we would simulate a plan which never happened in the data, and it would thus be impossible to design a powerful test of the hypotheses of interest. This is why we limit ourselves to simulating the average plan observed in the data for each country, and to assess if there is a significant difference between TB and EB average plans.

Within our framework, out of sample simulations of specific plans should only be conducted if such plans are sufficiently close to the average plans which have driven the estimation of our model. In a related paper (Alesina et al 2014) we use the model to simulate, out-of-sample, the output effect of the fiscal stabilization plans adopted sinchronously by various countries over the years 2010-2013. We find that out of sample simulations that project output growth conditional upon exogenous fiscal adjustments only, do reasonably well in predicting total output fluctuations over those years, particularly, and not surprisingly, for those countries where the main shock in that period was indeed a fiscal policy one. For example, the tax-based adjustment implemented in Italy in 2010-13 is sufficient by itself to explain the recession experienced by the country over the period 2011-2012 (with negative GDP growth of around 2 per cent in each year). Again, exercizes like these ones can be implemented only if the simulated plans are not too distant from those used to estimate our model. We examine this condition checking that the simulated plans do not violate the confidence intervals around the average estimated plans.

Our simulations are constructed computing impulse responses to an initial unexpected fiscal correction. The multi-year nature of the correction is then constructed using the auxiliary equations that relate unanticipated corrections in year $t$ to corrections announced in year $t$ to be implemented in years $t+1, t+2$ and $t+3$. That is when we simulate the response

\footnotetext{
${ }^{14}$ We are grateful to Jeff Frankel for this iconographic labelling of alternative plans.
} 
to an unanticipated correction we take into account the fact that such a correction typically does not occur in isolation but is accompanied by the contemporaneous announcement of future shifts in fiscal variables according to our estimates of the $\varphi$ parameters. The initial impulses are allowed to be correlated across countries. Impulse responses to correlated shocks can be computed using the Generalized Impulse Response Functions (GIRF) discussed in Garratt et al (2012), where contemporaneous linkages across shocks are constructed using the estimated covariances of the error terms. Following a similar approach we first estimate the $\varphi$ coefficients which describe the response of anticipated shocks to unanticipated ones. Then, when we simulate the impact of a realization of $e_{i, t}^{u}$, we also change $e_{i, t, 1}^{a}$ (by the estimate of $\varphi_{1, i}$ ), $e_{i, t, 2}^{a}$ (by the estimate of $\varphi_{2, i}$ ), and $e_{i, t, 3}^{a}$ (by the estimate of $\varphi_{3, i}$ ) ${ }^{15}$. We compute impulse responses to a shock in the unanticipated component of the fiscal corrections, $e_{i, t}^{u}$, equal to one per cent of GDP. The total size of the adjustment, however, will differ across countries as the response of anticipated corrections to unanticipated ones differs from one country to another. Finally, the effects of different style of fiscal adjustments can be gauged by comparing the impulse responses of different countries. We compute impulse responses to the announcement of a fiscal plan as the difference between two model-based forecasts: those obtained conditionally upon a fiscal adjustment

\footnotetext{
${ }^{15}$ Our estimates of the $\varphi$ parameters are simply meant to capture the correlation between observable anticipated and unanticipated corrections. Thus, for our purposes, there is no need to instrument the regressors to obtain valid estimates.
} 
plan and those obtained when there is no plan. ${ }^{16}$.

\subsection{Discussion}

In this sub-section we discuss two issues that arise in our estimation strategy. First our choices in restricting the more general specification to derive (2). Then we compare our strategy for the simulation of plans to those adopted in other studies.

\subsubsection{Model restrictions}

An unrestricted version of (2) would be

$$
\begin{aligned}
\Delta z_{i, t}= & \alpha+B_{1}(L) \tau_{i, t}^{u}+B_{2}(L) \tau_{i, t, 0}^{a}+ \\
& C_{1}(L) g_{i, t}^{u}+C_{2}(L) g_{i, t, 0}^{a}+ \\
& +\sum_{j=1}^{3} \gamma_{j}^{a} \tau_{i, t, j}^{a}+\sum_{j=1}^{3} \delta_{j} g_{i, t, j}^{a}+\lambda_{i}+\chi_{t}+u_{i, t}
\end{aligned}
$$

\footnotetext{
${ }^{16}$ We do this:

1. generating a baseline simulation for all variables, solving dynamically forward the estimated system setting all shocks to zero;

2. generating an alternative simulation for all variables giving a $1 \%$ of GDP shock to $e_{i, t}^{u}$, and letting all anticipated shocks react endogenously according to the $\varphi$ coefficients. We then solve dynamically forward the model for the alternative scenarios up to the same horizon used in the baseline simulation;

3. computing impulse responses as the difference between the simulated values in the two steps described above;

4. computating confidence intervals by block bootstrapping. (We use block bootstrap to take into account the possibility of autocorrelation in the residuals of the estimated system. In fact, the evidence for autocorrelation in the residuals is very weak and block bootstrapping makes very little difference for our empirical results). We bootstrap preserving the cross-country correlation between the $\mu_{i, t}$ in each replication of the bootstrap-that is bootstrapping two rows of residuals at the time. Bootstrapping requires saving the residuals from the estimated model and then iterating the following steps: a) re-sample rows of the saved residuals and generate a set of observations for all variables, b) re-estimate the model; c) compute impulse responses going through the steps described in the text; d) go back to step a). By going thruogh 1,000 iterations we produce bootstrapped distributions for impulse responses and compute confidence intervals.
} 


$$
\begin{array}{cc}
\tau_{i, t, 1}^{a}=\varphi_{1, i} \tau_{i, t}^{u}+v_{1, i, t} & \tau_{i, t, 1}^{a}=\varphi_{7, i} g_{i, t}^{u}+v_{7, i, t} \\
\tau_{i, t, 2}^{a}=\varphi_{2, i} \tau_{i, t}^{u}+v_{2, i, t} & \tau_{i, t, 2}^{a}=\varphi_{8, i} g_{i, t}^{u}+v_{8, i, t} \\
\tau_{i, t, 3}^{a}=\varphi_{3, i} \tau_{i, t}^{u}+v_{3, i, t} & \tau_{i, t, 3}^{a}=\varphi_{9, i} g_{i, t}^{u}+v_{9, i, t} \\
g_{i, t, 1}^{a}=\varphi_{4, i} g_{i, t}^{u}+v_{4, i, t} & g_{i, t, 1}^{a}=\varphi_{10, i} \tau_{i, t}^{u}+v_{10, i, t} \\
g_{i, t, 2}^{a}=\varphi_{5, i} g_{i, t}^{u}+v_{5, i, t} & g_{i, t, 2}^{a}=\varphi_{11, i} \tau_{i, t}^{u}+v_{11, i, t} \\
g_{i, t, 3}^{a}=\varphi_{6, i} g_{i, t}^{u}+v_{6, i, t} & g_{i, t, 3}^{a}=\varphi_{12, i} \tau_{i, t}^{u}+v_{12, i, t} \\
g_{i, t}^{u}=\varphi_{13, i} \tau_{i, t}^{u}+v_{13, i, t} &
\end{array}
$$

There are many more parameters in (3) than could be estimated given the available observations on the components of fiscal plans, since 140 more $\varphi^{\prime} s$ would need to be estimated.

Note that estimates of the $\varphi^{\prime} s$ are essential to measure tax and spending multipliers. Consider, for the sake of illustration, the case of a researcher interested in the output effect of an unanticipated tax change $\tau_{i, t}^{u}$. $B_{1}(L)$ would correctly measure this multiplier only if $\varphi_{1, i}=\varphi_{2, i}=\ldots=\varphi_{13, i}=0$. In fact, only in this case the experiment of introducing a shock to $\tau_{i, t}^{u}$ setting all the other innovations to zero would be a valid one. If, for example, $\varphi_{13, i} \neq 0$, one could not set $g_{i, t}^{u}=0$ when simulating the effect of an unanticipated tax shock $\tau_{i, t}^{u}$. In other words, since the parameters in our model are estimated allowing for the sample correlation between changes in taxes and spending as well as between unanticipated and anticipated changes, such correlations cannot be assumed away when the model is simulated.

The model illustrated in the previous paragraph, (2), saves degrees of freedom first by studying the correlation between unanticipated and anticipated total adjustments, that is by estimating only three $\varphi^{\prime} s$ per country instead of thirteen as in (3), and then by distinguishing between tax-based and expenditure-based adjustments. Our baseline specification also imposes the restriction that all anticipated shocks occurring at time $t$ have the same impact on the dependent variable independently on how far back they had been announced. This is why we use a single variable, $e_{i, t, 0}^{a}$. As already argued (Mertens and Ravn 2011) this seems a very reasonable way to save on degrees of freedom.

Alternative restrictions are possible and (2) is not the only option, although a reasonable one in our view. We have experimented with alternative restrictions finding results that convey a very similar message to what we find estimating (2) 


\subsubsection{Exogeneity}

The episodes of fiscal adjustment identified with the narrative method by D\&al have been used in Guajardo et al (forthcoming) to address a question similar to the one studied in this paper. These authors, however, instead of constructing and analyzing fiscal plans, use the D\&al episodes to construct "fiscal shocks". These shocks are defined (we shall call them "IMF shocks", $e_{t}^{I M F}$, based on the common institution of these authors) as the sum of the unexpected adjustments that occur in year $t$ and the past announced adjustments also implemented in year $t$ : they thus correspond to (a fraction of) the shifts in fiscal variables reported in the national accounts for year $t$. $e_{t}^{I M F}$ are thus defined:

$$
e_{t}^{I M F}=e_{t}^{u}+e_{t, 0}^{a}
$$

Jordà and Taylor (2013), have argued that $e_{t}^{I M F}$ are not exogenous shocks, and thus are not valid instruments, because they can be predicted using their own past, past values of debt dynamics and past values of output growth. The third source of predictability - the fact that the D\&al episodes appear to be predicted by past output growth - only arises if one transforms those episodes from a continuous variable into a 0/1 dummy variable, as done in Jordà and Taylor (2013). The reason, as a simple regression shows, is that transformation into a 0/1 dummy, and the loss of information it implies, introduces correlation with past output growth. We have further checked for predictability from past output growth running a simple regression of D\&al adjustments on a distributed lag of output growth. The only country for which the D\&al narrative identified fiscal adjustments can be predicted by past output growth is Holland, which we drop from the sample ${ }^{1718}$

The first two sources of predictability — from past episodes of fiscal adjustment and past values of debt dynamics - do not invalidate the type of exogeneity that is relevant for the estimation of the output effects of fiscal

\footnotetext{
${ }^{17}$ The exclusion of Holland is not crucial to determine our results. For the reson discussed above our results are also different from those reported in de Cos and Mora (2012) who, like Jordà and Taylor (2013), transform the D\&al adjustments into a 0/1 dummy and then find that this dummy can be predicted by past output growth.

${ }^{18}$ Mertens and Ravn (2013) have pointed out the potential measurement error associated with the measurement of fiscal shocks. Unfortunately the solution they propose - using narrative shocks as instruments for the true unobservable shocks - is not applicable to plans that include both anticipated and unanticipated components. Nevertheless, the issue raised by these authors is a relevant one, and an extension of their approach to plans is a very interesting agenda for future research.
} 
policy within a plan: this is beacuse exogeneity is different from predictability. Within our framework, as in Romer and Romer (2010), the correct estimation of the effects on output of a fiscal adjustment only requires the use of exogenous fiscal adjustments, i.e. those that cannot be predicted from past output growth. The exogeneity required to estimate fiscal multipliers within a dynamic model like the one used in this paper is different from the condition required if one were to estimate these parameters from an average treatment effect (ATE). What matters here is weak exogeneity for estimation, and strong exogeneity for simulation, not the random assignment of a treatment. Weak and strong exogeneity are satisfied by the original D\&al episodes.

To further illustrate this points, consider our plans and, for simplicity, drop the country index and restrict the anticipation horizon to only one period. Then

$$
\begin{aligned}
e_{t} & =e_{t}^{u}+e_{t, 0}^{a}+e_{t, 1}^{a} \\
e_{t, 1}^{a} & =\varphi e_{t}^{u}+v_{t} \\
e_{t, 0}^{a} & =e_{t-1,1}^{a}
\end{aligned}
$$

Based on this definition, the fact that $e_{t}^{I M F}$ are correlated across time is not surprising. In fact

$$
\begin{aligned}
\operatorname{Cov}\left(e_{t}^{I M F}, e_{t-1}^{I M F}\right) & =\operatorname{Cov}\left(\left(e_{t}^{u}+e_{t, 0}^{a}\right),\left(e_{t-1}^{u}+e_{t-1,0}^{a}\right)\right) \\
& =\operatorname{Cov}\left(\left(e_{t}^{u}+e_{t-1,1}^{a}\right),\left(e_{t-1}^{u}+e_{t-1,0}^{a}\right)\right) \\
& =\varphi \operatorname{Var}\left(e_{t-1}^{u}\right)
\end{aligned}
$$

since

$$
e_{t, 0}^{a}=e_{t-1,1}^{a}=\varphi e_{t-1}^{u}+v_{t-1}
$$

Importantly, however, the predictability of $e_{t}^{I M F}$ by their own past does not violate the weak exogeneity of $e_{t}^{u}, e_{t, 0}^{a}$ and $e_{t, 1}^{a}$ which is the condition required if one estimates the output effect of fiscal studying plans. Consider, for the sake of illustration, this simple model

$$
\begin{aligned}
\Delta y_{t} & =\beta_{0}+\beta_{1} e_{t}^{I M F}+u_{1 t} \\
e_{t}^{I M F} & =\rho e_{t-1}^{I M F}+u_{2 t} \\
\left(\begin{array}{c}
u_{1 t} \\
u_{2 t}
\end{array}\right) & \sim N\left[\left(\begin{array}{l}
0 \\
0
\end{array}\right),\left(\begin{array}{ll}
\sigma_{11} & \sigma_{12} \\
\sigma_{12} & \sigma_{22}
\end{array}\right)\right]
\end{aligned}
$$


The condition required for $e_{t}^{I M F}$ to be weakly exogenous for the estimation of $\beta_{1}$ is $\sigma_{12}=0$, and it is independent of $\rho$.

Other authors, as we have discussed above, have used the D\&al episodes to construct individual fiscal shocks, $e_{t}^{I M F}=e_{t}^{u}+e_{t, 0}^{a}$, and then simulate their effects, rather than the effects of plans. Jordà and Taylor (2013) follow this strategy using the Local Projections Method after having purged $e_{t}^{I M F}$ them from predictability. They need to do this because the autocorrelation of $e_{t}^{I M F}$ is problematic for the application of the Local Projections Method. To illustrate the point consider the following simple VAR, augmented with the observable, narratively identified, $e_{t}^{I M F}$ shocks

$$
Y_{t}=A Y_{t-1}+\boldsymbol{\beta}_{1} e_{t}^{I M F}+\epsilon_{t}
$$

The impulse response

$$
E\left(Y_{t+i} \mid \tau_{t}^{u}=1, I_{t}\right)-E\left(Y_{t+i} \mid \tau_{t}^{u}=0, I_{t}\right)=\frac{\partial Y_{t+i}}{\partial \tau_{t}^{u}}=A^{i} \boldsymbol{\beta}_{1}
$$

can be obtained by a series of country regressions

$$
y_{t+i}=\pi_{i}^{\prime} Y_{t-1}+h_{i} e_{t}^{I M F}+v_{t+i}
$$

These regressions omit $e_{t+i}^{I M F}, \ldots, e_{t+1}^{I M F}$. This omitted variables problem would not lead to inconsistent estimates of the parameters of $A^{i} \boldsymbol{\beta}_{1}\left(p \lim h_{i}=A^{i} \beta_{1}\right)$ only if $e_{t}^{I M F}$ were orthogonal to all omitted variables. ${ }^{19}$ Unfortunately, this orthogonality is lost when fiscal policy is implemented through plans because, as shown above, the very nature of plans generates a correlation in $e_{t}^{I M F}$.

Jordà and Taylor (2013) address this problem implementing the following correction of $e_{t}^{I M F}:$ (i) redefine $e_{t}^{I M F}$ innovations as a 0/1 dummy variable, (ii) estimate a propensity score deriving the probability with which a correction is expected by regressing it on its own past and predictors, (iii) use

\footnotetext{
${ }^{19}$ Consistency depends on the fact that the MA representation of the Data Generating Process is

$$
\begin{aligned}
Y_{t+i}= & A^{i+1} Y_{t-1}+A^{i} \beta_{1} e_{t}^{I M F}+v_{t+i} \\
v_{t+i}= & \beta_{1} e_{t+i}^{I M F}+A^{i} \beta_{1} e_{t+i-1}^{I M F}+\ldots A^{i-1} \beta_{1} e_{t+1}^{I M F}+ \\
& +\epsilon_{t+i}+A \epsilon_{t+i-1}+\ldots A^{i} \epsilon_{t}
\end{aligned}
$$

and therefore $e_{t}^{I M F}$ is orthogonal to $v_{t+i}$, provided they are orthogonal to the other structural shocks and not autocorrelated.
} 
the propensity score to derive an Average Treatment Effect based on Inverse Probability Weighting.

This method has a number of limitations. First, as already discussed, replacing $e_{t}^{I M F}$ innovations with a $0 / 1$ dummy variable gives up relevant information on the intensity and the nature of the adjustment. Second, the links between the announced and anticipated part of a stabilization plan are lost. Third, the presence of the forward looking component — which is omitted from the specification - introduces a bias in the impulse response computed via local-projections whenever there is a systematic relation between the forward looking component and the unexpected component of the adjustment, as in the case in the D\&al episodes. Fourth, fiscal plans are different across countries because the style of fiscal adjustments differs across countries: thus they cannot be assimilated to an identical common treatment administered to many patients.

\section{Results}

In this section we present our baseline results from the estimation of (2) and the associated equations used to estimate the $\varphi^{\prime} s$. The estimation runs from 1981 to 2007: we observe exogenous shifts in fiscal variables over the period 1978-2009, but we lose observations from the presence of leads and lags of the fiscal variables.

Table 4 illustrates the difference in the style of fiscal adjustments in the various countries. In this table (where we also report the results for Sweden and Finland which are not in the baseline regressions because for these two countries we lack data on confidence) we report the estimates of $\varphi_{1, i}, \varphi_{2, i}$, $\varphi_{3, i}$ with their standard errors in brackets. We show a coefficient of zero, with no standard error, whenever there are too few observations available for estimation. Canada and Australia and Sweden record a cumulative response (sum of the responses of one-, two- and three-year ahead announcements to an unanticipated correction) which is in the region of unity, and higher than one for Canada. Austria, Denmark, France, Japan and the U.K. feature a positive but milder response of anticipated corrections to current unanticipated ones with coefficients ranging from 0.12 to 0.85 . This correlation becomes not statistically different from zero in Belgium, Finland, Germany, Ireland, Japan, Ireland, Portugal, Spain, and the U.S., where fiscal policy corrections 
are implemented mainly via unanticipated shocks ${ }^{20}$. At the opposite end of the spectrum lies Italy, where one and two-year ahead anticipations are negatively correlated with unanticipated shocks (significantly at the one-year horizon). This suggests that at least part of a typical Italian stabilization is transitory.

\section{Insert Table 4 here}

Figure 1 illustrates visually the potential importance of this point by reporting $e_{i, t}^{u}$ and $e_{i, t, 1}^{a}$ for all countries in our sample. The figure shows a significant heterogeneity across countries in the design of their fiscal plans and confirms the results of Table 4. Compare, for instance, the results for Sweden and Italy. In Sweden the continuous and the dotted lines move together, indicating that unanticipated (the continuous line) and 1-year ahead anticipated (the dotted line) shifts in fiscal stance move in the same direction. That is, unanticipated tightenings are accompanied by the announcement of more tightening one year down the road. The opposite happens in Italy.

\section{Insert Figure 1 here}

Table 5 reports the estimated coefficients from the estimation of (2). The coefficients relative to tax-based episodes are always lower than their correspondent spending-based ones. Coefficients for taxes are almost always negative and significant.

\section{Insert Table 5 here}

Figure 2 reports impulse responses of output growth to EB and TB fiscal plans. As everywhere else in this paper, for comparability with the available empirical literature, we report one standard errors bands. It is probably worth noting that the difference between the effect of EB ant TB plans on output remains significant also if two standard errors bands, with 95 per cent confidence intervals are considered. (results are available form the authors). Countries are ordered starting from those that feature a positive but mild correlation between future anticipated and current unanticipated corrections

\footnotetext{
${ }^{20}$ Table 4 reports a zero with no standard error where the number of observations was not large enough to estimate the relevant $\varphi^{\prime} s$.
} 
(Australia, Austria, Denmark, France, the U.K. and Japan). Next we list the countries for which this correlation is close to zero (Belgium, Germany, Ireland, Portugal, Spain, and the U.S.). Finally the two opposite ends of the spectrum in terms of the relation between anticipated and unanticipated fiscal adjustments, Canada and Italy. The patterns differ across countries (because of the heterogeneity in styles) but in all of them the difference between EB and TB adjustments is large and statically significant. In all countries TB adjustments are recessionary and there is no sign of recovery for at least the three years following the start of a plan. In the case of EB adjustments recessions are on average much smaller and short-lived. Note that this is an average which could result from some bigger EB induced recessions and some expansionary EB adjustments. Interestingly, Canada features the largest difference between TB and EB plans while the smallest is observed in the case of Italy. This is not surprising because an unanticipated shift in taxes equal to $1 \%$ of GDP (our experiment) in Italy is partly offset by the anticipation of future shifts in the opposite direction. This comparison hints at the fact that adjustments have especially low cost when the announcement of a spending cut is not accompanied by that of a future reversal. On the contrary they are less effective when they are stop-and-go. ${ }^{21}$

\section{Insert Figure 2 here}

Figures 3 and 4 show the response of households' consumption on durables and non-durables and of business investment ${ }^{22}$. The results indicate that

\footnotetext{
${ }^{21}$ Guajardo et al (forthcoming) also use the (D\&al) data and also distinguish between EB and TB adjustments. Compared with our results, however, the impulse responses reported in that paper are constructed overlooking plans and country-specific styles i.e. overlooking the correlation between unanticipated and anticipated shifts in taxes and spending. Although the general message is similar - EB adjustments are less recessionary than TB ones - overlooking plans results in much wider confidence intervals. Note that Guajardo et al (forthcoming) report, in their Figure 9, one standard error bands, with 64 per cent confidence intervals. To allow comparability we do the same in this paper ( in a version of this paper previously circulated labels on confidence bound were wrongly indicating the width of our bands at two stadard deviations). It is probably worth noting that the difference between the effect of EB ant TB plans on output remains significat also if two standard errors bands, with 95 per cent confidence intervals are considered.

${ }^{22}$ The data refer to private capital formation for all countries except for Spain and Italy where, for the early part of the sample, we only have data total capital formation which includes both private and public capital formation. Our results are unchanged if we drop these two countries in our estimation.
} 
the different effect on output growth of TB and EB adjustments is to be attributed more to the response of private investment, than to that of private consumption. Consumption growth typically responds less heterogeneously than investment to TB and EB adjustments.

\section{Insert Figures 3 and 4}

Figures 5 and 6 report the responses of the indicators of consumer and business confidence. The evidence of heterogeneity between TB and EB adjustments is confirmed in the response of consumer confidence, and more strongly confirmed for business confidence. The evidence from the responses of business confidence and investment is consistent with a causal relation running from business confidence to investment and output.

\section{Insert Figures 5 and 6}

Finally, we consider the response of monetary policy and of inflation, which are reported in Figures 7 and 8.

\section{Insert Figures 7 and 8}

Overall, monetary policy (the change in 3-month interest rates) is more expansionary in the case of EB adjustments than in the case of TB ones. The differences in the responses of monetary policy to fiscal plans, however, appears to be too small to explain the large differences in output responses; moreover the pattern of cross-country heterogeneity in the responses of monetary policy to fiscal plans does not match the one observed for output.

The response of inflation helps understand why monetary policy might be tighter during TB plans. Figure 8 shows that TB adjustments are in general more inflationary than EB ones. One possibility, as discussed in Alesina and Perotti (1997), is that TB plans include increases in indirect taxes and in income taxes which trigger a response of wages. This evidence raises the issue of the importance of accompanying monetary policy in determining the heterogenous effects on output of TB and EB plans. Could it be that EB plans are less recessionary precisely because monetary policy is more expansionary during such plans? If this were the case the heterogeneity between the two types of plans could disappear at the zero lower bound, where interest rates are prevented from falling. We address this issue in 
the next section where we show that monetary policy cannot be the main explanation for the difference in the effects of TB vs EB adjustments.

Before turning to our robustness analysis it is worth comparing once again the results for Canada and Italy. These two countries, as we discussed above, are at the opposite ends of the spectrum in terms of their styles of adjustments. In Canada the government typically announces fiscal plans that are consistent over time. Italy, on the contrary, is the quintessential example of stop-and-go policies. Interestingly, the evidence for Canada suggests that EB adjustments, when they are part of a consistent plan, might be expansionary, driven by a surge in private investment. In Italy, instead, the difference between EB and TB plans is the smallest among the countries in our sample, and EB plans don't feature positive effects on output. This observation suggests that consistent plans over time seem to be superior to stop-and-go, largely unpredictable policies. ${ }^{23}$

\section{Robustness}

\subsection{Monetary policy}

Does the accompanying monetary policy explain the difference between EB and TB adjustments? In this section we show that the answer is negative ${ }^{24}$. We show this results in two ways: first, we exploit the fact that for a sizeable part of our sample monetary policy is constrained, since in the Euro area it is conducted by the ECB and it cannot respond to country-specific fiscal adjustments. Next, we design a counterfactual experiment aimed at evaluating what the effect of fiscal adjustment would be if policy rates remained unchanged.

\footnotetext{
${ }^{23}$ The policy reversals which are part of Italian plans might suggest the presence of intertemporal effects. For instance, if taxes are high today, but expected to fall tomorrow, labor supply and output migh increase today. This does not seem to be the case because policy reversals in Italy are typically the result of temporary measures such as temporary tax amnesties.

${ }^{24}$ Guajardo et al (forthcoming) also compare TB and EB adjustments and claim that this is the case. Their evidence, however, is based on the analysis of isolated shocks, rather than plans, a procedure which we have argued is incorrect, at least with these data.
} 


\subsubsection{The effect of fiscal policy in euro area countries}

We now separate our observations in two groups: in the first group we include observations for euro area countries (Austria, Belgium, France, Finland, Germany, Ireland, Italy, Portugal and Spain) from 1999; in the second group all other observations: non euro-area countries (Australia, Denmark, U.K., Japan, Sweden, U.S. and Canada) and euro-area countries before 1999. The motivation for this divisions is that the common currency prevents monetary policy from responding to fiscal developments in member countries ${ }^{25}$. We therefore proceed to the estimation of the following system

$$
\begin{aligned}
\Delta z_{i, t}= & \alpha+\delta_{k}(L) \Delta i_{t}+B_{1 k}(L) e_{i, t}^{u} * T B_{i, t}+B_{2 k}(L) e_{i, t}^{a} * T B_{i, t}+ \\
& C_{1 k}(L) e_{i, t}^{u} * E B_{i, t}+C_{2 k}(L) e_{i, t}^{a} * E B_{i, t}+ \\
& +\sum_{j=1}^{3} \gamma_{j k} e_{i, t, j}^{a} * E B_{i, t}+\sum_{j=1}^{3} \delta_{j k} e_{i, t, j}^{a} * T B_{i, t}+\lambda_{i}+\chi_{t}+u_{i, t} \\
e_{i, t, 1}^{a}= & \varphi_{1, i} e_{i, t}^{u}+v_{1, i, t} \\
e_{i, t, 2}^{a}= & \varphi_{2, i} e_{i, t}^{u}+v_{2, i, t} \\
e_{i, t, 3}^{a}= & \varphi_{3, i} e_{i, t}^{u}+v_{3, i, t} \\
k= & E M U, \text { non EU plus Europe before EMU }
\end{aligned}
$$

In (5) the coefficients describing the responses of the relevant macro variables to fiscal plans are restricted to be equal within each group, euro and non-euro members, respectively. No restrictions are imposed between the two groups.

The impulse responses for output generated by the unrestricted system, reported in Figure 9, confirms the robustness of our baseline results showing an heterogenous effect of $\mathrm{EB}$ and TB plans. Interestingly, this robustness results emerge even if the panel restrictions are rejected ${ }^{26}$.

\section{Insert Figure 9}

\footnotetext{
${ }^{25}$ A similar analysis is conducted by Jalil (2012). This paper considers fiscal shocks rather than fiscal plans and finds that the tax multiplier is of about 3, while the spending multiplier is close to zero in countries where monetary authorities are constrained in their ability to counteract shocks because they are in either a monetary union or a liquidity trap.

${ }^{26}$ In this estimation we have extended the sample to Sweden and Finland, the two countries which so far we had been excluded because of lack of some data. Introducing these two countries-and even doing so in a less restricted system- leaves the main result
} 


\subsubsection{Counterfactual Evidence}

Consider a simplified representation of the joint dynamics of output growth, $\Delta y_{t}$, the monetary policy variable (which for simplicity we denote $M P_{t}$ ), and of our narrative fiscal corrections consisting of both unanticipated and anticipated components

$$
\begin{aligned}
{\left[\begin{array}{c}
\Delta y_{t} \\
M P_{t}
\end{array}\right] } & =\left[\begin{array}{ll}
a_{11} & a_{12} \\
a_{21} & a_{22}
\end{array}\right]\left[\begin{array}{c}
\Delta y_{t-1} \\
M P_{t-1}
\end{array}\right]+\left[\begin{array}{c}
\varepsilon_{t}^{y} \\
\varepsilon_{t}^{m}
\end{array}\right] \\
\varepsilon_{t}^{y} & =\beta_{1} e_{t}^{f} * T B_{t}+\beta_{2} e_{t}^{f} * E B_{t}+\beta_{3} e_{t}^{n f}+e_{t}^{y} \\
\varepsilon_{t}^{m} & =\gamma_{1} e_{t}^{f} * T B_{t}+\gamma_{2} e_{t}^{f} * E B_{t}+\gamma_{3} e_{t}^{n f}+\gamma_{4} e_{t}^{y}+e_{t}^{m}
\end{aligned}
$$

The VAR innovations in the output growth equation, $\varepsilon_{t}^{y}$, include the narrative (structural) fiscal shocks, that are allowed to have heterogenous effects according to their nature, $e_{t}^{f} * T B_{t}$ and $e_{t}^{f} * E B_{t}$, non-fiscal shocks, $e_{t}^{n f}$, and a residual output shock $e_{t}^{y}$.that for our purposes we do not need to identify. The VAR innovations in the equation for the monetary policy variable, $\varepsilon_{t}^{m}$, include the same structural shocks affecting the output innovations, and a structural monetary shock $e_{t}^{m}$. This model makes the (usual) recursive assumption between macroeconomic variables and monetary policy - that is we assume that monetary policy reacts contemporaneously to macro shocks, but it takes at least one lag before monetary policy can affect macroeconomic outcomes. This assumption is standard in VAR models of the monetary transmission mechanism. In principle, the recursive assumption become less plausible the lower the frequency at which the data are observed. We shall check its plausibility by comparing the response of output to monetary policy derived in our extended empirical model with those available in the literature and based on higher frequency data.

The moving average representation for output growth, consistent with the above representation and truncated after two periods can be written as follows

unaltered. This is confirmed when Sweden and Finland are included in the restricted model. The results are available by the authors upon request. 


$$
\begin{aligned}
\Delta y_{t}= & \beta_{1} e_{t}^{f} T B_{t}+\beta_{2} e_{t}^{f} E B_{t}++\beta_{3} e_{t}^{n f}+e_{t}^{y}+ \\
& +a_{11}\left(\beta_{1} e_{t-1}^{f} * T B_{t-1}+\beta_{2} e_{t-1}^{f} * E B_{t-1}+\beta_{3} e_{t-1}^{n f}+e_{t-1}^{y}\right)+ \\
& +a_{12}\left(\gamma_{1} e_{t-1}^{f} T B_{t-1}+\gamma_{2} e_{t}^{f} E B_{t-1}+\gamma_{3} e_{t-1}^{n f}+\gamma_{4} e_{t-1}^{y}+e_{t-1}^{m}\right)+ \\
& \left(a_{11}^{2}+a_{12} a_{21}\right)\left(\beta_{1} e_{t-2}^{f} T B_{t-2}+\beta_{2} e_{t-2}^{f} E B_{t-2}+\beta_{3} e_{t-2}^{n f}+e_{t-2}^{y}\right)+ \\
& \left(a_{11} a_{12}+a_{12} a_{22}\right)\left(\gamma_{1} e_{t-2}^{f} T B_{t-2}+\gamma_{2} e_{t-2}^{f} E B_{t-2}+\gamma_{3} e_{t-2}^{n f}+\gamma_{4} e_{t-2}^{y}+e_{t-2}^{m}\right)
\end{aligned}
$$

As structural shocks are orthogonal to each other, projecting $\Delta y_{t}$ on $e_{t}^{f}$, $e_{t-1}^{f}$ and $e_{t-2}^{f}$ allows us to obtain consistent estimates of the impulse responses of output growth to $T B$ and $E B$ adjustments

$$
\Delta y_{t}=\sum_{i=1}^{3} \hat{\delta}_{i, T B} e_{t-i+1}^{f} * T B_{t-i+1}+\sum_{i=1}^{3} \hat{\delta}_{i, E B} e_{t-i+1}^{f} * E B_{t-i+1}+v_{1 t}
$$

This regression is equivalent (in the context of our example) to the output growth equation estimated in (2) in Section 3.5. Its coefficients reflect both the direct effect of fiscal policy on output (that depends on $\beta_{1}$ and $\beta_{2}$ ) and the indirect effect that depends on the response of monetary policy to the fiscal adjustment, namely $\gamma_{1}$ and $\gamma_{2}$. These two channels can be separated by estimating the following augmented moving average model where we allow output growth to respond directly to lagged monetary policy innovations through the coefficients $\hat{\pi}$. This augmented specification allows to "counterfactually" shut down the indirect monetary policy channel and therefore assess its importance in determining the heterogenous effect of EB and TB adjustments on output

$$
\begin{aligned}
\Delta y_{t}= & \sum_{i=1}^{3} \hat{\pi}_{i, T B} e_{t-i+1}^{f} * T B_{t-i+1}+\sum_{i=1}^{3} \hat{\pi}_{i, E B} e_{t-i+1}^{f} * E B_{t-i+1}+ \\
& +\sum_{i=1}^{2} \hat{\pi}_{i, M P} \varepsilon_{t-i}^{m}+v_{2 t}
\end{aligned}
$$

The following table compares the expected values of the coefficients estimated in (6) and (7) and illustrates how our augmented specification can 
be used to estimate the direct effect of fiscal policy on output controlling for the response of monetary policy to fiscal adjustments. ${ }^{27}$

\begin{tabular}{|c|c|c|c|}
\hline \multicolumn{4}{|c|}{ Closing the Monetary Policy Channel } \\
\hline \multicolumn{4}{|c|}{ baseline specification } \\
\hline & $\overline{\frac{\partial \Delta y_{t}}{\partial e_{t}^{f} * F_{i}}}$ & $\frac{\partial \Delta y t}{\partial \frac{\partial e_{t-1}^{f} * F_{i}}{f}}$ & $\frac{\partial \Delta y_{t}}{\partial e_{t-2}^{f} * F_{i}}$ \\
\hline$F_{i}=T B$ & $\beta$ & $a_{11} \beta_{1}+a_{10} \gamma$ & $\left(a^{2}+a_{10} a_{01}\right) \beta_{1}+\left(a_{11} a_{10}+a_{101} a_{00}\right) \gamma$ \\
\hline$F_{i}=E B$ & $\beta_{2}$ & $a_{11} \beta_{2}+a_{12} \gamma_{2}$ & $\left(a_{11}^{2}+a_{12} a_{21}\right) \beta_{2}+\left(a_{11} a_{12}+a_{12} a_{22}\right) \gamma_{2}$ \\
\hline \multicolumn{4}{|c|}{ "augmented specification } \\
\hline & $\left.\frac{\partial \Delta y_{t}}{\partial e_{t}^{f} * F_{i}}\right|_{\varepsilon_{t}^{m}=0}$ & $\left.\frac{\partial \Delta y_{t}}{\partial e_{t-1}^{f} * F_{i}}\right|_{\varepsilon_{t-1}^{m}=0}$ & $\left.\frac{\partial \Delta y_{t}}{\partial e_{t-2}^{f} * F_{i}}\right|_{\varepsilon_{t-2}^{m}=0}$ \\
\hline$F_{i}=T B$ & $\beta_{1}$ & $a_{11} \beta_{1}$ & $\left(a_{11}^{2}+a_{12} a_{21}\right) \beta_{1}$ \\
\hline$F_{i}=E B$ & $\beta_{2}$ & $a_{11} \beta_{2}$ & $\left(a_{11}^{2}+a_{12} a_{21}\right) \beta_{2}$ \\
\hline & $\overline{\frac{\partial \Delta y_{t}}{\partial e_{t-1}^{m}}}$ & $\frac{\overline{\partial \Delta y_{t}}}{\partial e_{t-2}^{m}}$ & \\
\hline & $a_{12}$ & $\left(a_{11} a_{12}+a_{12} a_{22}\right)$ & \\
\hline & $a_{12}$ & $\left(a_{11} a_{12}+a_{12} a_{22}\right)$ & \\
\hline
\end{tabular}

${ }^{27}$ First moments of all estimated parameters are conditonal upon the regressors in the relevant specification. 
Based on this analysis we have estimated an augmented version of (2) using $\Delta i_{t}$ as a proxy for monetary innovations ${ }^{28}$

$$
\begin{aligned}
\Delta z_{i, t}= & \alpha+\sum_{k=1}^{3} \delta_{k} \Delta i_{t-k}+B_{1}(L) e_{i, t}^{u} * T B_{i, t}+B_{2}(L) e_{i, t}^{a} * T B_{i, t}+ \\
& C_{1}(L) e_{i, t}^{u} * E B_{i, t}+C_{2}(L) e_{i, t}^{a} * E B_{i, t}+ \\
& +\sum_{j=1}^{3} \gamma_{j} e_{i, t, j}^{a} * E B_{i, t}+\sum_{j=1}^{3} \delta_{j} e_{i, t, j}^{a} * T B_{i, t}+\lambda_{i}+\chi_{t}+u_{i, t} \\
e_{i, t, 1}^{a}= & \varphi_{1, i} e_{i, t}^{u}+v_{1, i, t} \\
e_{i, t, 2}^{a}= & \varphi_{2, i} e_{i, t}^{u}+v_{2, i, t} \\
e_{i, t, 3}^{a}= & \varphi_{3, i} e_{i, t}^{u}+v_{3, i, t}
\end{aligned}
$$

Augmenting our baseline specification with lags of $\Delta i_{t}$ allows us to compute the impulse response to the fiscal plans by zeroing the response of monetary policy to all innovations and in particular to fiscal adjustments. The distributed lag of $\Delta i_{t}$ is significant in our output growth equation, but the effect of innovations in monetary policy on output are small relative to that of fiscal adjustments. The dynamic responses of output growth to the change in interest rates are described in the following table

\begin{tabular}{|c|c|c|c|}
\hline \multicolumn{4}{|c|}{ The Dynamic Response of $\Delta y_{t}$ to $\Delta i_{t-i}$} \\
\hline \hline period & $i=1$ & $i=2$ & $i=3$ \\
\hline coeff & -0.22 & -0.15 & -0.12 \\
\hline$t$-stat & -8.73 & -6.69 & -4.73 \\
\hline
\end{tabular}

These coefficients show a significant negative but small response of output growth to changes in the monetary policy rate. Technically speaking the response described by the coefficients in the table is not directly comparable with usual impulse responses describing the effect of monetary policy on output, because they are responses to monetary policy innovations and not to exogenous monetary policy shocks. However, taking into account the well established fact that monetary policy innovations are strongly correlated to exogenous monetary policy shocks (see e.g.. Rudebusch 1998) it is interesting

\footnotetext{
${ }^{28}$ Using a proxy for monetary policy innovations we are able to capture a more general monetary policy reaction function than that adopted in the illustrative example above.
} 
to note that the response implied by our estimated coefficients lies in between the typical response obtained on U.S. data (see e.g.. Christiano et al 1998) and that obtained on euro area data, which is smaller than that observed for the U.S. (see e.g.. Peersman and Smets 2001).

The counterfactual exercise aimed at shutting down the response of monetary policy to fiscal innovations is implemented by setting $\Delta i_{t-i}$ to zero. The impulse responses thus computed are reported in Figure 10 along with the responses obtained in the baseline model. The results in Figure 10 confirm the indications obtained estimating the baseline model. The conclusion is that the differential response of monetary policy to EB and TB adjustments cannot fully explain the different effect on output growth of EB and TB plans. ${ }^{29}$

\section{Insert Figure 10 here}

We have repeated this counterfactual experiment limiting the sample to the countries belonging to the euro area. Figure 11 shows that both the main evidence and the results of the counterfactual obtained by setting to zero the response of monetary policy to fiscal adjustments remain robust.

\section{Insert Figure 11}

\subsection{Is the choice between TB and EB plans related to the cycle, or to accompanying reforms?}

Some authors have found that the effects of fiscal contractions on output growth are asymmetric during economic expansions and recessions (see Auerbach and Gorodnichenko 2012, Bachmann and Sims 2011, Barro and Redlick $2011)^{30}$. Could the asymmetry we have documented between TB and EB plans be explained by the fact that the choice between the two types of adjustment is related to the cycle? In other words, is it the case that TB adjustments are chosen during recessions while EB ones are chosen during

\footnotetext{
${ }^{29}$ Note that some of these countries adopted the Euro therefore had an identical monetary policy for part of the period under consideration. Unfortunately we do not have enough cases of fiscal adjustment in the first decade of the Euro to use this feature of the data. it is in fact well known that after entering the monetary union, many countries relaxed rather than tighten their fiscal stance.

${ }^{30} \mathrm{~A}$ different results is however obtained by Ramey et al.(2013).
} 
periods of economic expansions? In principle the narrative approach should eliminate the correlation of the adjustments with the cycle, but the point is more subtle. The type of fiscal consolidation may be unrelated to the cycle when it is decided, but somehow it could happen that EB are chosen during booms and TB during recessions, possibly by chance. We will show below that this is not the case. A second concern may arise because of the possibility that the asymmetry between TB and EB plans might be explained by the fact that EB plans (differently from TB ones) often are adopted as part of a wider set of market-oriented reforms, such as labor and product market liberalizations. It could be that such reforms, rather than the character of the fiscal plan, is the reason for the milder effects on output growth.

To address the first concern we use a measure of the cycle, defined as the deviation of output from its Hodrick-Prescott trend. To address the second we use an index of labor market reforms constructed by the OECD. We then run a binary choice (panel) probit regression of the dummies identifying TB and EB episodes on these two measures separately. We find no evidence of a relation between the cycle or the degree of labor market reforms and the choice whether to implement a TB adjustment. The coefficient on the cyclical variable is 0.04 with an associated standard error of 0.73 . The McFadden $\mathrm{R}$-square of the regression is 0.001. There is instead very mild evidence for an higher likelihood to choose an EB plan during a recession: the coefficient on the cyclical variable is -0.16 with an associated standard error of 0.07 ; the McFadden R-square is 0.01. Interestingly, the marginal significance of the cycle variable disappears when time dummies, capturing common shocks, are included in the specification. Summing up. Our main result is not driven by the endogeneity of the type of adjustment to the cycle.

Similar results are obtained studying the relation between the choice whether to adopt an EB or a TB plan and the OECD index of labor market reforms. Note that this result is not inconsistent with the evidence and the case studies in Perotti (2013) and Alesina and Ardagna (1998, 2012). These papers argue that amongst all the fiscal adjustments the least costly are those accompanied but some supply side reforms and by wage moderation. So, for instance, amongst the EB adjustments those which are the least costly or even expansionary are those accompanied by such reforms. Our result is different. What we find is that the difference between EB and TB cannot be explained by supply side reforms. 


\section{Conclusions}

The main result of this paper is that while tax-based adjustments are associated with deep and long lasting recessions, expenditure-based adjustments are not. The output losses associated with the latter are very small, on average close to zero. This average is likely to be the result of some episodes of fiscal adjustment which are characterized by small output costs, and other which are accompanied by a (small) expansion. The aggregate demand component which reflects more closely the difference in the response of output to expenditure-based and tax-based adjustments is private investment. The confidence of investors also does not fall much after an expenditure-based adjustment, and promptly recovers and increases above the baseline; instead it falls for several years after a tax-based adjustment. The differences between the two types of adjustments appears not to be explained by a different response of monetary policy, and therefore it should not vanish at the zero lower bound. Nor is it explained by the cycle, or by systematically different choices of the supply side reforms that may accompany a fiscal correction. Finally, and importantly, we have shown that the correct methodology to answer the question What are the output effects of fiscal consolidations? is studying fiscal plans, rather than individual fiscal shocks as normally done in the literature.

\section{References}

Alesina A. and S. Ardagna (1998), "Tales of Fiscal Adjustment", Economic Policy, 13(27), 487-545.

Alesina A. and S. Ardagna (2010), "Large Changes in Fiscal Policy: Taxes versus Spending", Tax Policy and the Economy, vol. 24, 35-68, edited by J.R. Brown.

Alesina A. and S. Ardagna (2012), "What Makes Fiscal Adjustments Successful?", forthcoming in Tax Policy and the Economy, vol. 26. edited by J.R. Brown.

Alesina A., S. Ardagna, R. Perotti and F. Schiantarelli (2002), "Fiscal Policy, Profits and Investment", American Economic Review, 92(3), 571589.

Alesina A., O. Barbiero, C.Favero, F.Giavazzi and M.Paradisi(2014) "Aus- 
terity in 2009-2013", paper prepared for 60th panel meeting of Economic Policy, October 2014

Alesina A. and R. Perotti (1997) "The Welfare State and Competitiveness" American Economic Review 8\%, 347-66

Auerbach A. and Y. Gorodnichenko, (2012), "Measuring the Output Responses to Fiscal Policy", American Economic Journal: Economic Policy, $4(2), 1-27$.

Bachmann R. and E. Sims, (2011), "Confidence and the Transmission of Government Spending Shocks", NBER Working Paper No. 17063, National Bureau of Economic Research, Inc.

Barro R. J. and C. J. Redlick (2011), "Macroeconomic Effects from Government Purchases and Taxes", The Quarterly Journal of Economics, 126(1), 51-102.

Baxter M. and R. G. King (1993), "Fiscal Policy in General Equilibrium", American Economic Review, 83(3), 315-334.

Blanchard O. and R. Perotti (2002), "An Empirical Characterization of the Dynamic Effects of Changes in Government Spending and Taxes on Output", Quarterly Journal of Economics, 117(4), 1329-1368.

Bloom N. (2009), "The Impact of Uncertainty Shocks", Econometrica, $77(3), 623-685$.

Christiano, L. J., Eichenbaum, M., and Evans, C. L. (1998). 'Monetary Policy shocks: what have we learned and to what end?'. NBER working paper No. 6400.

Christiano, L., M. Eichenbaum and S. Rebelo (2011), "When is the Government Spending Multipliers Large?", Journal of Political Economy, 119 (1), 78-121.

Corsetti, G.and A. Meier (2009), "Fiscal stimulus with spending reversals", CEPR Discussion Paper no 7302

de Cos, Pablo Hernandez and E. Mora (2012), "Fiscal Consolidations and Economic Growth". working paper, Banco de Espana.

DeLong J. B. and L. H. Summers (2012), "Fiscal Policy in a Depressed Economy ", Working Paper.

DeVries P., J. Guajardo, D. Leigh and A. Pescatori (2011), "A New Action-based Dataset of Fiscal Consolidation" IMF Working Paper No. 11/128, International Monetary Fund.

Dixit A. and R. Pindick (1994), Investment Under Uncertainty Princeton, NJ: Princeton University Press. 
Drautzburg T. and H.Uhlig (2013) "Fiscal Stimulus and distortionary taxation", mimeo

Eggertsson, G. B. (2010), "What Fiscal Policy is Effective at Zero Interest Rates?", NBER Macroeconomic Annual, D. Acemoglu and M. Woodford (eds), Chicago University Press.

Favero C., F.Giavazzi and J.Perego (2011) "Country Heterogeneity and the International Evidence on the Effects of Fiscal Policy", IMF Economic Review, 59,4, 652-682

Galí J., J. D. López-Salido and J. Vallés (2007), "Understanding the Effects of Government Spending on Consumption", Journal of the European Economic Association, 5 (1), 227-270.

Garratt A., K. Lee, M. H. Pesaran and Y. Shin (2012), Global and National Macroeconometric Modelling: A Long-Run Structural Approach Oxford University Press.

Giavazzi F. and M. Pagano (1990), "Can Severe Fiscal Contractions Be Expansionary? Tales of Two Small European Countries ", NBER Chapters in NBER Macroeconomics Annual 1990, vol. 5, 75-122.

Giavazzi F. and M. McMahon (2013), "The Household effects of Government Spending", in A. Alesina and F. Giavazzi (eds.), Fiscal Policy After the Great Recession, University of Chicago Press and NBER, 2013

Guajardo, J., D. Leigh and A. Pescatori (forthcoming), "Expansionary Austerity New International Evidence", Journal of the European Economic Association.

Jalil A.(2012), "Comparing Tax and spending Multipliers: it is all about controlling for monetary policy" mimeo, Dept of Economics, Reed College

Jordà, Oscar (2005), "Estimation and Inference of Impulse Responses by Local Projections", American Economic Review, 95(1): 161-182

Jordà, Òscar and Alan M. Taylor (2013), "The Time for Austerity: Estimating the Average Treatment Effect of Fiscal Policy," NBER Working Papers 19414, National Bureau of Economic Research, Inc.

Leeper E. M. (2010), "Monetary Science, Fiscal Alchemy", NBER Working Papers No. 16510, National Bureau of Economic Research, Inc.

Leeper E. M., T. B. Walker and S.-C. Yang (2008), "Fiscal Foresight: Analytics and Econometrics", NBER Working Papers No. 14028, National Bureau of Economic Research, Inc.

Lippi M. and L. Reichlin (1994), "VAR Analysis, Non Fundamental Representations, Blaschke Matrices", Journal of Econometrics, 63(1), 307-325. 
Mertens K. and M. O. Ravn (2011), "Understanding the Aggregate Effects of Anticipated and Unanticipated Tax Policy Shocks", Review of Economic Dynamics, 14(1), 27-54.

Mertens K. and M. O. Ravn (2013), "The Dynamic Effects of Personal and Corporate Income Tax Changes in the United States", The American Economic Review , 103,4, 2012-47

Perotti R (2013), "The Austerity Myth: Gain without Pain?" forthcoming in A. Alesina and F. Giavazzi (eds.) Fiscal Policy After the Great Recession, University of Chicago Press and NBER.

Peersman G. and F.Smets (2001), "The Monetary Transmission Mechanism in the euro area" ECB Working Paper 91

Ramey, V. (2011a), "Identifying Government Spending Shocks: It's All in the Timing." Quarterly Journal of Economics 126 (1): 1-50.

Ramey V. (2011b), "Can Government Purchases Stimulate the Economy?", Journal of Economic Literature, 49(3), 673-685.

Ramey V. (2013), "Government Spending and Private Activities" in A. Alesina and F. Giavazzi (eds) Fiscal Policy after the Great Recession University of Chicago Press and NBER forthcoming

Ramey, V., Owyang and S. Zubairy (2013), "Are Government Spending Multipliers Greater During Periods of Slack? Evidence from 20th Century Historical Data, American Economic Review, Papers and Proceedings forthcoming

Romer C. and D. H. Romer (2010), "The Macroeconomic Effects of Tax Changes: Estimates Based on a New Measure of Fiscal Shocks", American Economic Review, 100(3), 763-801.

Rudebusch, G. D. (1998), 'Do Measures of Monetary Policy in a VAR Make Sense?'. International Economic Review, 39, 907-931. 


\begin{tabular}{|c|c|c|c|c|c|c|c|c|c|c|c|c|c|}
\hline \multicolumn{13}{|c|}{ Table 1: Stabilization plans in Italy (i=IT) 1991-1993 } & \\
\hline time & 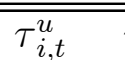 & 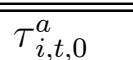 & 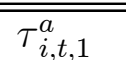 & 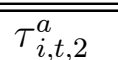 & $\overline{\overline{\tau_{i, t, 3}^{a}}}$ & 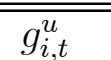 & 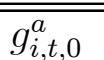 & 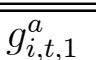 & 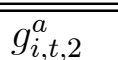 & 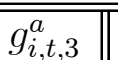 & $\overline{\mathrm{TB}}$ & $\overline{\mathrm{EB}}$ & \\
\hline 1991 & 1.69 & 0 & -1.26 & 0 & 0 & 1.08 & 0 & 0 & 0 & 0 & 0 & 1 & \\
\hline 1992 & $2.85-$ & -1.26 & -1.2 & 0 & 0 & 1.92 & 0 & 0 & 0 & 0 & 0 & 1 & \\
\hline 1993 & 3.2 & -1.2 & -0.57 & 0 & 0 & 3.12 & 0 & 0 & 0 & 0 & 0 & 1 & \\
\hline \multicolumn{14}{|c|}{ Table 2: Stabilization plan in Australia (i=AU) in 1984} \\
\hline time & 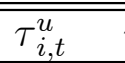 & $\overline{\overline{\tau_{i, t, 0}^{a}}}$ & 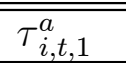 & $\overline{\tau_{i, t, 2}^{a}}$ & $\overline{\tau_{i, t, 3}^{a}}$ & $g_{i, t}^{u}$ & $\overline{\overline{g_{i, t, 0}^{a}}}$ & $\overline{g_{i, t, 1}^{a}}$ & $\bar{~} \overline{g_{i, t, 2}^{a}}$ & $\bar{~} \overline{g_{i, t, 3}^{a}}$ & $\overline{\mathrm{TB}}$ & $\overline{\mathrm{EB}}$ & \\
\hline 1985 & 0 & 0 & 0 & 0 & 0 & 0.45 & 0 & 0.45 & 0 & 0 & 0 & 1 & \\
\hline 1986 & 0.17 & 0 & 0.19 & -0.27 & 0 & 0.4 & 0.45 & 0.26 & -0.08 & 0 & 0 & 1 & \\
\hline 1987 & 0 & 0.19 & -0.27 & 0 & 0 & 0.45 & 0.26 & 0.37 & 0 & 0 & 0 & 1 & \\
\hline 1988 & 0 & -0.27 & 0 & 0 & 0 & 0 & 0.37 & 0 & 0 & 0 & 0 & 1 & \\
\hline Table 3 & \multicolumn{10}{|c|}{ Anticipated and unanticipated fiscal adjustments } & \multicolumn{2}{|c|}{ years } & plans \\
\hline country & 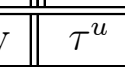 & $\overline{\tau_{i, t, 0}^{a}}$ & $\tau_{i, t, 1}^{a}$ & $\overline{\overline{\tau_{i, t, 2}^{a}}}$ & $\overline{\tau_{i, t, 3}^{a}}$ & 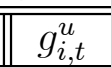 & $\overline{g_{i, t, 0}^{a}}$ & $\overline{g_{i, t, 1}^{a}}$ & 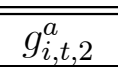 & \begin{tabular}{l|l}
$g_{i, t, 3}^{a}$ \\
\end{tabular} & TB & EB & \\
\hline$\overline{\mathrm{AU}}$ & 4 & 7 & 7 & 3 & 1 & 5 & 6 & 6 & 3 & 1 & 2 & 8 & 5 \\
\hline $\mathrm{OE}$ & 5 & 1 & 1 & 0 & 0 & 5 & 2 & 2 & 0 & 0 & 3 & 4 & 2 \\
\hline BG & 7 & 4 & 4 & 0 & 0 & 10 & 4 & 4 & 0 & 0 & 3 & 8 & 3 \\
\hline $\mathrm{CN}$ & 9 & 14 & 14 & 10 & 8 & 10 & 12 & 12 & 11 & 8 & 8 & 7 & 10 \\
\hline $\mathrm{DE}$ & 9 & 6 & 6 & 3 & 0 & 9 & 6 & 6 & 3 & 1 & 8 & 8 & 3 \\
\hline DK & 4 & 0 & 0 & 0 & 0 & 3 & 1 & 1 & 0 & 0 & 2 & 2 & 2 \\
\hline $\mathrm{ES}$ & 7 & 3 & 3 & 0 & 0 & 7 & 2 & 2 & 0 & 0 & 5 & 5 & 2 \\
\hline $\mathrm{FN}$ & 2 & 1 & 1 & 0 & 0 & 5 & 2 & 2 & 0 & 0 & 0 & 6 & 2 \\
\hline $\mathrm{FR}$ & 5 & 5 & 5 & 3 & 1 & 4 & 2 & 2 & 0 & 0 & 7 & 5 & 4 \\
\hline IR & 6 & 0 & 0 & 0 & 0 & 3 & 1 & 1 & 0 & 0 & 5 & 2 & 0 \\
\hline $\mathrm{IT}$ & 12 & 6 & 6 & 0 & 0 & 12 & 0 & 0 & 0 & 0 & 3 & 9 & 5 \\
\hline $\mathrm{JP}$ & 7 & 7 & 7 & 1 & 0 & 7 & 2 & 2 & 0 & 0 & 7 & 5 & 7 \\
\hline NL & 9 & 2 & 2 & 0 & 0 & 11 & 2 & 2 & 0 & 0 & 1 & 12 & 4 \\
\hline $\mathrm{PT}$ & 4 & 2 & 2 & 0 & 0 & 4 & 2 & 2 & 0 & 0 & 5 & 2 & 2 \\
\hline SW & 3 & 4 & 4 & 2 & 1 & 3 & 4 & 4 & 2 & 1 & 0 & 7 & 2 \\
\hline UK & 4 & 5 & 5 & 1 & 0 & 5 & 6 & 6 & 1 & 0 & 7 & 3 & 4 \\
\hline US & 5 & 12 & 12 & 10 & 7 & 3 & 8 & 8 & 7 & 6 & 5 & 10 & 3 \\
\hline Tot. & 102 & 79 & 79 & 33 & 18 & 106 & 62 & 62 & 27 & 17 & 71 & 103 & 60 \\
\hline
\end{tabular}

NB: A plan occurs when some unanticipated and anticipated adjustments are observed simulataneously or when some future adjuments are announced for the first time. 


\begin{tabular}{|c|c|c|c|c|c|c|c|c|}
\hline & $\overline{\mathrm{CAN}}$ & $\overline{\text { AUS }}$ & 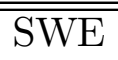 & $\overline{~ G B R}$ & 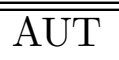 & 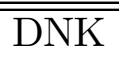 & 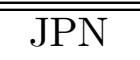 & 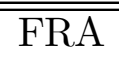 \\
\hline$\overline{\varphi_{1, i}}$ & $\begin{array}{c}0.99 \\
(0.19)\end{array}$ & $\begin{array}{c}0.85 \\
(0.12)\end{array}$ & $\begin{array}{c}0.48 \\
(0.09)\end{array}$ & $\begin{array}{c}0.34 \\
(0.02)\end{array}$ & $\begin{array}{c}0.31 \\
(0.06)\end{array}$ & $\begin{array}{c}0.24 \\
(0.03)\end{array}$ & $\begin{array}{c}0.27 \\
(0.03)\end{array}$ & $\begin{array}{c}0.18 \\
(0.08)\end{array}$ \\
\hline$\varphi_{2, i}$ & $\begin{array}{c}0.59 \\
(0.097)\end{array}$ & $\begin{array}{l}-0.14 \\
(0.08)\end{array}$ & $\begin{array}{c}0.31 \\
(0.06)\end{array}$ & $\begin{array}{c}0.04 \\
(0.02)\end{array}$ & 0 & 0 & $\begin{array}{c}-0.0005 \\
(0.003)\end{array}$ & $\begin{array}{l}-0.02 \\
(0.04)\end{array}$ \\
\hline$\varphi_{3, i}$ & $\begin{array}{l}0.022 \\
(0.04)\end{array}$ & $\begin{array}{l}-0.02 \\
(0.01)\end{array}$ & $\begin{array}{c}0.21 \\
(0.02)\end{array}$ & 0 & 0 & 0 & 0 & $\begin{array}{l}-0.03 \\
(0.03)\end{array}$ \\
\hline
\end{tabular}

\begin{tabular}{|c|c|c|c|c|c|c|c|c|}
\hline \hline & DEU & FIN & POR & USA & ESP & BEL & IRL & ITA \\
\hline \hline$\varphi_{1, i}$ & 0.11 & 0.11 & 0.07 & 0.07 & 0.06 & 0.04 & 0 & -0.22 \\
& $(0.11)$ & $(0.11)$ & $(0.14)$ & $(0.23)$ & $(0.06)$ & $(0.09)$ & & $(0.04)$ \\
\hline$\varphi_{2, i}$ & -0.096 & 0 & 0 & 0.07 & 0 & 0 & 0 & 0 \\
& $(0.08)$ & & & $(0.16)$ & & & & \\
\hline$\varphi_{3, i}$ & 0.03 & 0 & 0 & -0.01 & 0 & 0 & 0 & 0 \\
& $(0.01)$ & & & $(0.12)$ & & & & \\
\hline
\end{tabular}

The following equations are estimated

$$
\begin{aligned}
& e_{i, t, 1}^{a}=\varphi_{1, i} e_{i, t}^{u}+v_{1, i, t} \\
& e_{i, t, 2}^{a}=\varphi_{2, i} e_{i, t}^{u}+v_{2, i, t} \\
& e_{i, t, 3}^{a}=\varphi_{3, i} e_{i, t}^{u}+v_{3, i, t}
\end{aligned}
$$

$e_{i, t, j}^{a}$ are the corrections announced by the fiscal authorities of country $i$ at date $t$ with an anticipation horizon of $j$ years (i.e. to be implemented in year $t+j), e_{i, t}^{u}$ is instead the unanticipated fiscal correction announced and implemented in year $t$ by the fiscal authorities of country $i$. 
Table 5: Coefficient estimated in the benchmark specification

\begin{tabular}{llll}
\hline & Coefficient & Std. Error & t-Statistic \\
\hline \hline$e_{i, t}^{u} * T B_{i, t}$ & $-0.739441^{* * *}$ & 0.110423 & -6.696469 \\
$e_{i, t}^{u} * E B_{i, t}$ & $-0.152295^{* *}$ & 0.0748 & -2.036041 \\
$e_{i, t}^{a} * T B_{i, t}$ & $-0.511829^{* *}$ & 0.212689 & -2.406464 \\
$e_{i, t}^{a} * E B_{i, t}$ & $-0.400883^{* *}$ & 0.200242 & -2.001992 \\
$e_{i, t-1}^{u} * T B_{i, t-1}$ & $-0.621083^{* * *}$ & 0.106957 & -5.806868 \\
$e_{i, t-1}^{u} * E B_{i, t-1}$ & -0.127029 & 0.077569 & -1.637617 \\
$e_{i, t-1}^{a} * T B_{i, t-1}$ & 0.006857 & 0.204433 & 0.033539 \\
$e_{i, t-1}^{a} * E B_{i, t-1}$ & 0.220454 & 0.211094 & 1.04434 \\
$e_{i, t-2}^{u} * T B_{i, t-2}$ & $-0.236031^{* *}$ & 0.110466 & -2.136679 \\
$e_{i, t-2}^{u} * E B_{i, t-2}$ & $0.245177^{* * *}$ & 0.080692 & 3.038421 \\
$e_{i, t-2}^{a} * T B_{i, t-2}$ & 0.2974 & 0.219328 & 1.355961 \\
$e_{i, t-2}^{a} * E B_{i, t-2}$ & 0.294444 & 0.222495 & 1.323371 \\
$e_{i, t-3}^{u} * T B_{i, t-3}$ & $-0.457579 * * *$ & 0.11153 & -4.102726 \\
$e_{i, t-3}^{u} * E B_{i, t-3}$ & 0.079221 & 0.078838 & 1.004852 \\
$e_{i, t-3}^{a} * T B_{i, t-3}$ & 0.028441 & 0.195732 & 0.145304 \\
$e_{i, t-3}^{a} * E B_{i, t-3}$ & -0.013853 & 0.219581 & -0.063089 \\
$e_{i, t, 1}^{a} * T B_{i, t}$ & -0.437495 & 0.265148 & -1.650001 \\
$e_{i, t, 1}^{a} * E B_{i, t}$ & 0.089632 & 0.172574 & 0.519382 \\
$e_{i, t, 2}^{a} * T B_{i, t}$ & 0.413413 & 0.842011 & 0.490982 \\
$e_{i, t, 2}^{a} * E B_{i, t}$ & 0.33677 & 0.883182 & 0.381314 \\
\hline & & &
\end{tabular}



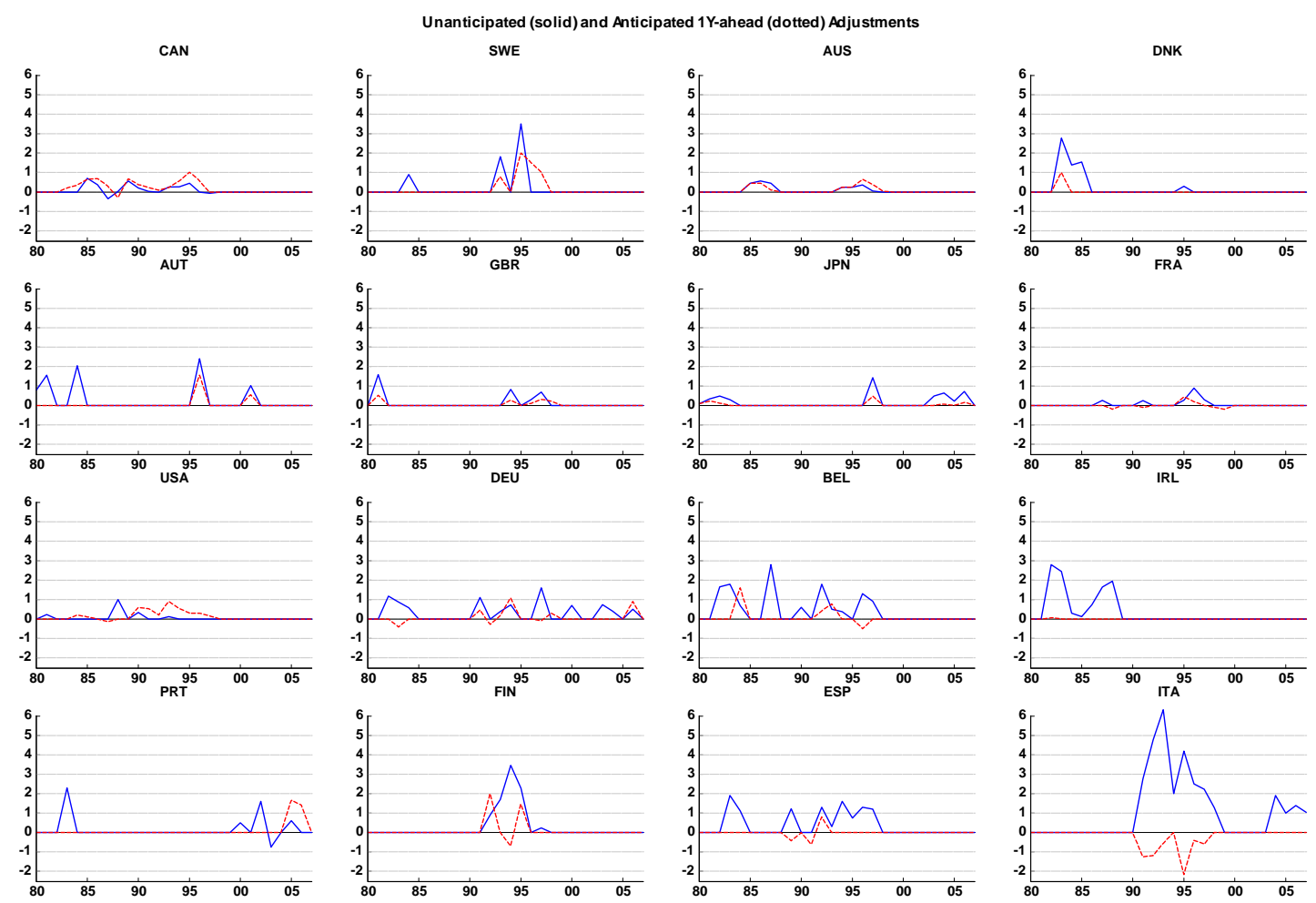

Figure 1: Unanticipated and Anticipated Fiscal Adjustments 


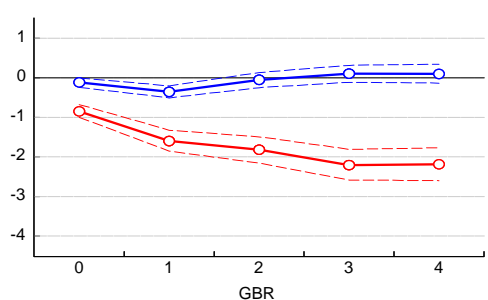

ESP
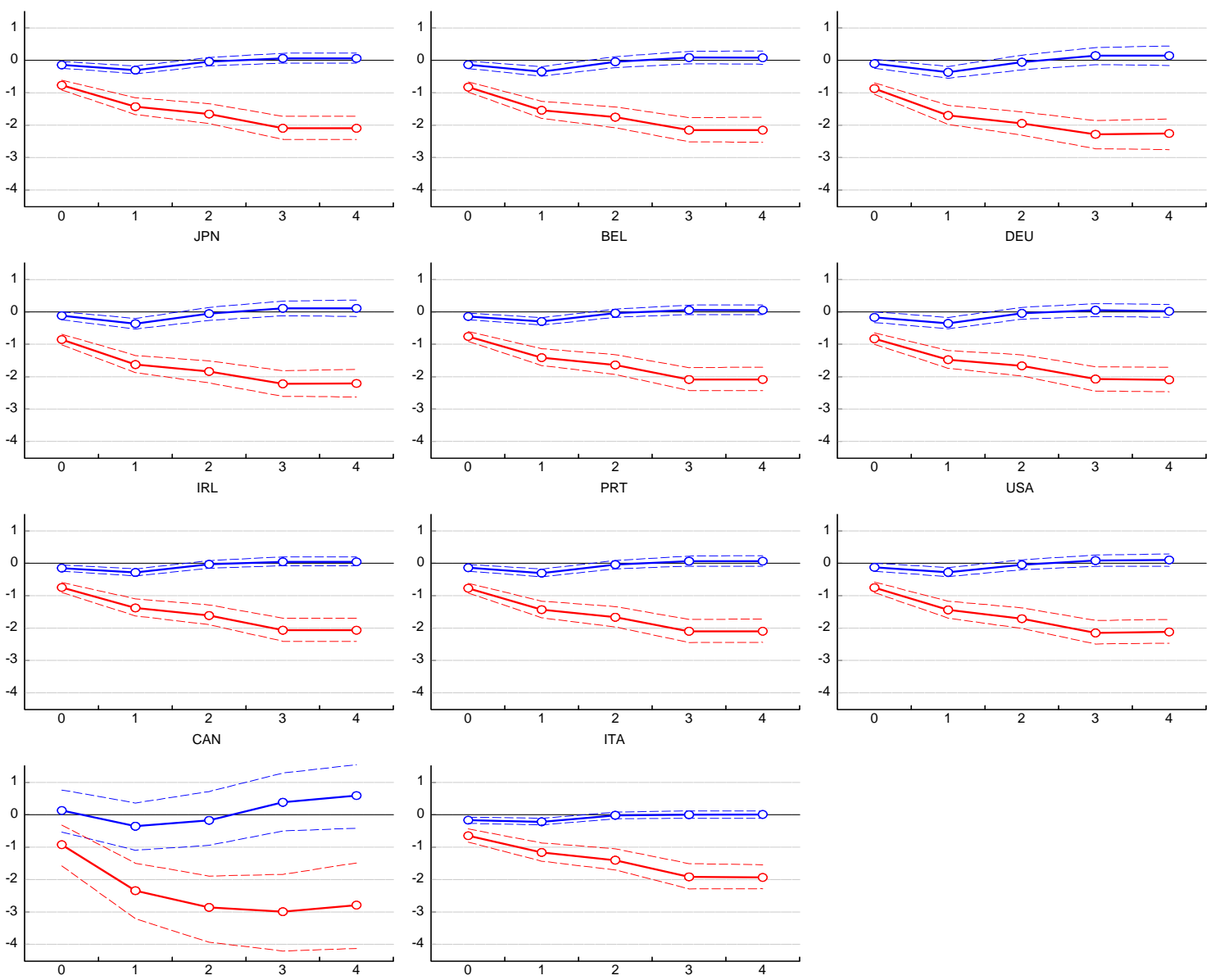

Figure 2: The effect of TB and EB adjustments on output growth 

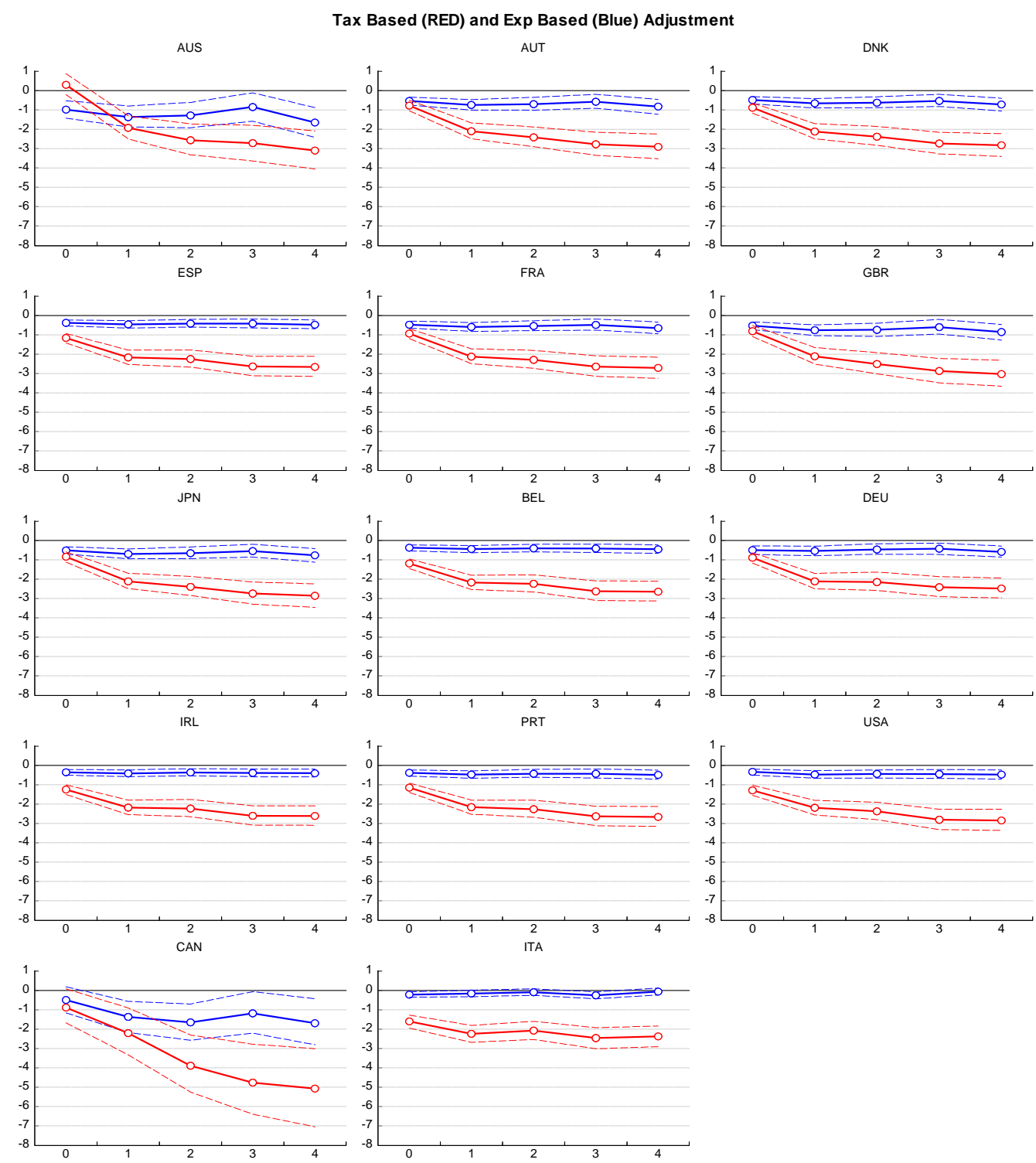

Figure 3: The effect of TB and EB adjustments on consumption growth 

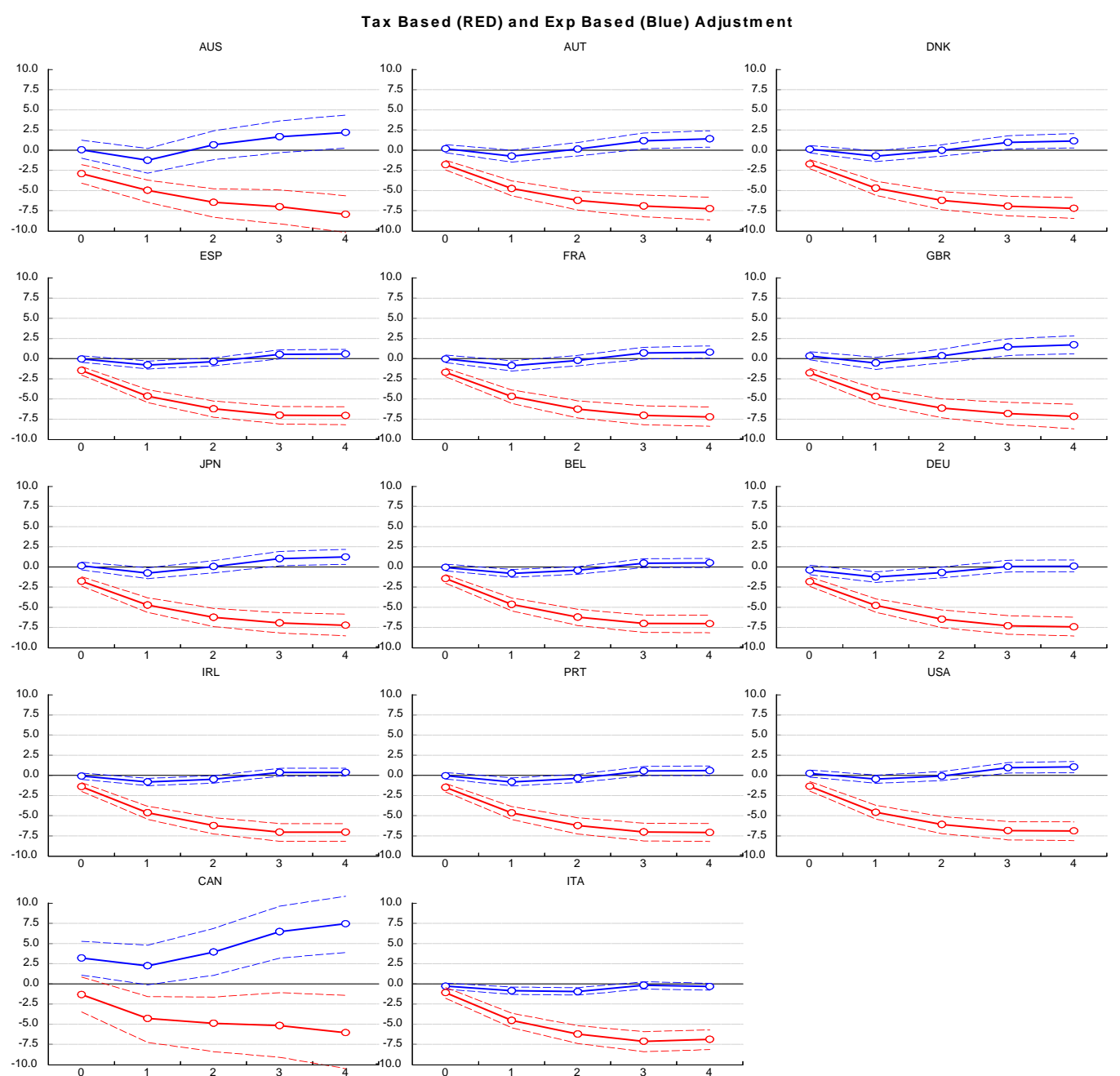

Figure 4: The effect of TB and EB adjustments on fixed capital formation growth 


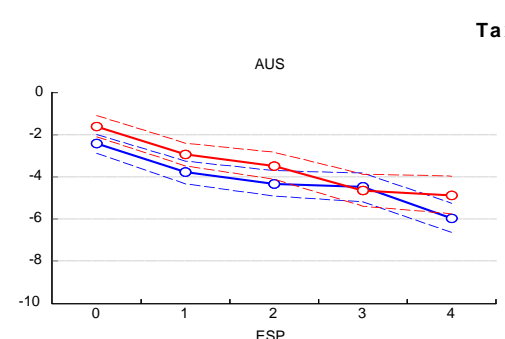

Tax Based (RED) and Exp Based (Blue) Adjustment
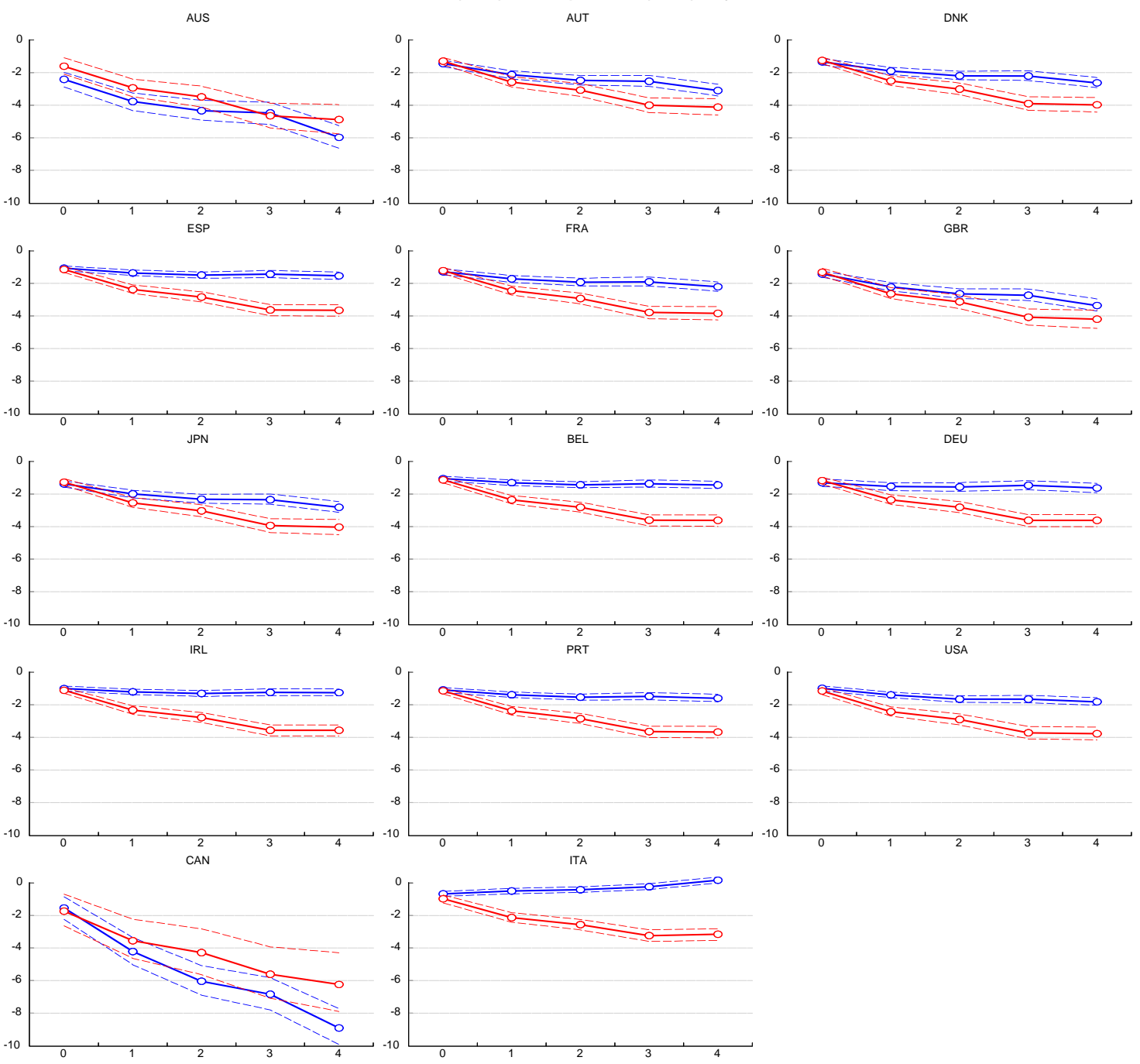

Figure 5: The effect of TB and EB adjustments on ESI Consumer Confidence 

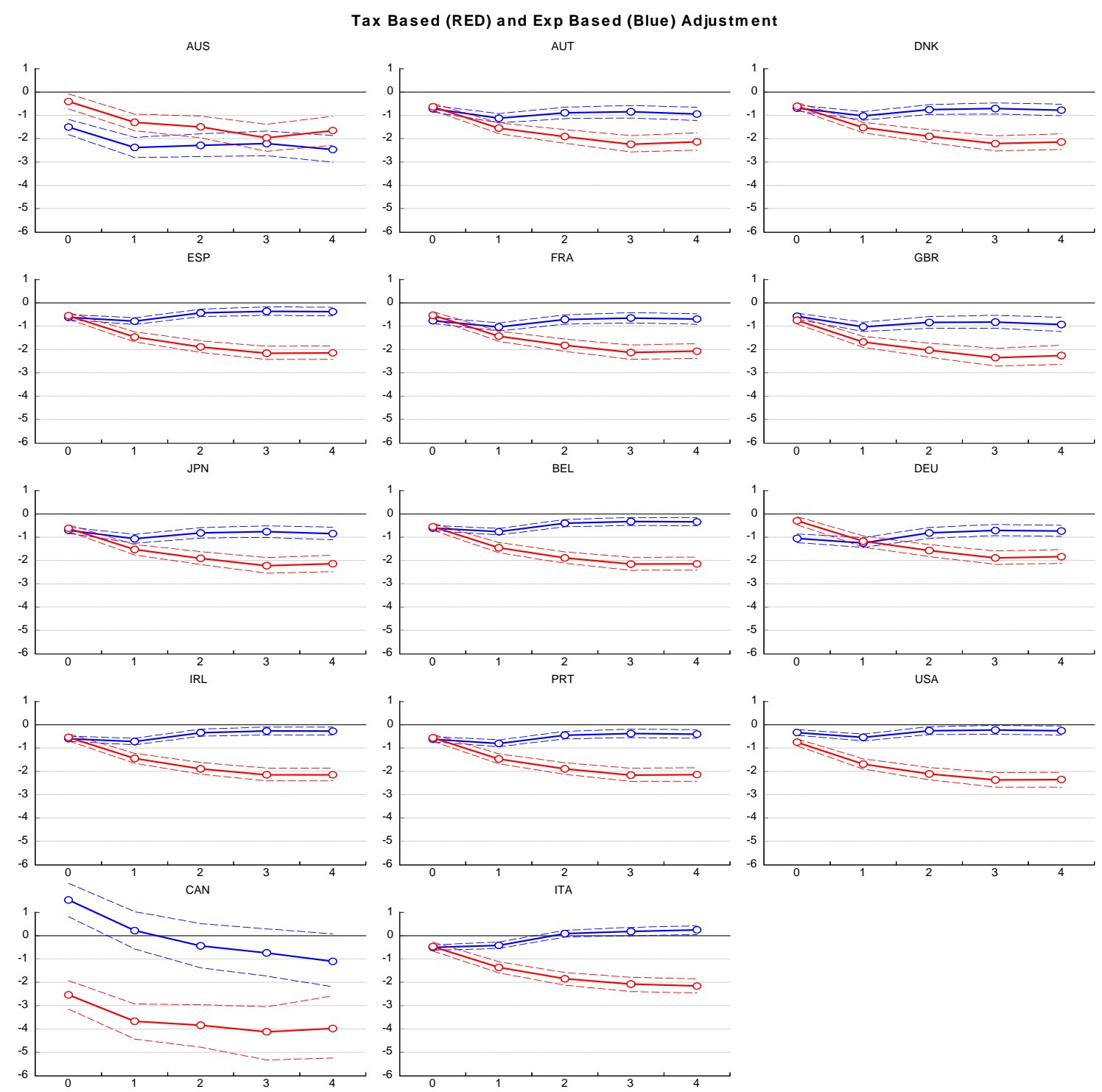

Figure 6: The effect of TB and EB adjustments on ESI Business Confidence 

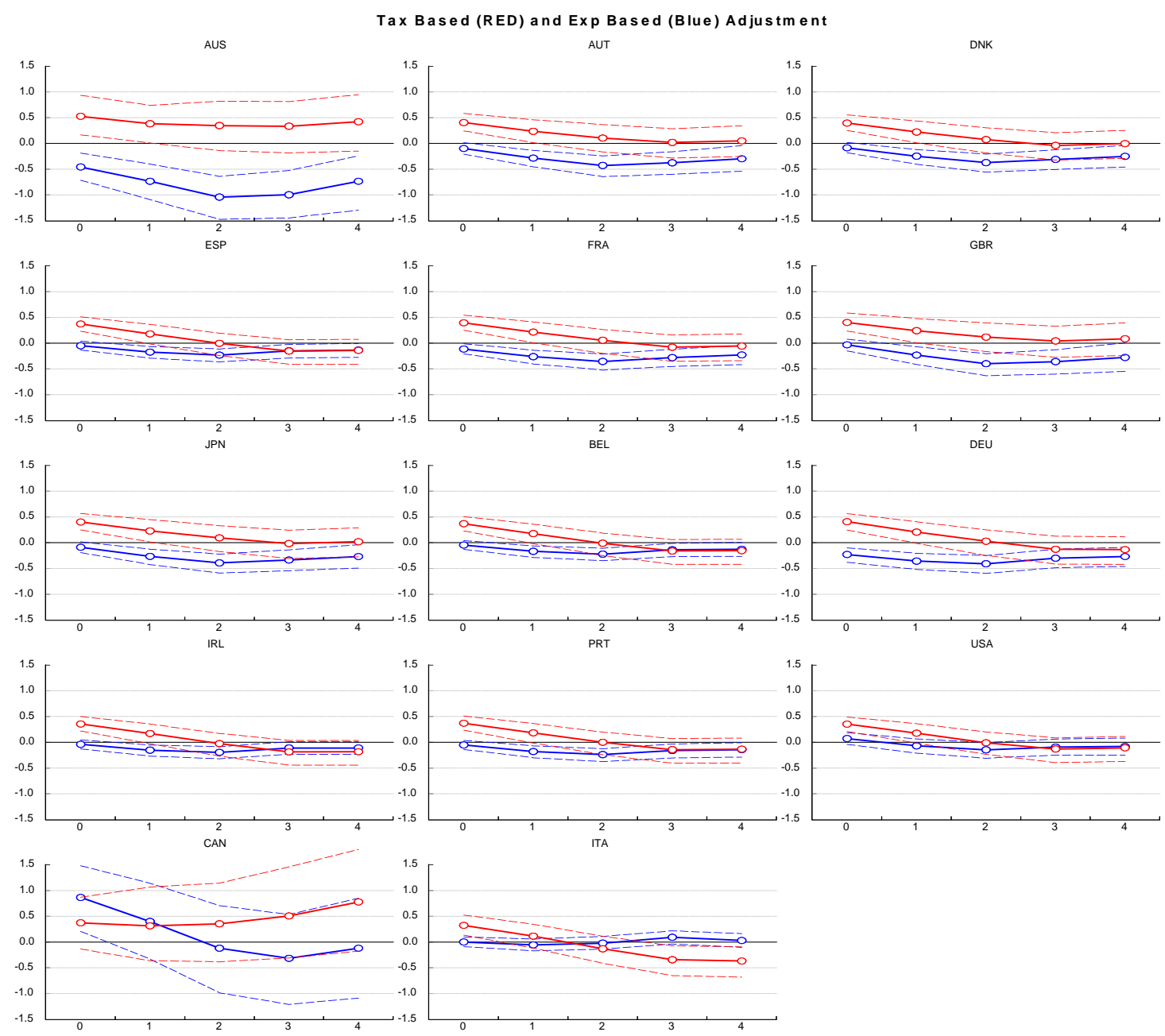

Figure 7: The effect of TB and EB adjustments on monetary policy (change in the 3M TBills Rates) 

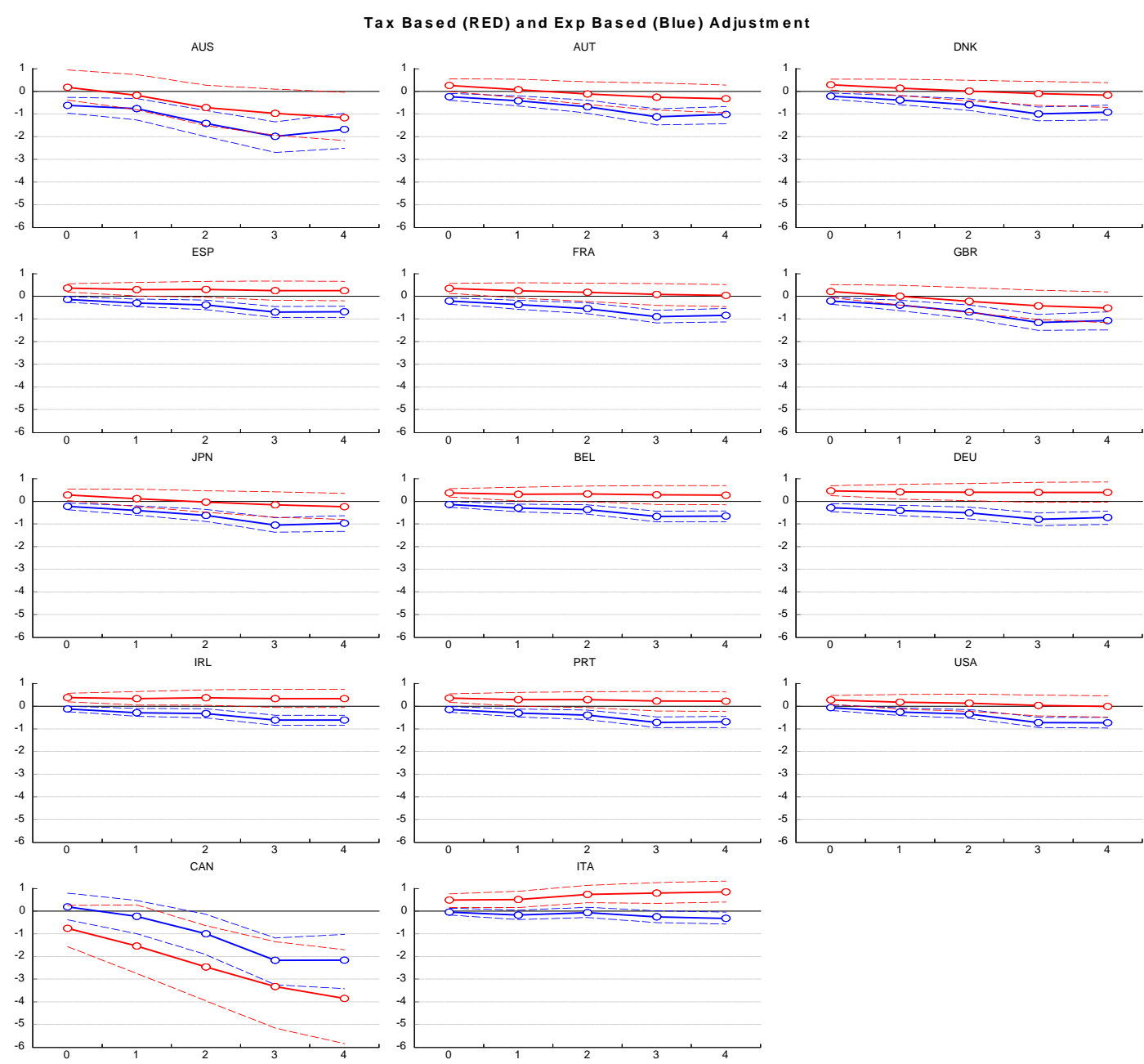

Figure 8: The effect of TB and EB adjustments on inflation (GDP deflator) 

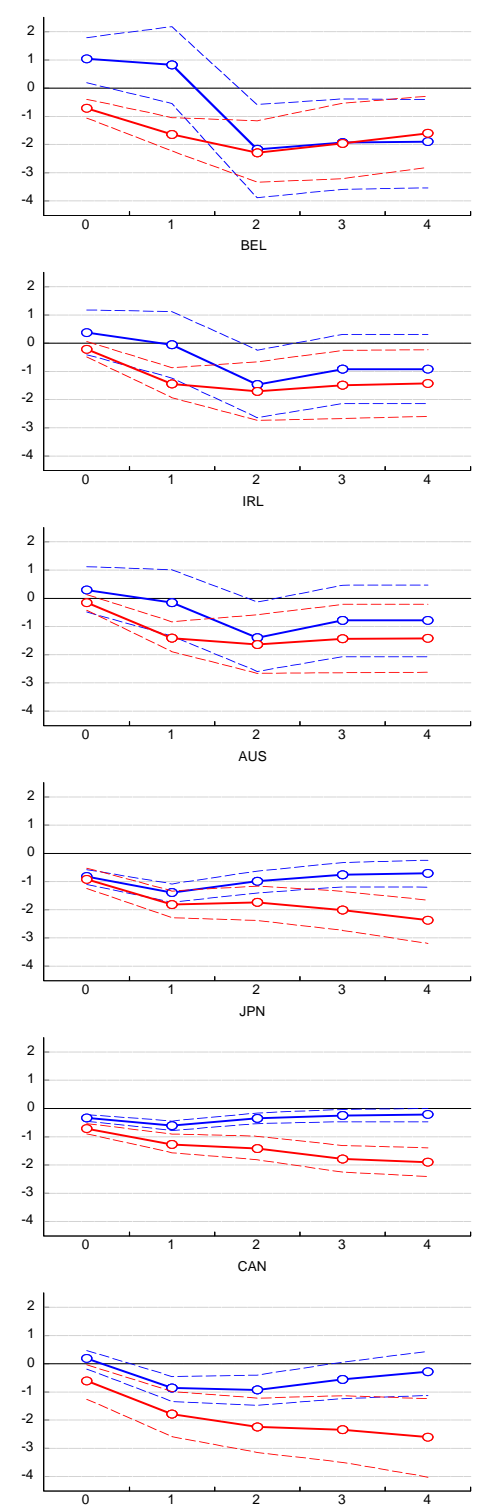

Tax Based (RED) and Exp Based (Blue) Adjustment

FRA
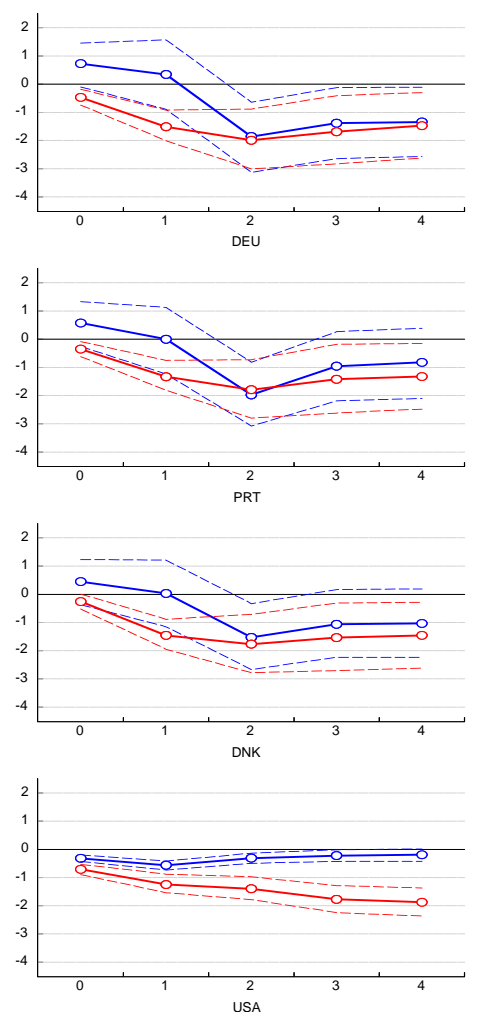

USA
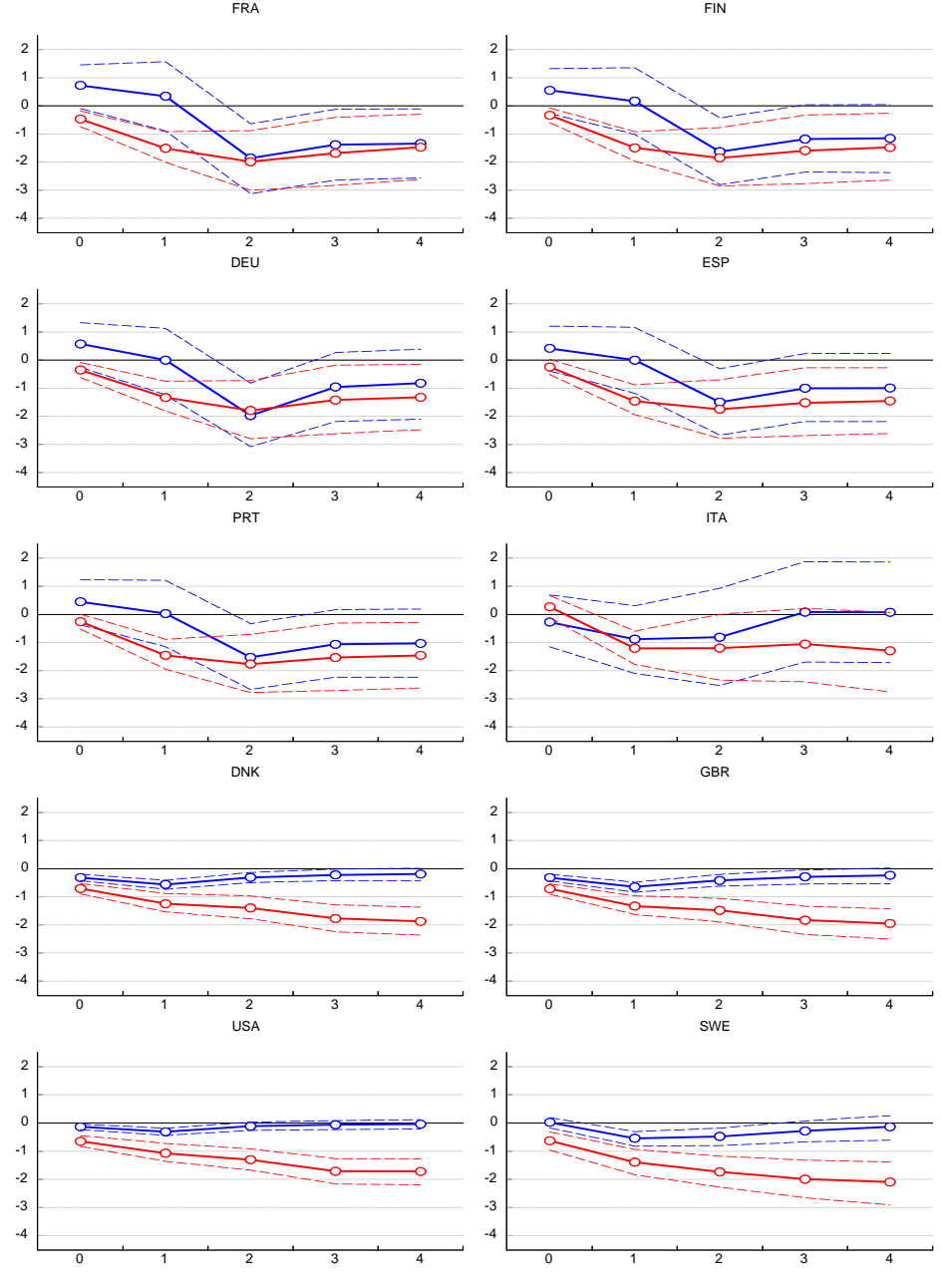

Figure 9: Impulse responses of output allowing for different coefficients in the euro area (top 9 countries) and non-euro area (bottom 7 countries) 
Baseline (Green) and Counterfactual (Zero MP response) (Blue) EB Adjustment, Baseline (Orange) and Counterfactual (Zero MP response) (Red) TB Adjustment Aus
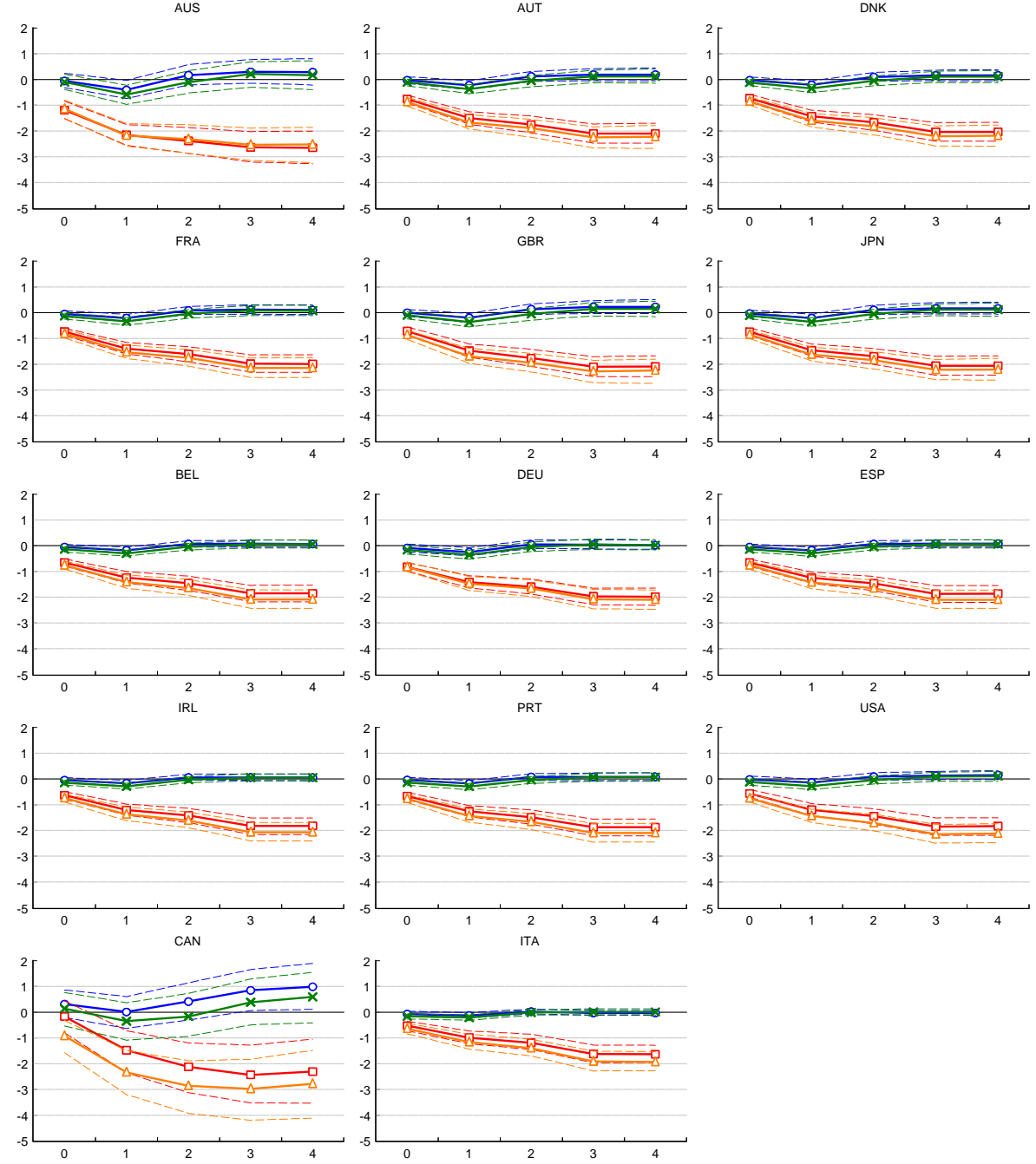

Figure 10: The effect of TB and EB adjustments: Baseline and Counterfactual for all countries 


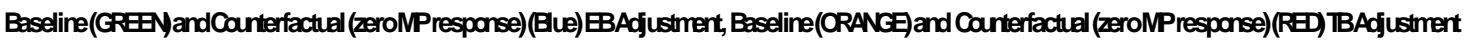
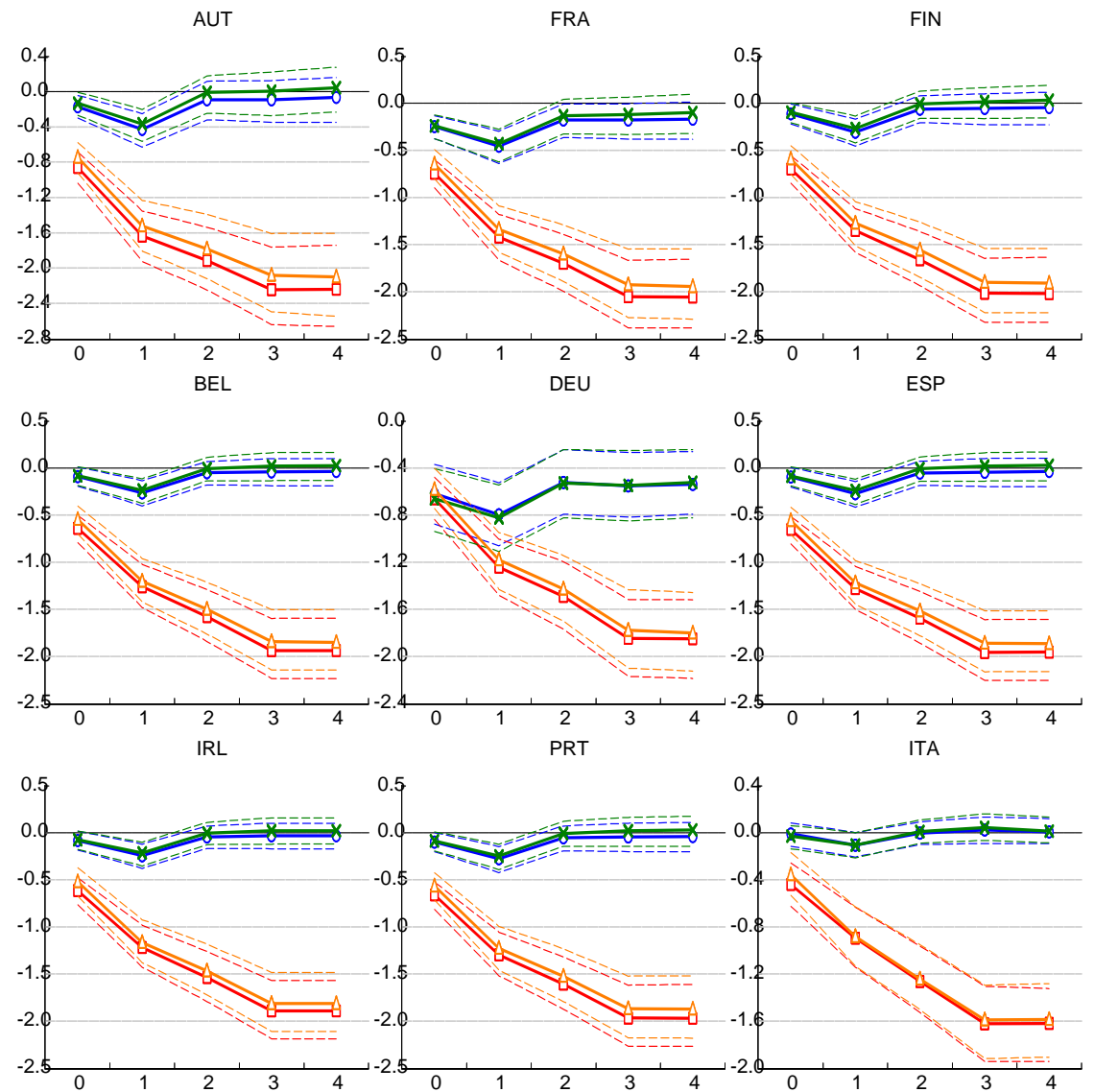

Figure 11: The effect of TB and EB adjustments: Baseline and Counterfactual for euro area countries 


\section{Data Appendix}

Our non fiscal macro data come from different public sources such as Thomson Reuters Datastream, the OECD Economic Outlook database, the Actionbased Dataset of Fiscal Consolidations compiled by DeVries et al (2011), which provide us with the fiscal consolidation episodes, and the IMF International Financial Statistics (IFS). Datastream was used to obtain time series of the Economic Sentiment Indicators originally produced by the European Commission. This confidence index was integrated with national sources. The series for private final consumption expenditure and gross fixed capital formation are from IFS. The other macroeconomic variables from the OECD Economic Outlook database.

\begin{tabular}{|l|l|l}
\hline \multicolumn{2}{|l}{ Macroeconomic and Confidence Data Sources } \\
\hline \hline Variable & Definition & Source \\
\hline Consumer Confidence indicator & Economic Sentiment Indicator & European Commission \\
\hline Business Confidence Indicator & Economic Sentiment Indicator & European Commission \\
\hline Long Term Interest rate & $10-$ Y Government bonds YTM & IMF IFS \\
\hline Short-Term Interest rate & 3 -M Treasury Bill YTM & IMF IFS \\
\hline Consumption & Total Final Consumption Expenditure & IMF IFS \\
\hline Investment & Gross Private fixed Capital Formation & IMF IFS \\
\hline Output & Gross Domestic Product & OECD \\
\hline Population & Total Resident Population & OECD \\
\hline
\end{tabular}

The variables included as dependent variables, for each country $i$, in the multy country moving average specification to compute the dynamic effects of fiscal adjustments where the following:

1. Real per capita GDP growth is defined as

$$
d y_{i, t}=\log \left(\frac{y_{i, t}}{y_{i, t,-1}}\right)-\log \left(\frac{\text { popt }_{i, t}}{\text { popt }_{i, t-1}}\right)
$$

where $y_{i, t}$ is the real gdp at time $\mathrm{t}$ and $p o p t_{i, t}$ is the total population at time t.

2. Final per capita real consumption expenditure growth is

$$
d f c e_{i, t}=\log \left(\frac{f c e_{i, t}}{f c e_{i, t-1}}\right)-\log \left(\frac{\text { popt }_{i, t}}{\text { popt }_{i, t-1}}\right)
$$

where $f c e_{i, t}$ is the final real consumption expenditure at time $\mathrm{t}$. 
3. Gross capital formation per capita growth is the change in the log of real gross capital formation

$$
d g c f_{i, t}=\log \left(\frac{g c f_{i, t}}{g c f_{i, t-1}}\right)-\log \left(\frac{\text { popt }_{i, t}}{\operatorname{popt}_{i, t-1}}\right)
$$

where $d g c f_{i, t}$ is the real gross capital formation growth from time t-1 to time $\mathrm{t}$ and $g c f_{i, t}$ is the gross fixed capital formation at time $\mathrm{t}$.

4. Consumer and business confidence indicators were defined in terms of $\operatorname{logs.}$

$$
\begin{aligned}
& l c c_{i, t}=\log \left(c c_{i, t}\right) \\
& l b c_{i, t}=\log \left(b c_{i, t}\right)
\end{aligned}
$$

where $l c_{i, t}$ is the log of the consumer confidence indicator at time $t$, $c_{i, t}$ is the consumer confidence indicator at time $t, l b_{i, t}$ is the log of the business confidence indicator, and $b_{t}$ is the business confidence indicator at time $t$.

5. Term spreads are computed between the yield on long-term government bonds (ten-year) and the yield on short-term (three-month) bills

$$
s_{i, t}=i r l_{i, t}-i r s_{i, t}
$$

where $s_{i, t}$ is the spread at time $\mathrm{t}, i r l_{i, t}$ is the long-term government bond (ten-year) at time $t$, and $i r s_{i, t}$ is the short-term (three-month) bill at time $t$.

\subsection{From the Action-based Dataset of Fiscal Consoli- dations to Fiscal Plans}

Table 1 illustrates how we obtained fiscal plans by reclassifying adjustments contained in the Action-based Dataset of Fiscal Consolidations of D\&al

The original database contains exogenous fiscal shifts in public revenues and spending with respect to the previous year. The episodes capture the changes in policy having effect in year t, compared to a baseline scenario of no policy change with respect to year $t-1$.

Although D\&al often specify the date of approval of the fiscal plans, when computing their impact they do not distinguish between measures that were 
announced in previous years or within the year of implementation. Hence, in order to take into account the multi-period feature of plans, we exploit the information about the date of approval to distinguish between unexpected and expected shocks. The date of announcement is either found within the text or using the sources indicated by D\&al Due to the annual nature of the data we define as 'unanticipated' all the fiscal plans which have impact on the calendar year $t$ and are approved between September of year $t-1$ and December of year t. All the plans approved before this window of time and supposed to have effect within the calendar year t are coded as 'anticipated'. For example, the Omnibus Budget Reconciliation Act of 1993 (OBRA-93) in the US was enacted on August 10, 1993 and had a budgetary impact (in percent of GDP) of 0.12 in 1993, 0.40 in 1994, 0.26 in 1995, 0.29 in 1996, 0.30 in 1997; 0.15 in 1998 (D\&al). Hence, the impact in 1993 is coded as unexpected, while all the other shocks are coded as announced components with an impact horizon from one to five years.

Thanks to this classification we can consider the combined effect, in a given year, of current and future policies with an impact horizon of up to five years. After summing up these components for both taxes and expenditures, we take the largest between the two in order to label the episodes to either be expenditure-based or tax-based.

As mentioned in the main text, the sum of the unanticipated and anticipated components of the fiscal episodes is always equal to the original D\&al shocks except for 7 cases in which we slightly diverge from D\&al for the following reasons:

\section{Belgium 1996}

Tax hikes of 0.5 percent of GDP revised in tax hikes of 0.8 percent of GDP. In entry 1996, Devries et al (2011) compute a tax shock totaling 0.5 percent of GDP. However, as can be read at p.19, the budgetary impact of tax-based deficit-reduction measures in the 1996 Budget (1996 IMF Recent Economic Developments, p.11) were of 0.9 percent of GDP (of which 0.1 percent of GDP consisting in sales of buildings and not considered in the analysis). As a consequence the shock in revenues is of 0.8 percent of GDP rather than 0.5 percent of GDP.

\section{Belgium 1997}

Spending cuts of 0.5 percent of GDP revised in spending cuts of 0.25 percent of GDP and tax hikes of 0.41 percent of GDP revised in tax hikes of 
0.16 percent of GDP. As clearly stated at p.19 of Devries et al (2011), the Budget 1996 included one-off measures equal to 0.5 percent of GDP, which should be allocated equally across spending and tax measures. However, Devries et al (2011) neglect to apply the expiration of these one-off measures in 1997. As a consequence, in 1997 the spending cuts should total 0.25 percent of GDP (0.5 percent of GDP from the 1997 Budget and -0.25 from the one-off measures expired in 1997) and tax hikes should be equal to 0.16 (0.41 percent of GDP introduced in the 1997 Budget and -0.25 from the expiration of previous one-off measures).

\section{Canada 1984}

Tax hikes of 0.27 percent of GDP revised in tax hikes of 0.2 percent of GDP. According to Table 1 p. 28 of Devries et al (2011) the 1983 Budget approved C\$1,215 million with impact in the fiscal year 1984-85. In order to allocate this amount in the calendar years 1984 and 1985 Devries et al (2011) should impute $\mathrm{C} \$ 3 / 4$ billion in 1984 and $\mathrm{C} \$ 1 / 4$ billion in 1985 . However, as can be seen in Table 1, all of the measures are allocated in 1984 and, in addition, $\mathrm{C} \$ 1 / 4$ are allocated in 1985 . This procedure ends up counting 1/4 of the measures twice. As a consequence, we calculate again the impact of the 1993 Budget in 1994, with tax hikes of 0.20 percent of GDP instead of 0.27 percent of GDP.

\section{Italy 1993}

Spending cuts of 2 percent of GDP revised in spending cuts of 3.1 percent of GDP. Fiscal consolidation in 1993 was the result of two different packages: the Delegation Law and the May 1993 package. According to Devries et al (2011) the Delegation Law included L 31 trillion of expenditure-based fiscal consolidation (1994 OECD Economic Surveys, p.44-45). However, the OECD report quantifies the expenditure cuts of the Delegation Law to actually be 43.5 trillion. The L 31 trillion is the primary deficit surplus of that year. As a consequence we revise the amount of spending cuts to be equal to 3.1 percent of GDP instead of 2 percent of GDP.

\section{Italy 2004}

Tax hikes of 0.67 percent of GDP revised in tax hikes of 1 percent of GDP and spending cuts of 0.63 percent of GDP revised in spending cuts of 0.9 percent of GDP. Devries et al (2011) state at p.53 that the 2004 Budget introduced savings of $€ 16$ billion ( 0.7 percent of GDP) and additional 
measures decided in July 2004 amounting to $€ 7.6$ billion ( 0.6 percent of GDP). It is clear that the proportion between the total amounts of the two measures and their percentage over GDP is not consistent. As a consequence we revised the fiscal consolidation shock in 2004 to be 1 percent of GDP of tax hikes (instead of 0.67 ) and 0.9 percent of GDP of spending cuts (instead of 0.63$)$.

Netherlands 1993 (not included in our empirical analysis)

Tax cuts of 0.16 of GDP revised in tax hikes of 0.04 and spending cuts of 0.28 percent of GDP revised in spending cuts of 0.88 percent of GDP. At the very end of entry 1993 (p.64 of Devries et al 2011) the total amount of tax hikes is computed as the sum of -0.39 percent of GDP coming from tax cuts decided in the 1993 Budget, +0.43 percent of GDP from additional measures introduced in 1993 and -0.2 percent of GDP that are not mentioned in the text. Probably, this -0.2 is considered to be the effect of the expiration of previous measures introduced in 1992. However, in entry 1992 these measures are declared to be exclusively spending cuts and indeed they are applied in the computation of the spending shock for 1993. As a consequence we revise the amount of tax hikes to be 0.04 percent of GDP $(-0.39+0.43)$.

On the spending side we figured that there is a typo in the computation at the very end of entry 1993 at p.64. Indeed, $0.78+0.3-0.2$ is equal to 0.88 percent of GDP rather than 0.28 percent of GDP.

\section{United Kingdom 1997}

Spending cuts of 0.16 percent of GDP revised in spending cuts of 0.26 percent of GDP. Devries et al (2011) neglect to apply the impact of 0.1 percent of GDP of spending cuts corresponding to a quarter of the measures decided in the FSBR 1996-97 (see entry for 1996 and 1997 p. 77). As a consequence, we consider the total amount of spending cuts introduced in 1997 to be 0.26 percent of GDP $(0.16+0.1)$. 


\begin{tabular}{|c|c|c|c|c|c|c|c|c|c|c|c|c|c|c|c|c|}
\hline & & Total & Tax & Snend & & & Taxes & & & & & Spendi & & & T月 & 8 \\
\hline & & & $10 x$ & Spend & $\mathrm{T}_{\mathrm{t}}{ }^{\prime}$ & $T^{2}{ }_{t, 0}$ & $T_{t, 1}^{n}$ & $T_{\mathrm{t}, 2}^{0}$ & $T_{t, 3}^{2}$ & $g_{t}^{u}$ & $g_{t 0}^{o}$ & $g_{t, 1}^{o}$ & $g_{\mathrm{t}, 2}^{a}$ & $g_{\mathrm{t}, 3}^{0}$ & & \\
\hline AUS & 1985 & 0.45 & 0.00 & 0.45 & 0 & 0 & 0 & 0 & 0 & 0.45 & 0 & 0.45 & 0 & 0 & 0 & 1 \\
\hline AUS & 1986 & 1.02 & 0.17 & 0.85 & 0.17 & 0 & 0.19 & -0.27 & 0 & 0.4 & 0.45 & 0.26 & -0.08 & 0 & 0 & \\
\hline AUS & 1987 & 0.90 & 0.19 & $0.71 \|$ & 0 & 0.19 & -0.27 & 0 & 0 & 0.45 & 0.26 & 0.37 & 0 & 0 & 0 & \\
\hline AUS & 1988 & 0.10 & -0.27 & 0.37 & 0 & -0.27 & 0 & 0 & 0 & 0 & 0.37 & 0 & 0 & 0 & 0 & \\
\hline AUS & 1994 & 0.25 & 0.25 & 0.00 & 0.25 & 0 & 0.25 & 0 & 0 & 0 & 0 & 0 & 0 & 0 & 1 & 0 \\
\hline AUS & 1995 & 0.50 & 0.50 & 0.00 & 0.25 & 0.25 & 0.25 & 0 & 0 & 0 & 0 & 0 & 0 & 0 & 1 & 0 \\
\hline AUS & 1996 & 0.62 & 0.34 & 0.28 & 0.09 & 0.25 & 0.175 & 0.05 & -0.04 & 0.275 & 0 & 0.475 & 0.17 & -0.03 & 0 & \\
\hline AUS & 1997 & 0.70 & 0.18 & 0.53 & 0 & 0.175 & 0.05 & -0.04 & 0 & 0.05 & 0.475 & 0.32 & 0.07 & 0 & 0 & \\
\hline AUS & 1998 & 0.37 & 0.05 & 0.32 & 0 & 0.05 & -0.04 & 0 & 0 & 0 & 0.32 & 0.07 & 0 & 0 & 0 & 1 \\
\hline AUS & 1999 & 0.04 & -0.04 & 0.07 & 0 & -0.04 & 0 & 0 & 0 & 0 & 0.07 & 0 & 0 & 0 & 0 & 1 \\
\hline AUT & 1980 & 0.80 & 0.11 & 0.69 & 0.11 & 0 & 0 & 0 & 0 & 0.69 & 0 & 0 & 0 & 0 & 0 & t \\
\hline AUT & 1981 & 1.56 & 0.50 & 1.06 & 0.5 & 0 & 0 & 0 & 0 & 1.06 & 0 & 0 & 0 & 0 & 0 & 1 \\
\hline AUT & 1984 & 2.04 & 1.30 & 0.74 & 1.3 & 0 & 0 & 0 & 0 & 0.74 & 0 & 0 & 0 & 0 & 1 & t \\
\hline AUT & 1996 & 2.41 & 0.88 & 1.53 & 0.88 & 0 & 0.44 & 0 & 0 & 1.53 & 0 & 1.12 & 0 & 0 & 0 & t \\
\hline AUT & 1997 & 1.56 & 0.44 & 1.12 & 0 & 0.44 & 0 & 0 & 0 & 0 & 1.12 & 0 & 0 & 0 & 0 & 1 \\
\hline AUT & 2001 & 1.02 & 0.90 & 0.12 & 0.9 & 0 & 0 & 0 & 0 & 0.12 & 0 & 0.55 & 0 & 0 & 1 & 0 \\
\hline AUT & 2002 & 0.55 & 0.00 & 0.55 & 0 & 0 & 0 & 0 & 0 & 0 & 0.55 & 0 & 0 & 0 & 0 & 1 \\
\hline BEL & 1982 & 1.66 & 0.00 & 1.66 & 0 & 0 & 0 & 0 & 0 & 1.66 & 0 & 0 & 0 & 0 & 0 & 1 \\
\hline BEL & 1983 & 1.79 & 0.69 & 1.10 & 0.69 & 0 & 0 & 0 & 0 & 1.1 & 0 & 0 & 0 & 0 & 0 & 1 \\
\hline BEL & 1984 & 0.69 & 0.28 & 0.41 & 0.28 & 0 & 0.73 & 0 & 0 & 0.41 & 0 & 0.88 & 0 & 0 & 0 & 1 \\
\hline BEL & 1985 & 1.61 & 0.73 & 0.88 & 0 & 0.73 & 0 & 0 & 0 & 0 & 0.88 & 0 & 0 & 0 & 0 & 1 \\
\hline BEL & 1987 & 2.80 & 0.00 & 2.80 & 0 & 0 & 0 & 0 & 0 & 2.8 & 0 & 0 & 0 & 0 & 0 & 1 \\
\hline BEL & 1990 & 0.60 & 0.40 & 0.20 & 0.4 & 0 & 0 & 0 & 0 & 0.2 & 0 & 0 & 0 & 0 & 1 & 0 \\
\hline BEL & 1992 & 1.79 & 0.99 & 0.80 & 0.99 & 0 & 0.03 & 0 & 0 & 0.8 & 0 & 0.39 & 0 & 0 & 0 & t \\
\hline BEL & 1993 & 0.92 & 0.43 & 0.49 & 0.4 & 0.03 & 0.55 & 0 & 0 & 0.1 & 0.39 & 0.23 & 0 & 0 & 1 & t \\
\hline BEL & 1994 & 1.15 & 0.55 & 0.60 & 0 & 0.55 & 0 & 0 & 0 & 0.37 & 0.23 & 0 & 0 & 0 & 0 & t \\
\hline BEL & 1996 & 1.30 & 0.80 & 0.50 & 0.8 & 0 & -0.25 & 0 & 0 & 0.5 & 0 & -0.25 & 0 & 0 & 1 & 0 \\
\hline BEL & 1997 & 0.41 & 0.16 & 0.25 & 0.41 & -0.25 & 0 & 0 & 0 & 0.5 & -0.25 & 0 & 0 & 0 & 0 & t \\
\hline CAN & 1983 & 0.00 & 0.00 & 0.00 & 0 & 0 & 0.203 & 0.351 & 0.227 & 0 & 0 & 0 & 0 & 0 & 1 & 0 \\
\hline CAN & 1984 & 0.20 & 0.20 & 0.00 & 0 & 0.203 & 0.351 & 0.227 & 0.044 & 0 & 0 & 0 & 0 & 0 & 1 & t \\
\hline CAN & 1985 & 1.03 & 0.53 & 0.50 & 0.203 & 0.325 & 0.594 & 0.308 & 0.046 & 0.502 & 0 & 0.053 & 0.071 & 0.0365 & 1 & 0 \\
\hline CAN & 1986 & 0.99 & 0.84 & 0.15 & 0.279 & 0.563 & 0.537 & 0.148 & 0.018 & 0.1 & 0.05 & 0.147 & 0.055 & 0.0017 & 1 & 0 \\
\hline CAN & 1987 & 0.28 & 0.14 & 0.14 & -0.35 & 0.492 & 0.32 & -0.23 & 0.088 & 0 & 0.135 & -0.03 & -0.095 & -0.0284 & 1 & 0 \\
\hline CAN & 1988 & 0.30 & 0.33 & -0.03 & 0.034 & 0.292 & -0.2 & 0.082 & $2 E-04$ & 0 & -0.03 & -0.09 & -0.026 & 0 & 1 & 0 \\
\hline CAN & 1989 & 0.31 & 0.24 & 0.08 & 0.421 & -0.18 & 0.588 & 0.127 & $1 \mathrm{E}-03$ & 0.156 & -0.08 & 0.087 & 0.052 & 0.0108 & 1 & 0 \\
\hline CAN & 1990 & 0.86 & 0.57 & 0.29 & 0 & 0.569 & 0.123 & $9 \mathrm{E}-04$ & 0 & 0.207 & 0.084 & 0.25 & 0.042 & -0.0041 & 1 & 4 \\
\hline CAN & 1991 & 0.40 & 0.13 & 0.27 & 0.011 & 0.122 & -0.01 & 0 & 0 & 0.022 & 0.248 & 0.228 & 0.093 & 0.0196 & 0 & 1 \\
\hline CAN & 1992 & 0.21 & -0.01 & 0.22 & 0 & -0.01 & -0.01 & 0 & 0 & 0 & 0.224 & 0.099 & 0.019 & 0 & 0 & 1 \\
\hline CAN & 1993 & 0.35 & -0.01 & 0.36 & 0 & -0.01 & -0.02 & 0 & 0 & 0.263 & 0.095 & 0.255 & 0.083 & 0.0146 & 0 & 1 \\
\hline CAN & 1994 & 0.49 & 0.04 & 0.45 & 0.056 & -0.02 & 0.098 & 0.04 & 0.004 & 0.213 & 0.24 & 0.469 & 0.302 & 0.0606 & 0 & t \\
\hline CAN & 1995 & 0.99 & 0.18 & 0.81 & 0.082 & 0.094 & 0.098 & 0.03 & 0 & 0.368 & 0.446 & 0.917 & 0.525 & 0 & 0 & t \\
\hline CAN & 1996 & 0.97 & 0.09 & 0.88 & 0 & 0.095 & 0.029 & 0 & 0 & -0.01 & 0.888 & 0.538 & 0 & 0 & 0 & 1 \\
\hline CAN & 1997 & 0.47 & 0.01 & 0.47 & -0.02 & 0.027 & 0 & 0 & 0 & -0.04 & 0.51 & 0 & 0 & 0 & 0 & 1 \\
\hline DEU & 1982 & 1.18 & 0.56 & 0.62 & 0.56 & 0 & 0 & -0.41 & 0 & 0.62 & 0 & 0 & 0 & 0 & 0 & 1 \\
\hline EU & 1983 & 0.87 & 0.30 & 0.57 & 0.3 & 0 & -0.41 & 0 & 0 & 0.57 & 0 & 0 & 0 & 0 & 0 & 1 \\
\hline EU & 1984 & 0.18 & -0.41 & 0.59 & 0 & -0.41 & 0 & 0 & 0 & 0.59 & 0 & 0 & 0 & 0 & 0 & 1 \\
\hline DEU & 1991 & 1.11 & 1.08 & 0.03 & 1.08 & 0 & 0.27 & -0.46 & 0 & 0.03 & 0 & 0.19 & 0.18 & 0.18 & 1 & 0 \\
\hline DEU & 1992 & 0.46 & 0.27 & 0.19 & 0 & 0.27 & -0.46 & 0 & 0 & 0 & 0.19 & 0.18 & 0.18 & $0 \|$ & 0 & 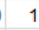 \\
\hline DEU & 1993 & 0.11 & -0.07 & 0.18 & 0.39 & -0.46 & 0 & 0.77 & 0 & 0 & 0.18 & 0.18 & 0.11 & $0 \|$ & 1 & t \\
\hline DEU & 1994 & 0.91 & 0.08 & 0.83 & 0.08 & 0 & 0.84 & 0 & 0 & 0.65 & 0.18 & 0.245 & 0 & 0 & 0 & 1 \\
\hline DEU & 1995 & 1.09 & 0.84 & 0.25 & 0 & 0.84 & 0 & 0 & 0 & 0 & 0.245 & 0 & 0 & 0 & 1 & 0 \\
\hline DEU & 1997 & 1.60 & 0.50 & 1.10 & 0.5 & 0 & 0 & 0 & 0 & 1.1 & 0 & -0.1 & 0 & 0 & 0 & 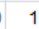 \\
\hline DEU & 1998 & -0.10 & 0.00 & -0.10 & 0 & 0 & 0.3 & 0 & 0 & 0 & -0.1 & 0 & 0 & 0 & 1 & 0 \\
\hline DEU & 1999 & 0.30 & 0.30 & 0.00 & 0 & 0.3 & 0 & 0 & 0 & 0 & 0 & 0 & 0 & 0 & 1 & 0 \\
\hline DEU & 2000 & 0.70 & -0.05 & 0.75 & -0.05 & 0 & 0 & 0 & 0 & 0.75 & 0 & 0 & 0 & 0 & 0 & 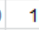 \\
\hline DEU & 2003 & 0.74 & 0.74 & 0.00 & 0.74 & 0 & 0 & 0 & 0 & 0 & 0 & 0 & 0 & 0 & 1 & 0 \\
\hline DEU & 2004 & 0.40 & -0.70 & 1.10 & -0.7 & 0 & 0 & 0 & 0 & 1.1 & 0 & 0 & 0 & 0 & 0 & 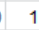 \\
\hline DEU & 2006 & 0.50 & 0.00 & 0.50 & 0 & 0 & 0.5 & 0 & 0 & 0.5 & 0 & 0.4 & 0 & 0 & 0 & 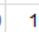 \\
\hline DEU & 2007 & 0.90 & 0.50 & 0.40 & 0 & 0.5 & 0 & 0 & 0 & 0 & 0.4 & 0 & 0 & $0 \|$ & 1 & 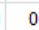 \\
\hline
\end{tabular}




\begin{tabular}{|c|c|c|c|c|c|c|c|c|c|c|c|c|c|c|c|c|}
\hline \multicolumn{17}{|c|}{ Table 1: Classification of fiscal adjustments } \\
\hline & & \multirow{2}{*}{ Total } & \multirow{2}{*}{$\operatorname{Tax}$} & \multirow{2}{*}{ Spend } & \multicolumn{5}{|c|}{ Taxes } & \multicolumn{5}{|c|}{ Spending } & \multirow{2}{*}{ TB } & \multirow{2}{*}{ EB } \\
\hline & & & & & $T_{t}^{n}$ & $T_{t, 0}^{2}$ & $T_{t, 1}^{2}$ & $T_{t, 2}^{2}$ & $T_{t, 3}^{2}$ & $g_{t}^{u}$ & $g_{\text {to }}^{2}$ & $g_{t, 1}^{g}$ & $g_{t, 2}^{s}$ & $g_{t, 3}^{o}$ & & \\
\hline DNK & 1983 & 2.77 & 0.92 & 1.85 & 0.92 & 0 & 0 & 0 & 0 & 1.85 & 0 & 1 & 0 & 0 & 0 & 1 \\
\hline DNK & 1984 & 2.38 & 0.67 & 1.71 & 0.67 & 0 & 0 & 0 & 0 & 0.71 & 1 & 0 & 0 & 0 & 0 & d \\
\hline DNK & 1985 & 1.54 & 0.77 & 0.77 & 0.77 & 0 & 0 & 0 & 0 & 0.77 & 0 & 0 & 0 & 0 & 1 & 0 \\
\hline DNK & 1995 & 0.30 & 0.30 & 0.00 & 0.3 & 0 & 0 & 0 & 0 & 0 & 0 & 0 & 0 & 0 & 1 & 0 \\
\hline ESP & 1983 & 1.90 & 1.90 & 0.00 & 1.9 & 0 & 0 & 0 & 0 & 0 & 0 & 0 & 0 & 0 & 1 & 0 \\
\hline ESP & 1984 & 1.12 & 0.37 & 0.75 & 0.37 & 0 & 0 & 0 & 0 & 0.75 & 0 & 0 & 0 & 0 & 0 & ' \\
\hline ESP & 1989 & 1.22 & 0.98 & 0.24 & 0.98 & 0 & -0.28 & 0 & 0 & 0.24 & 0 & -0.15 & 0 & 0 & 1 & 0 \\
\hline ESP & 1990 & -0.40 & -0.25 & -0.15 & 0 & -0.25 & 0 & 0 & 0 & 0 & -0.15 & 0 & 0 & 0 & 1 & 0 \\
\hline ESP & 1991 & 0.00 & 0.00 & 0.00 & 0 & 0 & -0.6 & 0 & 0 & 0 & 0 & 0 & 0 & 0 & 1 & t \\
\hline ESP & 1992 & 0.70 & 0.30 & 0.40 & 0.9 & -0.6 & 0.5 & 0 & 0 & 0.4 & 0 & 0.3 & 0 & 0 & 1 & t \\
\hline ESP & 1993 & 1.10 & 0.80 & 0.30 & 0.3 & 0.5 & 0 & 0 & 0 & 0 & 0.3 & 0 & 0 & 0 & 1 & 0 \\
\hline ESP & 1994 & 2.40 & 0.80 & 1.60 & 0.3 & 0.5 & 0 & 0 & 0 & 1.6 & 0 & 0 & 0 & 0 & 0 & 1 \\
\hline ESP & 1995 & 0.74 & 0.00 & 0.74 & 0 & 0 & 0 & 0 & 0 & 0.74 & 0 & 0 & 0 & 0 & 0 & 1 \\
\hline ESP & 1996 & 1.30 & 0.20 & 1.10 & 0.2 & 0 & 0 & 0 & 0 & 1.1 & 0 & 0 & 0 & 0 & 0 & 1 \\
\hline ESP & 1997 & 1.20 & 0.10 & 1.10 & 0.1 & 0 & 0 & 0 & 0 & 1.1 & 0 & 0 & 0 & 0 & 0 & 1 \\
\hline FIN & 1992 & 0.91 & 0.00 & 0.91 & 0 & 0 & 0 & 0 & 0 & 0.91 & 0 & 2.005 & 0 & 0 & 0 & 1 \\
\hline FIN & 1993 & 3.71 & 0.00 & $3.71 \|$ & 0 & 0 & 0 & 0 & 0 & 1.705 & 2.005 & 0 & 0 & 0 & 0 & 1 \\
\hline FIN & 1994 & 3.46 & 0.69 & 2.77 & 0.69 & 0 & -0.69 & 0 & 0 & 2.77 & 0 & 0 & 0 & 0 & 0 & 1 \\
\hline FIN & 1995 & 1.65 & -0.63 & 2.28 & 0 & -0.63 & 0 & 0 & 0 & 2.28 & 0 & 1.47 & 0 & 0 & 0 & 1 \\
\hline FIN & 1996 & 1.47 & 0.00 & 1.47 & 0 & 0 & 0 & 0 & 0 & 0 & 1.47 & 0 & 0 & 0 & 0 & 1 \\
\hline FIN & 1997 & 0.23 & -0.70 & 0.93 & -0.7 & 0 & 0 & 0 & 0 & 0.93 & 0 & 0 & 0 & 0 & 0 & 1 \\
\hline FRA & 1979 & 0.85 & 0.85 & 0.00 & 0.85 & 0 & 0 & 0 & 0 & 0 & 0 & 0 & 0 & 0 & 1 & 0 \\
\hline FRA & 1987 & 0.26 & -0.50 & 0.76 & -0.5 & 0 & 0 & -0.2 & 0 & 0.76 & 0 & 0 & 0 & 0 & 0 & 1 \\
\hline FRA & 1988 & 0.00 & 0.00 & 0.00 & 0 & 0 & -0.2 & 0 & 0 & 0 & 0 & 0 & 0 & 0 & 1 & 0 \\
\hline FRA & 1989 & -0.20 & -0.20 & 0.00 & 0 & -0.2 & 0 & 0 & 0 & 0 & 0 & 0 & 0 & 0 & 1 & 0 \\
\hline FRA & 1991 & 0.25 & 0.00 & 0.25 & 0 & 0 & 0 & 0 & 0 & 0.25 & 0 & -0.1 & 0 & 0 & 0 & 1 \\
\hline FRA & 1992 & -0.10 & 0.00 & -0.10 & 0 & 0 & 0 & 0 & 0 & 0 & -0.1 & 0 & 0 & 0 & 0 & 1 \\
\hline FRA & 1995 & 0.28 & 0.43 & -0.15 & 0.43 & 0 & 0.45 & 0 & 0 & -0.15 & 0 & 0 & 0 & 0 & 1 & 0 \\
\hline FRA & 1996 & 1.34 & 0.87 & 0.47 & 0.42 & 0.45 & 0.11 & 0 & 0 & 0.47 & 0 & 0.09 & 0 & 0 & 1 & 0 \\
\hline FRA & 1997 & 0.50 & 0.41 & 0.09 & 0.3 & 0.11 & 0 & -0.1 & -0.2 & 0 & 0.09 & 0 & 0 & 0 & 1 & 0 \\
\hline FRA & 1998 & 0.00 & 0.00 & 0.00 & 0 & 0 & -0.1 & -0.2 & 0 & 0 & 0 & 0 & 0 & 0 & 1 & 0 \\
\hline FRA & 1999 & -0.10 & -0.10 & 0.00 & 0 & -0.1 & -0.2 & 0 & 0 & 0 & 0 & 0 & 0 & 0 & 1 & . \\
\hline FRA & 2000 & -0.20 & -0.20 & 0.00 & 0 & -0.2 & 0 & 0 & 0 & 0 & 0 & 0 & 0 & 0 & 1 & t \\
\hline GBR & 1979 & 0.27 & -0.45 & 0.72 & -0.45 & 0 & -0.13 & 0 & 0 & 0.72 & 0 & 0.21 & 0 & 0 & 0 & 1 \\
\hline GBR & 1980 & 0.08 & -0.13 & 0.21 & 0 & -0.13 & 0 & 0 & 0 & 0 & 0.21 & 0 & 0 & 0 & 0 & 1 \\
\hline GBR & 1981 & 1.58 & 1.43 & 0.16 & 1.425 & 0 & 0.475 & 0 & 0 & 0.155 & 0 & 0.053 & 0 & 0 & 1 & 0 \\
\hline GBR & 1982 & 0.53 & 0.48 & 0.05 & 0 & 0.475 & 0 & 0 & 0 & 0 & 0.053 & 0 & 0 & 0 & 1 & 0 \\
\hline GBR & 1994 & 0.83 & 0.68 & 0.15 & 0.675 & 0 & 0.225 & 0 & 0 & 0.15 & 0 & 0.05 & 0 & 0 & 1 & 0 \\
\hline GBR & 1995 & 0.28 & 0.23 & 0.05 & 0 & 0.225 & 0 & 0 & 0 & 0 & 0.05 & 0 & 0 & 0 & 1 & 0 \\
\hline GBR & 1996 & 0.30 & 0.00 & 0.30 & 0 & 0 & 0 & 0 & 0 & 0.3 & 0 & 0.1 & 0 & 0 & 0 & 1 \\
\hline GBR & 1997 & 0.79 & 0.53 & 0.26 & 0.53 & 0 & 0.3 & 0.206 & 0 & 0.16 & 0.1 & 0.01 & 0.005 & 0 & 1 & 0 \\
\hline GBR & 1998 & 0.31 & 0.30 & 0.01 & 0 & 0.3 & 0.206 & 0 & 0 & 0 & 0.01 & 0.005 & 0 & 0 & 1 & 0 \\
\hline GBR & 1999 & 0.21 & 0.21 & 0.01 & 0 & 0.206 & 0 & 0 & 0 & 0 & 0.005 & 0 & 0 & 0 & 1 & 0 \\
\hline IRL & 1982 & 2.80 & 2.54 & 0.26 & 2.54 & 0 & 0 & 0 & 0 & 0.26 & 0 & 0.06 & 0 & 0 & 1 & 0 \\
\hline IRL & 1983 & 2.50 & 2.44 & 0.06 & 2.44 & 0 & 0 & 0 & 0 & 0 & 0.06 & 0 & 0 & 0 & 1 & 0 \\
\hline IRL & 1984 & 0.29 & 0.29 & 0.00 & 0.29 & 0 & 0 & 0 & 0 & 0 & 0 & 0 & 0 & 0 & 1 & t \\
\hline IRL & 1985 & 0.12 & 0.12 & 0.00 & 0.12 & 0 & 0 & 0 & 0 & 0 & 0 & 0 & 0 & 0 & 1 & 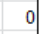 \\
\hline IRL & 1986 & 0.74 & 0.74 & 0.00 & 0.74 & 0 & 0 & 0 & 0 & 0 & 0 & 0 & 0 & 0 & 1 & 0 \\
\hline IRL & 1987 & 1.65 & 0.53 & 1.12 & 0.53 & 0 & 0 & 0 & 0 & 1.12 & 0 & 0 & 0 & 0 & 0 & 1 \\
\hline IRL & 1988 & 1.95 & 0.00 & 1.95 & 0 & 0 & 0 & 0 & 0 & 1.95 & 0 & 0 & 0 & 0 & 0 & 1 \\
\hline ITA & 1991 & 2.77 & 1.69 & 1.08 & 1.69 & 0 & -1.26 & 0 & 0 & 1.08 & 0 & 0 & 0 & 0 & 0 & 1 \\
\hline ITA & 1992 & 3.51 & 1.59 & 1.92 & 2.85 & -1.26 & -1.2 & 0 & 0 & 1.92 & 0 & 0 & 0 & 0 & 0 & d \\
\hline ITA & 1993 & 5.12 & 2.00 & 3.12 & 3.2 & -1.2 & -0.57 & 0 & 0 & 3.12 & 0 & 0 & 0 & 0 & 0 & 1 \\
\hline ITA & 1994 & 1.43 & -0.27 & 1.70 & 0.3 & -0.57 & 0 & 0 & 0 & 1.7 & 0 & 0 & 0 & 0 & 0 & 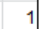 \\
\hline ITA & 1995 & 4.20 & 2.41 & 1.79 & 2.41 & 0 & -2.16 & 0 & 0 & 1.79 & 0 & 0 & 0 & 0 & 0 & 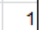 \\
\hline ITA & 1996 & 0.35 & -0.74 & 1.09 & 1.42 & -2.16 & -0.41 & 0 & 0 & 1.09 & 0 & 0 & 0 & 0 & 1 & 0 \\
\hline ITA & 1997 & 1.82 & 0.89 & 0.93 & 1.3 & -0.41 & -0.6 & 0 & 0 & 0.93 & 0 & 0 & 0 & 0 & 0 & 1 \\
\hline ITA & 1998 & 0.68 & 0.01 & 0.67 & 0.61 & -0.6 & 0 & 0 & 0 & 0.67 & 0 & 0 & 0 & 0 & 0 & 1 \\
\hline ITA & 2004 & 1.90 & 1.00 & 0.90 & 1 & 0 & 0 & 0 & 0 & 0.9 & 0 & 0 & 0 & 0 & 1 & 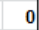 \\
\hline ITA & 2005 & 1.00 & 0.40 & 0.60 & 0.4 & 0 & 0 & 0 & 0 & 0.6 & 0 & 0 & 0 & 0 & 0 & 1 \\
\hline ITA & 2006 & 1.39 & 0.50 & 0.89 & 0.5 & 0 & 0 & 0 & 0 & 0.89 & 0 & 0 & 0 & 0 & 0 & \\
\hline ITA & 2007 & 1.03 & 1.32 & -0.29 & 1.32 & 0 & 0 & 0 & 0 & -0.29 & 0 & 0 & 0 & 0 & 1 & t \\
\hline
\end{tabular}




\begin{tabular}{|c|c|c|c|c|c|c|c|c|c|c|c|c|c|c|c|c|c|}
\hline & & \multirow{2}{*}{ Total } & \multirow{2}{*}{ Tax } & \multirow{2}{*}{ Spend } & \multicolumn{5}{|c|}{ Taxes } & \multicolumn{5}{|c|}{ Spending } & \multirow[t]{2}{*}{ TB } & \multirow{2}{*}{\multicolumn{2}{|c|}{ EB }} \\
\hline & & & & & $T_{t}{ }_{t}$ & $T^{2} t_{0}$ & $T_{t, 1}^{2}$ & $T_{t, 2}^{2}$ & $T_{t, 3}^{n}$ & $g_{t}^{u}$ & $g_{t, 0}^{a}$ & $g_{t, 1}^{s}$ & $g_{t, 2}^{0}$ & $g_{t, 3}^{s}$ & & & \\
\hline JPN & 1979 & 0.12 & 0.12 & 0.00 & 0.115 & 0 & 0.123 & 0.031 & 0 & 0 & 0 & 0 & 0 & 0 & 1 & & 0 \\
\hline JPN & 1980 & 0.21 & 0.21 & 0.00 & 0.09 & 0.123 & 0.091 & 0 & 0 & 0 & 0 & 0 & . & 0 & 1 & & 0 \\
\hline JPN & 1981 & 0.43 & 0.43 & 0.00 & 0.342 & 0.091 & 0.227 & 0 & 0 & 0 & 0 & 0 & 0 & 0 & 1 & & 0 \\
\hline JPN & 1982 & 0.71 & 0.31 & 0.40 & 0.085 & 0.227 & 0.057 & 0 & 0 & 0.398 & 0 & 0.065 & 0 & 0 & 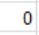 & & \\
\hline JPN & 1983 & 0.42 & 0.06 & 0.37 & 0 & 0.057 & 0 & 0 & 0 & 0.3 & 0.065 & 0 & 0 & 0 & 0 & & \\
\hline JPN & 1997 & 1.43 & 0.98 & 0.45 & 0.975 & 0 & 0.325 & 0 & 0 & 0.45 & 0 & 0.15 & 0 & 0 & 1 & & \\
\hline JPN & 1998 & 0.48 & 0.33 & 0.15 & 0 & 0.325 & 0 & 0 & 0 & 0 & 0.15 & 0 & 0 & 0 & 1 & & \\
\hline JPN & 2003 & 0.48 & 0.00 & 0.48 & 0 & 0 & 0 & 0 & 0 & 0.48 & 0 & 0 & 0 & 0 & 0 & . & 1 \\
\hline JPN & 2004 & 0.64 & 0.19 & 0.45 & 0.188 & 0 & 0.063 & 0 & . & 0.45 & 0 & 0 & 0 & 0 & 0 & 0 & \\
\hline JPN & 2005 & 0.28 & 0.06 & 0.22 & 0 & 0.063 & 0 & 0 & 0 & 0.22 & 0 & 0 & 0 & 0 & 0 & & \\
\hline JPN & 2006 & 0.72 & 0.45 & 0.27 & 0.45 & 0 & 0.15 & 0 & 0 & 0.27 & 0 & 0 & 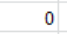 & 0 & 1 & 1 & \\
\hline JPN & 2007 & 0.15 & 0.15 & 0.00 & 0 & 0.15 & 0 & 0 & 0 & 0 & 0 & 0 & 0 & 0 & 1 & s & 0 \\
\hline NLD & 1981 & 1.75 & 0.53 & 1.22 & 0.53 & 0 & 0 & 0 & 0 & 1.22 & 0 & 0 & 0 & 0 & 0 & . & 1 \\
\hline NLD & 1982 & 1.71 & 0.00 & $1.71 \|$ & 0 & 0 & 0 & 0 & 0 & 1.71 & 0 & 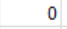 & 0 & 0 & 0 & & 1 \\
\hline NLD & 1983 & 3.24 & 0.49 & 2.75 & 0.49 & 0 & 0 & 0 & 0 & 75 & 0 & 0 & 0 & 0 & 0 & & 1 \\
\hline NLD & 1984 & 1.76 & 0.00 & 1.76 & 0 & 0 & 0 & 0 & 0 & 1.76 & 0 & 0 & 0 & 0 & 0 & & \\
\hline NLD & 1985 & 1.24 & 0.00 & 1.24 & 0 & 0 & 0 & 0 & 0 & 1.24 & 0 & 0 & 0 & 0 & 0 & & \\
\hline NLD & 1986 & 1.74 & 0.00 & 1.74 & 0 & 0 & 0 & 0 & 0 & 1.74 & 0 & 0 & 0 & 0 & 0 & & \\
\hline NLD & 1987 & 1.48 & 1.48 & 0.00 & 1.48 & 0 & -0.3 & 0 & 0 & 0 & 0 & 0 & 0 & 0 & 1 & & \\
\hline NLD & 1988 & 0.05 & -0.70 & 0.75 & -0.4 & -0.3 & 0 & 0 & 0 & 0.75 & 0 & 0 & 0 & 0 & 0 & & \\
\hline NLD & 1991 & 0.87 & 0.87 & 0.00 & 0.87 & 0 & -0.61 & 0 & 0 & 0 & 0 & 0.82 & 0 & 0 & 0 & . & 1 \\
\hline NLD & 1992 & 0.74 & -0.58 & 1.32 & 0.03 & -0.61 & 0 & 0 & 0 & 0.5 & 0.82 & -0.2 & 0 & 0 & 0 & 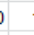 & \\
\hline NLD & 1993 & 0.92 & 0.04 & 0.88 & 0.04 & 0 & 0 & 0 & 0 & 1.08 & -0.2 & 0 & 0 & 0 & 0 & D & 1 \\
\hline NLD & 2004 & 1.70 & 0.40 & 1.30 & 0.4 & 0 & 0 & 0 & 0 & 1.3 & 0 & 0 & 0 & 0 & 0 & 0 & \\
\hline NLD & 2005 & 0.50 & 0.20 & 0.30 & 0.2 & 0 & 0 & 0 & 0 & 0.3 & 0 & 0 & 0 & 0 & 0 & D & 1 \\
\hline PRT & 1983 & 2.30 & 1.35 & 0.95 & 1.35 & 0 & 0 & 0 & 0 & 0.95 & 0 & 0 & 0 & 0 & 1 & ( & 0 \\
\hline PRT & 2000 & 0.50 & 0.00 & 0.50 & 0 & 0 & 0 & 0 & 0 & 0.5 & 0 & 0 & 0 & 0 & 0 & 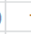 & 1 \\
\hline PRT & 2002 & 1.60 & 1.20 & 0.40 & 1.2 & 0 & 0 & 0 & 0 & 0.4 & 0 & 0 & 0 & 0 & 1 & & \\
\hline PRT & 2003 & -0.75 & -0.75 & 0.00 & -0.75 & 0 & 0 & 0 & 0 & 0 & 0 & 0 & 0 & 0 & 1 & ( & \\
\hline PRT & 2005 & 0.60 & 0.52 & 0.08 & 0.52 & 0 & 1.1 & 0 & 0 & 0.08 & 0 & 0.55 & 0 & 0 & 1 & & \\
\hline PRT & 2006 & 1.65 & 1.10 & $0.55 \|$ & 0 & 1.1 & 0.5 & 0 & $0 \|$ & 0 & 0.55 & 0.9 & 0 & 0 & 1 & & 0 \\
\hline PRT & 2007 & 1.40 & 0.50 & $0.90 \|$ & 0 & 0.5 & 0 & 0 & 0 & 0 & 0.9 & 0 & 0 & 0 & 0 & & 1 \\
\hline SWE & 1984 & 0.90 & 0.21 & 0.69 & 0.21 & 0 & 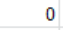 & 0 & 0 & 0.69 & 0 & 0 & 0 & 0 & 0 & . & 1 \\
\hline SWE & 1993 & 1.81 & 0.42 & 1.39 & 0.42 & 0 & 0.19 & 0 & 0 & 1.392 & 0 & 0.586 & 0 & 0 & 0 & . & 1 \\
\hline SWE & 1994 & 0.78 & 0.19 & 0.59 & 0 & 0.19 & 0 & 0 & 0 & 0 & 0.586 & 0 & 0 & 0 & 0 & . & \\
\hline SWE & 1995 & 3.50 & 1.40 & 2.10 & 1.4 & 0 & 0.8 & 0.6 & 0.4 & 2.1 & 0 & 1.2 & 0.9 & 0.6 & 0 & 0 & \\
\hline SWE & 1996 & 2.00 & 0.80 & 1.20 & 0 & 0.8 & 0.6 & 0.4 & 0 & 0 & 1.2 & 0.9 & 0.6 & 0 & 0 & D & \\
\hline SWE & 1997 & 1.50 & 0.60 & 0.90 & 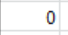 & 0.6 & 0.4 & 0 & 0 & 0 & 0.9 & 0.6 & 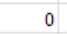 & 0 & 0 & 0 & 1 \\
\hline SWE & 1998 & 1.00 & 0.40 & 0.60 & 0 & 0.4 & 0 & 0 & 0 & 0 & 0.6 & 0 & 0 & 0 & 0 & . & 1 \\
\hline USA & 1978 & 0. & 0.14 & 0.00 & 0.135 & 0 & 0 & 062 & 0 & 0 & 0 & 0 & 0 & 0 & 1 & & \\
\hline USA & 1979 & 0. & 0.00 & 0.00 & 0 & 0 & 0.062 & 0 & 0 & 0 & 0 & 0 & 0 & 0 & 1 & & \\
\hline USA & 1980 & 0. & 0.06 & 0.00 & 0 & 0.062 & 0 & 0 & 0 & 0 & 0 & 0 & 0 & 0 & 1 & & \\
\hline USA & 1981 & 0 & 0.23 & 0.00 & 0.23 & 0 & 0 & 0 & 0 & 0 & 0 & 0 & 0 & 0 & 1 & & \\
\hline USA & 1983 & 0.00 & 0.00 & 0.00 & 0 & 0 & 0 & 0.21 & 0.096 & 0 & 0 & 0 & 0 & 0 & 1 & & 0 \\
\hline USA & 1984 & 0.00 & 0.00 & 0.00 & 0 & 0 & 0.21 & 0.096 & 0 & 0 & 0 & 0 & 0 & 0 & 1 & & \\
\hline USA & 1985 & 0.21 & 0.21 & 0.00 & 0 & 0.21 & 0.096 & 0 & 0 & 0 & 0 & 0 & 0 & 0 & 1 & 1 & \\
\hline USA & 1986 & 0.10 & 0.10 & 0.00 & 0 & 0.096 & 0 & 0 & II & 0 & 0 & 0 & 0 & 0 & 1 & 1 & \\
\hline USA & 1987 & 0.00 & 0.00 & 0.00 & 0 & 0 & -0.15 & 0 & 0 & 0 & 0 & 0 & 0 & 0 & 1 & & \\
\hline USA & 1988 & 0.85 & 0.39 & 0.46 & 0.54 & -0.15 & 0 & 0 & 0 & 0.46 & 0 & 0 & 0 & 0 & 0 & & \\
\hline USA & 1990 & 0.33 & 0.26 & 0.07 & 0.26 & 0 & 0.29 & 0.24 & -0.02 & 0.07 & 0 & 0.29 & 0.29 & 0.214 & 0 & & 1 \\
\hline USA & 1991 & 0.58 & 0.29 & 0.29 & 0 & 0.29 & 0.24 & -0.02 & 0.07 & 0 & 0.29 & 0.29 & 0.214 & 0.43 & 0 & 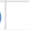 & \\
\hline USA & 1992 & 0.53 & 0.24 & 0.29 & 0 & 0.24 & -0.02 & 0.07 & 0.02 & 0 & 0.29 & 0.214 & 0.43 & 0.25 & 0 & & 1 \\
\hline USA & 199 & 0. & 0.08 & 0.23 & 0.1 & -0.02 & 0.4 & 0.19 & 0.075 & 0.02 & 0.214 & 0.5 & 0.34 & 0.215 & 0 & & \\
\hline USA & & 0. & 0.40 & $0.50 \|$ & 0 & 0.4 & 0.19 & 0.075 & 0.06 & 0 & 0.5 & 0.34 & 0.215 & 0.24 & 0 & & \\
\hline USA & 1995 & 0.53 & 0.19 & 0.34 & 0 & 0.19 & 0.075 & 0.06 & -0.02 & 0 & 0.34 & .215 & 0.24 & 0.17 & 0 & & \\
\hline US & 19 & 0.2 & 0.08 & 0.22 & 0 & 0.075 & 0.06 & -0.02 & 0 & 0 & 0.215 & 0.24 & 0.17 & 0 & 0 & & \\
\hline USA & 1997 & 0.30 & 0.06 & $0.24 \|$ & 0 & 0.06 & -0.02 & 0 & $0 \|$ & 0 & 0.24 & 0.17 & 0 & 0 & 0 & J & \\
\hline USA & 1998| & 0.15 & -0.02 & $0.17 \|$ & 0 & -0.02 & 0 & 0 & & 0 & 0.17 & 0 & 0 & 0 & 0 & & \\
\hline
\end{tabular}




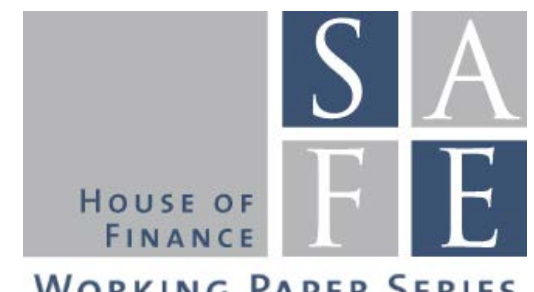

WORKING PAPER SERIES

\section{Recent Issues}

No. 75 Markus Behn, Rainer Haselmann, Vikrant Vig

No. 74 Nicole Branger, Patrick Konermann, Christoph Meinerding, Christian

Schlag

No. 73 Max Groneck, Alexander Ludwig, Alexander Zimpel

No. 72 Alexander Ludwig, Matthias Schön

No.71 Daniel Harenberg, Alexander Ludwig

No. 70 Deyan Radev

No. 69 Nina Biljanovska, Spyros Palligkinis

No. 68 Tobias Tröger

No. 67 Sascha Baghestanian, Paul J. Gortner, Joel van der Weele

No.66 Tobias Tröger

No. 65 Elia Berdin, Helmut Gründl

No.64 Daniel Herbold

No. 63 Nicola Fuchs-Schündeln, Michael Haliassos

No. 62 Patrick Behr, Alejandro H. Drexler, Reint Gropp, Andre Guettler
The Limits of Model-Based Regulation

Equilibrium Asset Pricing in Networks with Mutually Exciting Jumps

A Life-Cycle Model with Ambiguous Survival Beliefs

Endogenous Grids in Higher Dimensions: Delaunay Interpolation and Hybrid Methods

Social Security in an Analytically Tractable Overlapping Generations Model with Aggregate and Idiosyncratic Risk

Assessing Systemic Fragility - a Probabilistic Perspective

Control Thyself: Self-Control Failure and Household Wealth

How Special Are They? - Targeting Systemic Risk by Regulating Shadow Banking

Peer Effects and Risk Sharing in Experimental Asset Markets

Corporate Groups

The Effects of a Low Interest Rate Environment on Life Insurers

A Repeated Principal-Agent Model with Onthe-Job Search

Does Product Familiarity Matter for Participation?

Financial Incentives and Loan Officers Behavior: Multitasking and Allocation of Effort Under an Incomplete Contract 